\title{
Candida tropicalis CE017: a New Brazilian Enzymatic Source for the Bioreduction of Aromatic Prochiral Ketones
}

\author{
Gizelle A. B. Vieira, ${ }^{a}$ Daniel M. de Freitas Araujo, ${ }^{a}$ Telma L. G. Lemos, ${ }^{a}$ \\ Marcos Carlos de Mattos, ${ }^{*}$, Maria da Conceição F. de Oliveira, ${ }^{a}$ Vânia M. M. Melo, ${ }^{a}$ \\ Gonzalo de Gonzalo, ${ }^{b}$ Vicente Gotor-Fernández ${ }^{b}$ and Vicente Gotor ${ }^{*, b}$ \\ ${ }^{a}$ Departamento de Química Orgânica e Inorgânica, Universidade Federal do Ceará, \\ 60451-970 Fortaleza-CE, Brazil \\ ${ }^{b}$ Departamento de Química Orgánica e Inorgánica, Instituto Universitario de Biotecnología de \\ Asturias, Universidad de Oviedo, c/ Julián Clavería 8, 33006, Oviedo, Spain
}

\begin{abstract}
A reatividade e estereosseletividade apresentadas por uma nova cepa de Candida tropicalis na redução de cetonas pró-quirais foram comparadas com cepas de microrganismos, estudadas em nosso laboratório, provenientes da biodiversidade brasileira. Neste caso, Candida tropicalis demonstrou-se como um agente redutor versátil e estereosseletivo na biorredução de uma série de cetonas aromáticas. Estes compostos pró-quirais foram convertidos aos correspondentes álcoois opticamente ativos com moderada a excelente estereopreferência dependendo da estrutura do substrato. Entre as cetonas utilizadas, as nitroacetofenonas foram enzimaticamente reduzidas aos correspondentes $(S)$-álcoois enantiopuros com completa conversão.
\end{abstract}

The reactivity and stereoselectivity showed by a new strain of Candida tropicalis in the reduction of prochiral ketones have been compared with the ones previously attained in our laboratory using microorganisms from the Brazilian biodiversity. In this manner, Candida tropicalis has demonstrated its versatility as stereoselective agent in the bioreduction of a series of aromatic ketones. These prochiral compounds were converted into their corresponding optically alcohols with moderate to excellent stereopreference depending on the substrate structure. Among ketones tested, nitroacetophenones were enzymatically reduced to enantiopure $(S)$-alcohol with complete conversion.

Keywords: alcohol dehydrogenases, biocatalysis, Candida tropicalis, ketones, yeast

\section{Introduction}

Chiral alcohols are an important class of organic substrates due to their properties as bioactive compounds and as starting materials for the synthesis of various biologically active materials. ${ }^{1}$ For example, enantiopure 1-phenylethanol is a chiral building block used in the fine chemical and pharmaceutical industries as an ophthalmic preservative, a solvatochromic dye, an inhibitor of cholesterol intestinal absorption and a mild floral fragrance. ${ }^{2}$ In the synthesis of enantiopure chiral secondary alcohols, prochiral ketones are commonly used as starting materials using stereoselective chemical transformations or biocatalytic methods. Asymmetric reduction by chemical

\footnotetext{
*e-mail: mcdmatto@ufc.br; vgs@fq.uniovi.es
}

methods usually involves the use of expensive reagents or heavy metal catalysts. ${ }^{3}$ By contrast, biocatalysis applied to industrial processes has been shown as a very advantageous alternative to conventional chemical methods, and is widely used for the preparation of enantiomerically pure pharmaceuticals and other high added value compounds. ${ }^{4}$

Enzymatic reduction of carbonyl groups represents one of the most important reactions employed in the synthesis of chiral alcohols. Enzymes that can be used for this transformation are oxidoreductases, which require the presence of a coenzyme, such as NADH or NADPH, which transfers the hydride anion to the carbonyl compound, being formed $\mathrm{NAD}^{+}$or $\mathrm{NADP}^{+}$. Whole cells of microorganisms can be also used in the enzymatic reduction of the carbonyl group. Each cell represents a small factory fully equipped for the reduction of the substrate bearing 
the carbonyl moiety. In order to find optimal conditions for the action of cell factories, the process designer has only to plan in which way the ketonic substrate should be added, and which medium should be used for the designed reaction. Nowadays, a wide variety of cultured cells from microorganisms or vegetables are available for enzymemediated reduction of carbonyl compounds. ${ }^{5}$

It is well known that the screening of a wide variety of microorganisms living in the environment is an efficient method to obtain the desired enzyme towards an unnatural substrate. Acetophenone has been used as a model substrate for the isolation of microorganisms having ketone reductase activity. ${ }^{6}$ Recently, a new strain of Candida tropicalis PBR-2 MTCC 5158 has been reported as an efficient reducing agent to acetophenone and its derivatives. ${ }^{7}$

The use of microorganism new strains as biocatalysts may offer an alternative opportunity to investigate the local resources for the effective conduct of key synthetic transformations with significant economic and ecological implications. ${ }^{8}$

Our research interest is based on the development of chemoenzymatic methodologies to obtain chiral alcohols using Brazilian local sources of low cost. Herein, we report our current investigations in the study of the Candida tropicalis CE017 strain behavior as a novel stereoselective reducing agent of aromatic prochiral ketones to the corresponding chiral alcohols. The experimental results obtained will be compared to the one previously obtained by our research group using different Brazilian enzymatic sources. ${ }^{9,10}$

\section{Results and Discussion}

\section{Bioreduction of acetophenone using C. tropicalis CE017}

Acetophenone 1a was tested in the bioreduction using growing cells of the yeast as biocatalyst in a potato dextrose broth medium.<smiles>CC(=O)c1ccccc1</smiles>

$1 \mathrm{a}$<smiles>C[C@H](O)c1ccccc1</smiles>

(S)-1b
Scheme 1. Bioreduction of acetophenone 1a by $C$. tropicalis.

Enzymatic reductions have been followed by analyzing the product $\mathbf{1 b}$ formed after 1, 3, 6, 9, 12 and 15 days of reaction, being summarized the data in Table 1 . (S)-1-phenylethanol 1b was obtained with high optical purities $(97-99 \%$ ee) in all cases, observing the maximum conversion (62\%, entry 4) after 9 days of reaction. Longer reaction times led to the formation of acetophenone due to an oxidizing activity showed by Candida tropicalis.

Table 1. Effect of incubation time on the reduction of acetophenone by C.tropicalis $\mathrm{CE} 017$ at $28^{\circ} \mathrm{C}$ and $\mathrm{pH} 7.0$

\begin{tabular}{lccc}
\hline Entry & time / days & Conversion / $(\%)^{\mathrm{a}}$ & $e e /(\%)^{\mathrm{b}}$ \\
\hline 1 & 1 & 20 & $>99(S)$ \\
2 & 3 & 35 & $98(S)$ \\
3 & 6 & 38 & $97(S)$ \\
4 & 9 & 62 & $97(S)$ \\
5 & 12 & 60 & $97(S)$ \\
6 & 15 & 56 & $97(S)$ \\
\hline
\end{tabular}

${ }^{\mathrm{a}}$ Conversion was determined by GC. ${ }^{\mathrm{b}}$ Determined by GC. By comparison with $(S)$ - and $(R)$-1-phenylethanol standards was possible to verify that the major enantiomer formed in the enzymatic process possesses the $S$ configuration.

In our efforts to improve the yield of (S)-1-phenylethanol $\mathbf{1 b}$, some other reaction parameters were analyzed as culture medium, $\mathrm{pH}$, temperature and substrate concentration.

\section{Culture medium}

Acetophenone bioreductions were performed during 9 days, at $28{ }^{\circ} \mathrm{C}$, using two different culture media to obtain whole cells of $C$. tropicalis CE017: (i) peptone

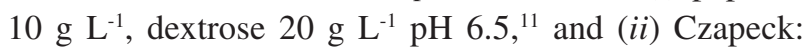
$\mathrm{NaNO}_{3}\left(3 \mathrm{~g} \mathrm{~L}^{-1}\right), \mathrm{K}_{2} \mathrm{HPO}_{4}\left(1.0 \mathrm{~g} \mathrm{~L}^{-1}\right), \mathrm{MgSO}_{4} 7 \mathrm{H}_{2} \mathrm{O}, \mathrm{KCl}$ $\left(0.5 \mathrm{~g} \mathrm{~L}^{-1}\right), \mathrm{FeSO}_{4}\left(0.01 \mathrm{~g} \mathrm{~L}^{-1}\right)$, dextrose $\left(30 \mathrm{~g} \mathrm{~L}^{-1}\right), \mathrm{pH} 8.5 .^{12}$ Additionally the bioreduction was performed adjusting the $\mathrm{pH}$ of both media to 5.5 with a sterile solution of tartaric acid $10 \%$. The results obtained are listed in Table 2.

Table 2. Effect of culture medium on the bioreduction of acetophenone by C. tropicalis $\mathrm{CE} 017$

\begin{tabular}{lcccc}
\hline Entry & Culture medium & $\mathrm{pH}$ & Conversion / $(\%)^{\mathrm{a}}$ & $e e /(\%)^{\mathrm{a}}$ \\
\hline 1 & Peptone/Dextrose & 5.5 & 13 & $99(S)$ \\
2 & Peptone/Dextrose & 6.5 & 13 & $99(S)$ \\
3 & Czapeck & 8.5 & 11 & $99(S)$ \\
4 & Czapeck & 5.5 & 12 & $99(S)$ \\
\hline \multicolumn{4}{l}{ a Conversion and enantiomeric excesses were determined by GC. }
\end{tabular}

These results revealed that all the new culture media have similar effect in the enzymatic activity (11-13\% conversion), allowing the recovery of (S)-1-phenylethanol in enantiomerically pure form. All these media led to notable lower isolated yields in comparison with potato dextrose medium (62\% yield at $\mathrm{pH} 7.0$ ). 


\section{pH Influence}

Reactions were analyzed after 9 days using potato dextrose broth as culture medium in the following $\mathrm{pHs}$ : 4.0, 5.5, 7.0 and 8.0. The medium was adjusted to $\mathrm{pH} 8.0$ and 7.0 with a sterile solution of $\mathrm{NaOH} 1.0 \mathrm{~mol} \mathrm{~L}^{-1}$, and $\mathrm{pH} 4.0$ was adjusted by using a sterilized $10 \%$ tartaric acid solution. The results were summarized in Table 3.

Table 3. Effect of $\mathrm{pH}$ on the bioreduction of acetophenone by $C$. tropicalis CE017

\begin{tabular}{lccc}
\hline Entry & $\mathrm{pH}$ & Conversion / $(\%)^{\mathrm{a}}$ & $e e /(\%)^{\mathrm{a}}$ \\
\hline 1 & 4.0 & 50 & $98(S)$ \\
2 & 5.5 & 60 & $98(S)$ \\
3 & 7.0 & 62 & $98(S)$ \\
4 & 8.0 & 42 & $98(S)$ \\
\hline
\end{tabular}

${ }^{\mathrm{a}}$ Conversion and enantiomeric excesses $(e e)$ were determined by GC.

The optimal $\mathrm{pH}$ for this biocatalytic system varied from 5.5 to 7.0 (entries 2 and 3), observing a decrease of conversion when more acidic or basic media were employed (entries 1 and 4).

\section{Temperature effect on Candida tropicalis}

Reactions were performed using potato dextrose broth at higher temperatures $\left(45\right.$ and $\left.55^{\circ} \mathrm{C}\right)$, as shown in Table 4.

Table 4. Effect of temperature on the bioreduction of acetophenone by C. tropicalis $\mathrm{CE} 017$

\begin{tabular}{lcccc}
\hline Entry & $\begin{array}{c}\text { Temperature / } \\
\left({ }^{\circ} \mathrm{C}\right)\end{array}$ & Days & $\begin{array}{c}\text { Conversion / } \\
(\%)^{\mathrm{a}}\end{array}$ & $\begin{array}{c}e e / \\
(\%)^{\mathrm{a}}\end{array}$ \\
\hline 1 & 45 & 3 & 16 & $97(S)$ \\
2 & 45 & 9 & 51 & $97(S)$ \\
3 & 55 & 9 & 14 & $68(S)$ \\
\hline
\end{tabular}

${ }^{a}$ Conversion and enantiomeric excesses $(e e)$ were determined by GC.

These results revealed that $C$. tropicalis does not present a good thermostabilitity, as a decrease of the ketone reductase activity was observed by working at temperatures above $28^{\circ} \mathrm{C}$ (entries 1 and 2), leading to a dramatic loss of yield and also of the enantiomeric excess especially over $45^{\circ} \mathrm{C}$ (entry 3 ).

\section{Quantity of substrate}

Bioreduction reactions were performed during 9 days at $28{ }^{\circ} \mathrm{C}$ in potato dextrose broth using $6,8,10,12$, $14,15,20,30$ and $40 \mu \mathrm{L}$ of acetophenone $1 \mathrm{a}$ to obtain
(S)-1-phenylethanol in high to excellent enantiomeric excess (Table 5).

A slight improvement was observed in the conversion when less quantity of substrate $(6-12 \mu \mathrm{L})$ was used, but in these conditions was observed a $85 \%$ ee in $(S)-1$ phenylethanol (entries 1-4). The conversion decreased when more quantity of substrate was used (entries 5-9), however higher concentrations of ketone led to better stereopreference values, being in this case $15-20 \mu \mathrm{L}$ the appropriate quantity of ketone (entries 6-7).

Thus, a temperature of $28^{\circ} \mathrm{C}, 9$ days of reaction time, $\mathrm{pH}$ of 5.5, potato-dextrose broth as culture medium and $20 \mu \mathrm{L}$ of acetophenone proved to be the optimum conditions to obtain $(S)$-1-phenylethanol (1b) in good yield (62\%) and high enantiomeric excess $(97 \%$ ee $)$.

Table 5. Effect of the quantity of substrate on the bioreduction of acetophenone (1a) by C. tropicalis CE017

\begin{tabular}{lccc}
\hline Entry & Quantity of $\mathbf{1 a} / \mu \mathrm{L}$ & Conversion $/(\%)^{\mathrm{a}}$ & $e e /(\%)^{\mathrm{a}}$ \\
\hline 1 & 6 & 75 & 85 \\
2 & 8 & 75 & 85 \\
3 & 10 & 71 & 85 \\
4 & 12 & 72 & 85 \\
5 & 14 & 61 & 92 \\
6 & 15 & 60 & 97 \\
7 & 20 & 62 & 97 \\
8 & 30 & 48 & 91 \\
9 & 40 & 44 & 94 \\
\hline
\end{tabular}

\section{Bioreduction of acetophenone derivatives}

After these encouraging results, we decided to extend our studies toward the analysis of the bioreduction of substituted acetophenones. Thus, ketones 2a-10a (Scheme 2) were reduced by growing cells of $C$. tropicalis CE017 using the optimal reaction conditions attained in the bioreduction of acetophenone. The results are summarized in Table 6.

The influence of an electron-donor (OMe) group and an electron-withdrawing $\left(\mathrm{NO}_{2}\right)$ group in ortho, meta- and para- position of the aromatic moiety was analyzed. Reduction of nitroacetophenones occurred with complete conversion yielding the corresponding alcohols $(S)$ 2b-4b with excellent enantioselectivities (entries 1-3). The presence of the nitro group strongly increased the enzymatic activity when compared with acetophenone. Ketone 5a having the methoxy group in the ortho position yielded the corresponding alcohol $(S)-5 \mathbf{b}$ with moderate 
<smiles>[2H]c1cc(C(=O)CBr)ccc1Br</smiles>

2a-10a

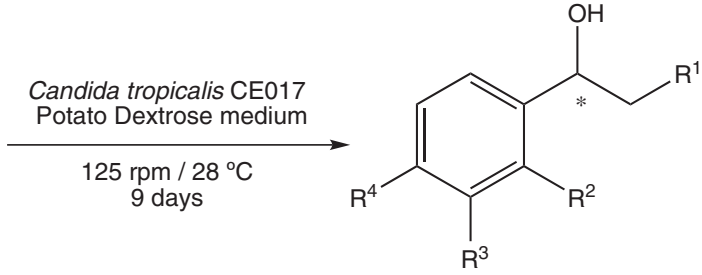

$(S)$ - or $(R)-\mathbf{2 b}-\mathbf{1 0 b}$

$$
\begin{aligned}
& 2 \mathrm{R}^{1}=\mathrm{H}^{2} \quad \mathrm{R}^{2}=\mathrm{NO}_{2} \quad \mathrm{R}^{3}=\mathrm{H} \quad \mathrm{R}^{4}=\mathrm{H} \\
& \begin{array}{llll}
3 \mathrm{R}^{1}=\mathrm{H} & \mathrm{R}^{2}=\mathrm{H} & \mathrm{R}^{3}=\mathrm{NO}_{2} & \mathrm{R}^{4}=\mathrm{H}
\end{array} \\
& 4 \mathrm{R}^{1}=\mathrm{H} \quad \mathrm{R}^{2}=\mathrm{H} \quad \mathrm{R}^{3}=\mathrm{H} \quad \mathrm{R}^{4}=\mathrm{NO}_{2} \\
& 5 \mathrm{R}^{1}=\mathrm{H} \quad \mathrm{R}^{2}=\mathrm{OMe} \mathrm{R}^{3}=\mathrm{H} \quad \mathrm{R}^{4}=\mathrm{H} \\
& 6 \mathrm{R}^{1}=\mathrm{H}^{2} \quad \mathrm{R}^{2}=\mathrm{H} \quad \mathrm{R}^{3}=\mathrm{OMe} \quad \mathrm{R}^{4}=\mathrm{H}
\end{aligned}
$$

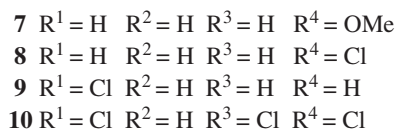

\begin{tabular}{|c|c|c|c|c|c|c|c|}
\hline Entry & Ketone & $\mathrm{R}^{1}$ & $\mathrm{R}^{2}$ & $\mathrm{R}^{3}$ & $\mathrm{R}^{4}$ & Conversion / $(\%)^{\mathrm{a}}$ & $e e /(\%)^{\mathrm{a}}$ \\
\hline 1 & $2 a$ & $\mathrm{H}$ & $\mathrm{NO}_{2}$ & $\mathrm{H}$ & $\mathrm{H}$ & $>99$ & $>99(S)$ \\
\hline 2 & $3 a$ & $\mathrm{H}$ & $\mathrm{H}$ & $\mathrm{NO}_{2}$ & $\mathrm{H}$ & $>99$ & $>99(S)$ \\
\hline 3 & $4 a$ & $\mathrm{H}$ & $\mathrm{H}$ & $\mathrm{H}$ & $\mathrm{NO}_{2}$ & $>99$ & $96(S)$ \\
\hline 4 & $5 a$ & $\mathrm{H}$ & $\mathrm{OMe}$ & $\mathrm{H}$ & $\mathrm{H}$ & 51 & $56(S)$ \\
\hline 5 & $6 a$ & $\mathrm{H}$ & $\mathrm{H}$ & $\mathrm{OMe}$ & $\mathrm{H}$ & 35 & $80(S)$ \\
\hline 6 & $7 a$ & $\mathrm{H}$ & $\mathrm{H}$ & $\mathrm{H}$ & $\mathrm{OMe}$ & 7 & $9(S)$ \\
\hline 7 & $8 a$ & $\mathrm{H}$ & $\mathrm{H}$ & $\mathrm{H}$ & $\mathrm{Cl}$ & 65 & $62(S)$ \\
\hline 8 & $9 a$ & $\mathrm{Cl}$ & $\mathrm{H}$ & $\mathrm{H}$ & $\mathrm{H}$ & 12 & $89(R)$ \\
\hline 9 & 10a & $\mathrm{Cl}$ & $\mathrm{H}$ & $\mathrm{Cl}$ & $\mathrm{Cl}$ & 63 & $90(R)$ \\
\hline
\end{tabular}

Scheme 2. Bioreduction of prochiral aromatic ketones 2a-10a using C. tropicalis CE017.

Table 6. Candida tropicalis $\mathrm{CE} 017$ biocatalyzed reduction of ketones $\mathbf{2 a - 1 0 a}$ in potato-dextrose medium at $28{ }^{\circ} \mathrm{C}, 125 \mathrm{rpm}$ and 9 days

${ }^{a}$ Conversion and enantiomeric excesses (ee) were determined by HPLC or GC (see Experimental section). Absolute configuration of the optically alcohol in brackets.

conversion and selectivity (entry 4). When the methoxy group was located at meta position, the conversion was lower when compared with ketone 5a, being achieved a higher selectivity (entry 5). A strongly decrease in the activity and selectivity was observed for the reduction of 4-methoxyacetophenone (entry 6). The presence of the methoxy group in the para position seemed to be worst for enzymatic activity and selectivity.

4-Chloroacetophenone $\mathbf{8 a}$ yielded the $(S)$-8b with moderate conversion and selectivity (entry 7$)$. The presence of the chlorine atom in the $\alpha$-position to the carbonyl group produced a strong decrease in the product conversion with a good enantioselectivity, as shown in entry 8 for the preparation of alcohol $(S)-\mathbf{9 b}$, yielding in this case the $(R)$-alcohol due to CIP rules (entry 8).

Bioreduction of $\mathbf{1 0 a}$, compound presenting two chlorine atoms in the aromatic ring and one chlorine atom in the $\alpha$-position to the carbonyl group, occurred with a similar conversion to acetophenone 8a and a similar stereoselectivity compared to ketone 9a (entry 9). Again, $(R)$-10b was obtained due to a change of priority in the CIP rules.
Our research group has been working to select several microorganisms from Brazilian biodiversity in order to perform selective bioreduction reactions using whole cells. We have found some interesting suppliers of alcohol dehydrogenases such Lasiodiplodia theobromae ${ }^{9}$ and Lentinus strigellus ${ }^{10}$ and now we can compare the results previously obtained in these manuscripts with Candida tropicalis. Each one is worth of attention due to their particularities. Candida tropicalis has not a good affinity for acetophenones bearing methoxy group moiety. Opposite, fungal cells of $L$. theobromae and L. strigellus catalyze the bioreduction of these methoxyacetophenones with higher enantioselectivities (87-99\%). On the other hand, L. theobromae had poor selectivity for nitroacetophenones, 3a (only $45 \%$ of $e e$ ) and $\mathbf{4 a}$ (42\% of ee). Lentinus strigellus had good enantioselectivities (98-99\%) but moderate conversion of $\mathbf{2 a}(48 \%)$, that could not be improved after longer reaction times. Candida tropicalis was the most successful among them to reduce nitroacetophenones with high to excellent conversion and enantioselectivity values. It must be emphasize that nitrocompounds are important building blocks in organic synthesis ${ }^{13}$ as well as precursors 
of the corresponding amines after a reduction process. ${ }^{14} \mathrm{In}$ addition, alcohol $\mathbf{6 b}$ is a relevant compound in the synthesis of $(S)$-Rivastigmine ${ }^{15}$ and the alcohol $\mathbf{1 0 b}$ can be used in the preparation of the pharmacological active Sertraline. ${ }^{16}$

In conclusion, all this family of chiral alcohols can be obtained by an enzymatic strategy, just selecting the best local microorganism in each specific case.

\section{Conclusions}

Growing cells of a new yeast strain, C. tropicalis CE017 in potato dextrose have been shown as an excellent and inexpensive biocatalyst for the introduction of chirality in bioreduction processes. When reducing substituted aromatic ketones, the presence of a nitro group in the aromatic moiety has a positive effect in the biocatalytic properties of C. tropicalis CE017, yielding the corresponding alcohols with complete conversion and $e e>95 \%$. On the other hand, methoxyacetophenones seemed to be poorer substrates for this yeast. In all cases the biocatalyst has presented Prelog selectivity for the production of optically active alcohols. Comparison with two microorganisms previously studied in our group (L. theobromae and L. strigellus) revealed its particularities. In this case, Candida tropicalis was the most successful among them to reduce nitroacetophenones with great conversion and enantioselectivity. The evaluation of locally available microorganisms for a selection of standard organic chemical reactions of commercial significance could prove to be a very valuable economic endeavor. It may well offer new opportunities to expand the local resources as sustainable enzymatic systems where highcost, unstable coenzymes are presently used.

\section{Experimental}

\section{General}

All reagents were purchased from Aldrich and used without further purification. Dry solvents were distilled over an adequate desiccant under nitrogen. Flash chromatographies were performed using silica gel 60 (230-240 mesh). High performance liquid chromatography (HPLC) analysis were carried out in a Hewlett Packard 1100 chromatograph UV detector at $210 \mathrm{~nm}$ using a Daicel Chiralcel OB-H, Chiralpak AS or Chiralpak IA column $(25 \mathrm{~cm} \times 4.6 \mathrm{~mm}$ I.D.) varying the conditions depending on the specific substrate, and using mixtures of hexane and 2-propanol (IPA). Gas chromatography (GC) analysis were performed on a Hewlett Packard 6890 Series II chromatograph equipped with a CP-Chiralsil DEX CB or a HP-1 column $\left(30 \mathrm{~m} \times 0.25 \mathrm{~mm} \times 0.25 \mu \mathrm{m}, 1.0 \mathrm{bar}_{\mathrm{N}}\right)$ from
Varian for determining the optical purities. ${ }^{1} \mathrm{H},{ }^{13} \mathrm{C}$ NMR, DEPT, and ${ }^{1} \mathrm{H}-{ }^{13} \mathrm{C}$ heteronuclear experiments were obtained using AC-200 $\left({ }^{1} \mathrm{H}, 200.13 \mathrm{MHz}\right.$ and $\left.{ }^{13} \mathrm{C}, 50.3 \mathrm{MHz}\right)$, AC-300 $\left({ }^{1} \mathrm{H}, 300.13 \mathrm{MHz}\right.$ and $\left.{ }^{13} \mathrm{C}, 75.5 \mathrm{MHz}\right), \mathrm{DPX}-300$ $\left({ }^{1} \mathrm{H}, 300.13 \mathrm{MHz}\right.$ and $\left.{ }^{13} \mathrm{C}, 75.5 \mathrm{MHz}\right)$ or AV-400 $\left({ }^{1} \mathrm{H}\right.$, $400.13 \mathrm{MHz}$ and $\left.{ }^{13} \mathrm{C}, 100.6 \mathrm{MHz}\right)$ Bruker spectrometers. The chemical shifts are given in delta $(\delta)$ values and the coupling constants $(J)$ in Hertz $(\mathrm{Hz})$. Optical rotations were performed in a Perkin-Elmer 241 polarimeter. General procedure for preparation of racemic alcohols
$\mathbf{1 a - 1 0 a}$

To a solution of the corresponding ketone 1a-10a $(200 \mathrm{mg})$ in dry $\mathrm{MeOH}(4.0 \mathrm{~mL})$ was slowly added sodium borohydride (4 equiv) at $0{ }^{\circ} \mathrm{C}$ under nitrogen atmosphere. The reaction was stirred at room temperature during $3 \mathrm{~h}$ and followed by TLC analysis (20\% EtOAc/hexane) until complete disappearance of the starting ketone. Solvent was evaporated under reduced pressure and the resulting suspension was redissolved in $\mathrm{H}_{2} \mathrm{O}$ and extracted with EtOAc $(3 \times 100 \mathrm{~mL})$. Organic phases were combined and dried over anhydrous $\mathrm{Na}_{2} \mathrm{SO}_{4}$. After solvent distillation under reduced pressure, the resulting crude product was purified by flash chromatography [10\% EtOAc/hexane for $\mathbf{1 b}(88 \%$ yield) and $\mathbf{1 0 b}$ (92\% yield), 15\% EtOAc/hexane for $\mathbf{5 b}$ ( $74 \%$ yield), $\mathbf{6 b}$ (86\% yield), $7 \mathbf{b}$ (96\% yield), $\mathbf{8 b}$ (83\% yield), $9 \mathbf{b}$ (90\% yield) and $20 \%$ EtOAc/hexane for $\mathbf{2 b}$ (97\% yield), 3b (95\% yield), and $\mathbf{4 b}$ (95\% yield)].

\section{Candida tropicalis strain CE017}

The strain CE017 was previously isolated from an oil refinery wastewater located in Fortaleza city (Ceara state, Brazil) by enrichment cultivation. ${ }^{17}$ This strain was identified as Candida tropicalis according to micromorphological and biochemical characteristics. ${ }^{18}$ It is noteworthy that C. tropicalis CE017 showed a particular ability to degrade high phenol concentration and might be useful in bioremediation activities. ${ }^{17}$ This strain is deposited in the Culture Collection of the Microbial Ecology and Biotechnology Laboratory at Biology Department of the Federal University of Ceará, Brazil.

\section{Culture conditions}

For inoculums preparation, stock cultures were cultivated in potato broth (Potato $4 \mathrm{~g} \mathrm{~L}^{-1}$, Dextrose $20 \mathrm{~g} \mathrm{~L}^{-1}$, HIMEDIA) $\mathrm{pH} 5.5$ for $24 \mathrm{~h}$ at $28{ }^{\circ} \mathrm{C}$ under shaking conditions (125 rpm). After this, the absorbance of the culture was adjusted with $0.15 \mathrm{~mol} \mathrm{~L}^{-1} \mathrm{NaCl}$ solution to 
0.5 at $600 \mathrm{~nm}$ to obtain a suspension of $32 \times 10^{6} \mathrm{CFU} \mathrm{mL}^{-1}$ determined by counting of colony forming units (CFU) on Potato Agar Plates. An aliquot of $1.0 \mathrm{~mL}$ of this suspension was inoculated in $250 \mathrm{~mL}$ Erlenmeyer flask containing $100 \mathrm{~mL}$ of Potato broth to produce biomass. When Peptone/ Dextrose was used as medium the counting of CFU was $15 \times 10^{6} \mathrm{CFU} \mathrm{mL}{ }^{-1}$. In the case of Czapeck medium the $\mathrm{CFU}$ value was $57 \times 10^{3} \mathrm{CFU} \mathrm{mL}^{-1}$.

Procedure for the bioreduction of acetophenone and its derivatives using Candida tropicalis

The growing cells of $C$. tropicalis CE017 were used for bioreduction reactions according literature procedure. ${ }^{19}$ Then, $20 \mathrm{mg}$ of substrate were added into erlenmeyer flask and the reactions were shaken for 9 days of reaction. The content of each flask was saturated with sodium chloride, and then the aqueous phase was extracted with EtOAc $(3 \times 80 \mathrm{~mL})$. The organic phase was dried over with $\mathrm{Na}_{2} \mathrm{SO}_{4}$ and then the solvent was evaporated under reduced pressure. The reaction crude was analyzed by the appropriate condition and purified by flash chromatography. All the bioreduction experiments were done in triplicate.

\section{(S)-1-Phenylethanol, $\mathbf{1 b}$}

${ }^{1} \mathrm{H} \mathrm{NMR}\left(\mathrm{CDCl}_{3}, 300.13 \mathrm{MHz}\right): \delta 1.39(\mathrm{~d}, J 6.5 \mathrm{~Hz}, 3 \mathrm{H}$, $\left.\mathrm{H}_{2}\right), 2.03(\mathrm{~s}, 1 \mathrm{H}, \mathrm{OH}), 4.77\left(\mathrm{q}, J 6.5 \mathrm{~Hz}, 1 \mathrm{H}, \mathrm{H}_{1}\right), 7.25(\mathrm{~m}$, $5 \mathrm{H}, \mathrm{H}_{2},+\mathrm{H}_{3},+\mathrm{H}_{4},+\mathrm{H}_{5}$, ; ${ }^{13} \mathrm{C} \mathrm{NMR}\left(\mathrm{CDCl}_{3}, 75.5 \mathrm{MHz}\right)$ : $\delta 25.3\left(\mathrm{C}_{2}\right) ; 70.5\left(\mathrm{C}_{1}\right), 125.5\left(\mathrm{C}_{2}, \mathrm{C}_{6}\right), 127.6\left(\mathrm{C}_{4}\right), 128.6$ $\left(\mathrm{C}_{3},+\mathrm{C}_{5},\right), 146.0\left(\mathrm{C}_{1}\right)$. Conditions for determination of

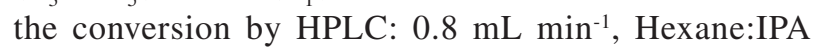
(95:5), $20^{\circ} \mathrm{C}, t_{\mathrm{R}}(\mathbf{1 a}) 5.8 \mathrm{~min}$ and $t_{\mathrm{R}}$ (1) $8.4 \mathrm{~min}$. Column Spherisorb. Conditions for determination of the ee by HPLC: $0.8 \mathrm{~mL} \mathrm{~min}^{-1}$, hexane:IPA (95:5), $20^{\circ} \mathrm{C}, t_{\mathrm{R}} 10.2(S)$ and $t_{\mathrm{R}} 15.4(R)$ min. Column OB-H. $[\alpha]_{\mathrm{D}}^{25}=-47.0, \mathrm{c} 1.1$, $\mathrm{CHCl}_{3}$, for $97 \%$ ee of $(S)$-enantiomer. lit.: $[\alpha]_{\mathrm{D}}^{22}=-62.8$ (c 1.0, $\left.\mathrm{CHCl}_{3}\right), 98.5 \% e e .{ }^{20}$

\section{(S)-1-(2-Nitrophenyl)ethanol, $2 \boldsymbol{b}$}

${ }^{1} \mathrm{H}$ NMR $\left(\mathrm{CDCl}_{3}, 300.13 \mathrm{MHz}\right): \delta 1.55(3 \mathrm{H}, \mathrm{d}, J 6.3$ $\left.\mathrm{Hz}, \mathrm{H}_{2}\right), 5.40\left(1 \mathrm{H}, \mathrm{q}, J 6.3 \mathrm{~Hz}, \mathrm{H}_{1}\right), 7.41(1 \mathrm{H}, \mathrm{dt}, J 8.1$ and $\left.1.2 \mathrm{~Hz}, \mathrm{H}_{4}\right), 7.63\left(1 \mathrm{H}, \mathrm{dt}, J 8.1\right.$ and $\left.1.5 \mathrm{~Hz}, \mathrm{H}_{5}\right), 7.82(1 \mathrm{H}$, dd, $J 8.1$ and $\left.1.2 \mathrm{~Hz}, \mathrm{H}_{6}\right), 7.88(1 \mathrm{H}, \mathrm{dd}, J 8.1$ and $1.5 \mathrm{~Hz}$, $\left.\mathrm{H}_{3},\right) ;{ }^{13} \mathrm{C} \mathrm{NMR}\left(\mathrm{CDCl}_{3}, 75.5 \mathrm{MHz}\right): \delta 24.2\left(\mathrm{C}_{2}\right), 65.4\left(\mathrm{C}_{1}\right)$, $124.2\left(\mathrm{C}_{3}\right), 127.5\left(\mathrm{C}_{6}\right), 128.0\left(\mathrm{C}_{4}\right), 133.5\left(\mathrm{C}_{5}\right), 140.9$ $\left(\mathrm{C}_{1},+\mathrm{C}_{2}\right)$. Conditions for determination of the conversion by GC: Injector $225^{\circ} \mathrm{C}$, Detector $250^{\circ} \mathrm{C}, 80^{\circ} \mathrm{C}\left(5^{\circ} \mathrm{C} \mathrm{min}{ }^{-1}\right)$ $180^{\circ} \mathrm{C}(0 \mathrm{~min}), t_{\mathrm{R}}(\mathbf{2 a}) 8.4 \mathrm{~min}$ and $t_{\mathrm{R}}(\mathbf{2 b}) 9.2 \mathrm{~min}$. Column HP-1. Conditions for determination of the ee by HPLC: $0.8 \mathrm{~mL} \mathrm{~min}^{-1}$, hexane:IPA (97:3), $20^{\circ} \mathrm{C}, t_{\mathrm{R}} 22.1 \mathrm{~min}(R)$ and
$t_{\mathrm{R}} 23.9(S)$ min. Column AS. $[\alpha]_{\mathrm{D}}^{25}=+29.8$, c $0.4, \mathrm{CHCl}_{3}$, for $99 \%$ ee of $(S)$-enantiomer. ${ }^{21}$

\section{(S)-1-(3-Nitrophenyl)ethanol, $3 \boldsymbol{b}$}

${ }^{1} \mathrm{H} \mathrm{NMR}\left(\mathrm{CDCl}_{3}, 300.13 \mathrm{MHz}\right): \delta 1.47(3 \mathrm{H}, \mathrm{d}, J 6.6 \mathrm{~Hz}$, $\left.\mathrm{H}_{2}\right), 4.96\left(1 \mathrm{H}, \mathrm{q}, J 6.6 \mathrm{~Hz}, \mathrm{H}_{1}\right), 7.47\left(1 \mathrm{H}, \mathrm{t}, J 7.8 \mathrm{~Hz}, \mathrm{H}_{5}\right)$, $7.67\left(1 \mathrm{H}, \mathrm{d}, J 7.8 \mathrm{~Hz}, \mathrm{H}_{6}\right), 8.04(1 \mathrm{H}$, ddd, $J 8.3,2.1$ and $\left.0.9 \mathrm{~Hz}, \mathrm{H}_{4}\right), 8.18\left(1 \mathrm{H}, \mathrm{t}, J 1.8 \mathrm{~Hz}, \mathrm{H}_{2}\right) ;{ }^{13} \mathrm{C} \mathrm{NMR}\left(\mathrm{CDCl}_{3}\right.$, $75.5 \mathrm{MHz}): \delta 25.2\left(\mathrm{C}_{2}\right), 69.1\left(\mathrm{C}_{1}\right), 120.2\left(\mathrm{C}_{4}\right), 122.1\left(\mathrm{C}_{2},\right)$, $129.3\left(\mathrm{C}_{5}\right), 131.6\left(\mathrm{C}_{6}\right), 147.8\left(\mathrm{C}_{1}\right), 148.1\left(\mathrm{C}_{3}\right)$. Conditions for determination of the conversion by GC: Injector $225^{\circ} \mathrm{C}$, Detector $250{ }^{\circ} \mathrm{C}, 80^{\circ} \mathrm{C}\left(5^{\circ} \mathrm{C} \mathrm{min}{ }^{-1}\right) 180^{\circ} \mathrm{C}(0 \mathrm{~min}), t_{\mathrm{R}}$ (3a) $9.5 \mathrm{~min}$ and $t_{\mathrm{R}}(\mathbf{3 b}) 11.4 \mathrm{~min}$. Column HP-1. Conditions for determination of the ee by HPLC: $0.8 \mathrm{~mL} \mathrm{~min}^{-1}$, hexane:IPA (90:10), $20^{\circ} \mathrm{C}, t_{\mathrm{R}} 12.8 \min (S)$ and $t_{\mathrm{R}} 14.2(R)$ min. Column OB-H. $[\alpha]_{\mathrm{D}}^{25}=-34.9$, c $0.5 \mathrm{CH}_{2} \mathrm{Cl}_{2}$, for $99 \%$ $e e$ of $(S)$-enantiomer. ${ }^{22}$

\section{(S)-1-(4-Nitrophenyl)ethanol, $4 \boldsymbol{b}$}

${ }^{1} \mathrm{H} \mathrm{NMR}\left(\mathrm{CDCl}_{3}, 300.13 \mathrm{MHz}\right): \delta 1.50(3 \mathrm{H}, \mathrm{d}, J 6.6 \mathrm{~Hz}$, $\left.\mathrm{H}_{2}\right), 5.01\left(1 \mathrm{H}, \mathrm{q}, J 6.6 \mathrm{~Hz}, \mathrm{H}_{1}\right), 7.53(2 \mathrm{H}, \mathrm{d}, J 8.7 \mathrm{~Hz}$, $\left.\mathrm{H}_{2},+\mathrm{H}_{6}\right), 8.17\left(2 \mathrm{H}, \mathrm{d}, J 8.7 \mathrm{~Hz}, \mathrm{H}_{3},+\mathrm{H}_{5}\right) ;{ }^{13} \mathrm{C} \mathrm{NMR}$ $\left(\mathrm{CDCl}_{3}, 75.5 \mathrm{MHz}\right): \delta 25.3\left(\mathrm{C}_{2}\right), 69.5\left(\mathrm{C}_{1}\right), 123.6$ $\left(\mathrm{C}_{2},+\mathrm{C}_{6}\right), 126.0\left(\mathrm{C}_{3},+\mathrm{C}_{5}\right), 147.0\left(\mathrm{C}_{1}\right), 153.1\left(\mathrm{C}_{4}\right)$. Conditions for determination of the conversion by $\mathrm{GC}$ : Injector $225^{\circ} \mathrm{C}$, Detector $250^{\circ} \mathrm{C}, 80^{\circ} \mathrm{C}\left(5^{\circ} \mathrm{C} \mathrm{min}{ }^{-1}\right) 180^{\circ} \mathrm{C}$ $(0 \mathrm{~min}), t_{\mathrm{R}}(\mathbf{4 a}) 9.6 \mathrm{~min}$ and $t_{\mathrm{R}}(\mathbf{4 b}) 11.8 \mathrm{~min}$. Column HP-1. Conditions for determination of the ee by HPLC: $0.8 \mathrm{~mL} \mathrm{~min}^{-1}$, hexane:IPA $(95: 5), 20^{\circ} \mathrm{C}, t_{\mathrm{R}} 11.7 \mathrm{~min}(R)$ and $t_{\mathrm{R}} 12.8(S)$ min. Column AS. $[\alpha]_{\mathrm{D}}^{25}=-24.6, \mathrm{c} 0.5, \mathrm{CHCl}_{3}$, for $96 \%$ ee of $(S)$-enantiomer. ${ }^{23}$

\section{(S)-1-(2-Methoxyphenyl)ethanol, $5 \boldsymbol{b}$}

${ }^{1} \mathrm{H} \mathrm{NMR}\left(\mathrm{CDCl}_{3}, 300.13 \mathrm{MHz}\right): \delta 1.52(3 \mathrm{H}, \mathrm{d}, J 6.6 \mathrm{~Hz}$, $\left.\mathrm{H}_{2}\right), 3.88\left(3 \mathrm{H}, \mathrm{s}, \mathrm{OCH}_{3}\right), 5.11\left(1 \mathrm{H}, \mathrm{q}, J 6.6 \mathrm{~Hz}, \mathrm{H}_{1}\right), 6.90$ $\left(1 \mathrm{H}, \mathrm{dd}, J 7.5\right.$ and $\left.1.5 \mathrm{~Hz}, \mathrm{H}_{3}\right), 6.98(1 \mathrm{H}, \mathrm{dt}, J 8.5$ and $\left.1.5 \mathrm{~Hz}, \mathrm{H}_{5}\right), 7.29\left(1 \mathrm{H}, \mathrm{dt}, J 8.5\right.$ and $\left.1.5 \mathrm{~Hz}, \mathrm{H}_{6}\right), 7.36(1 \mathrm{H}$, dd, $J 7.5$ and $\left.1.5 \mathrm{~Hz}, \mathrm{H}_{4}\right)$; ${ }^{13} \mathrm{C} \mathrm{NMR}\left(\mathrm{CDCl}_{3}, 75.5 \mathrm{MHz}\right)$ : $\delta 22.8\left(\mathrm{C}_{2}\right), 55.2\left(\mathrm{OCH}_{3}\right), 66.3\left(\mathrm{C}_{1}\right), 110.3\left(\mathrm{C}_{3}\right), 120.7$ $\left(\mathrm{C}_{5}\right), 126.0\left(\mathrm{C}_{6}\right), 128.2\left(\mathrm{C}_{4}\right), 133.4\left(\mathrm{C}_{1}\right), 156.4\left(\mathrm{C}_{2}\right)$. Conditions for determination of the conversion by HPLC: $0.8 \mathrm{~mL} \mathrm{~min}^{-1}$, hexane:IPA (95:5), $20^{\circ} \mathrm{C}, t_{\mathrm{R}}$ (5a) $6.3 \mathrm{~min}$ and $t_{\mathrm{R}}(\mathbf{5 b}) 7.1 \mathrm{~min}$. Column Spherisorb. Conditions for determination of the ee by HPLC: $0.8 \mathrm{~mL} \mathrm{~min}^{-1}$, hexane:IPA (95:5), $20^{\circ} \mathrm{C}, t_{\mathrm{R}} 10.3(S)$ and $t_{\mathrm{R}} 16.8(R)$ min. Column OB-H. $[\alpha]_{\mathrm{D}}^{25}=-4.5, \mathrm{c} 0.4, \mathrm{CH}_{2} \mathrm{Cl}_{2}$, for $56 \%$ ee of $(S)$-enantiomer. ${ }^{24}$

\section{(S)-1-(3-Methoxyphenyl)ethanol, $6 \boldsymbol{b}$}

${ }^{1} \mathrm{H} \mathrm{NMR}\left(\mathrm{CDCl}_{3}, 300.13 \mathrm{MHz}\right): \delta 1.47(3 \mathrm{H}, \mathrm{d}, J 6.6 \mathrm{~Hz}$, $\left.\mathrm{H}_{2}\right), 3.81\left(3 \mathrm{H}, \mathrm{s}, \mathrm{OCH}_{3}\right), 4.83\left(1 \mathrm{H}, \mathrm{q}, J 6.6 \mathrm{~Hz}, \mathrm{H}_{1}\right), 6.81$ $\left(1 \mathrm{H}, \mathrm{dd}, J 8.5\right.$ and $\left.1.2 \mathrm{~Hz}, \mathrm{H}_{6}\right), 6.93\left(2 \mathrm{H}, \mathrm{m}, \mathrm{H}_{2},+\mathrm{H}_{4}\right)$, 
$7.26\left(1 \mathrm{H}, \mathrm{t}, J 8.5 \mathrm{~Hz}, \mathrm{H}_{5}\right) ;{ }^{13} \mathrm{C} \mathrm{NMR}\left(\mathrm{CDCl}_{3}, 75.5 \mathrm{MHz}\right)$ : $\delta 25.0\left(\mathrm{C}_{2}\right), 55.1\left(\mathrm{OCH}_{3}\right), 70.0\left(\mathrm{C}_{1}\right), 110.8\left(\mathrm{C}_{2}\right), 112.7\left(\mathrm{C}_{4}\right)$, 117.6 $\left(\mathrm{C}_{6}\right), 129.3\left(\mathrm{C}_{5}\right), 147.6\left(\mathrm{C}_{1}\right), 159.6\left(\mathrm{C}_{3}\right)$. Conditions for determination of the conversion by HPLC: $0.8 \mathrm{~mL} \mathrm{~min}^{-1}$, hexane:IPA (95:5), $20{ }^{\circ} \mathrm{C}, t_{\mathrm{R}}(\mathbf{6 a}) 5.1 \mathrm{~min}$ and $t_{\mathrm{R}}(\mathbf{6 b})$ 5.9 min. Column Spherisorb. Conditions for determination of the ee by HPLC: $0.8 \mathrm{~mL} \mathrm{~min}{ }^{-1}$, hexane:IPA (95:5), $20^{\circ} \mathrm{C}, t_{\mathrm{R}} 20.1 \mathrm{~min}(S)$ and $t_{\mathrm{R}} 29.5 \mathrm{~min}(R)$. Column OB-H. $[\alpha]_{\mathrm{D}}^{25}=-21.6, \mathrm{c} 0.34, \mathrm{MeOH}$, for $80 \%$ ee of $(S)$-enantiomer. ${ }^{25}$

\section{(S)-1-(4-Methoxyphenyl)ethanol, $7 \boldsymbol{b}$}

${ }^{1} \mathrm{H} \mathrm{NMR}\left(\mathrm{CDCl}_{3}, 300.13 \mathrm{MHz}\right): \delta 1.48(3 \mathrm{H}, \mathrm{d}, J 6.3 \mathrm{~Hz}$, $\left.\mathrm{H}_{2}\right), 3.82\left(3 \mathrm{H}, \mathrm{s}, \mathrm{OCH}_{3}\right), 4.84\left(1 \mathrm{H}, \mathrm{q}, J 6.3 \mathrm{~Hz}, \mathrm{H}_{1}\right), 6.88$ $\left(2 \mathrm{H}, \mathrm{d}, J 8.7 \mathrm{~Hz}, \mathrm{H}_{3},+\mathrm{H}_{5}\right), 7.30\left(2 \mathrm{H}, \mathrm{d}, J 8.7 \mathrm{~Hz}, \mathrm{H}_{2},+\mathrm{H}_{6}\right)$; ${ }^{13} \mathrm{C}$ NMR $\left(\mathrm{CDCl}_{3}, 75.5 \mathrm{MHz}\right): \delta 24.3\left(\mathrm{C}_{2}\right), 55.2(\mathrm{OMe})$, $69.8\left(\mathrm{C}_{1}\right), 126.6\left(\mathrm{C}_{2},+\mathrm{C}_{6}\right), 113.8\left(\mathrm{C}_{3}, \mathrm{C}_{5}\right), 137.9\left(\mathrm{C}_{1}\right)$, $158.9\left(\mathrm{C}_{4}\right)$. Conditions for determination of the conversion by HPLC: $0.8 \mathrm{~mL} \mathrm{~min}^{-1}$, Hexane:IPA (95:5), $20^{\circ} \mathrm{C}$, $t_{\mathrm{R}}$ (7a) 7.3 min and $t_{\mathrm{R}}$ (7b) 8.5 min. Column Spherisorb. Conditions for determination of the ee by HPLC: $0.8 \mathrm{~mL} \mathrm{~min}^{-1}$; hexane:IPA $(95: 5) ; 20^{\circ} \mathrm{C}, t_{\mathrm{R}} 13.4 \mathrm{~min}(S)$ and $t_{\mathrm{R}} 18.7(R)$ min. Column OB-H. $[\alpha]_{\mathrm{D}}^{25}=-2.2, \mathrm{c} 0.5, \mathrm{CH}_{2} \mathrm{Cl}_{2}$, for $9 \%$ ee of $(S)$-enantiomer. ${ }^{24}$

\section{(S)-1-(4-Chlorophenyl)ethanol, $8 \boldsymbol{b}$}

${ }^{1} \mathrm{H} \mathrm{NMR}\left(\mathrm{CDCl}_{3}, 300.13 \mathrm{MHz}\right): \delta 1.45(1 \mathrm{H}, \mathrm{d}, J 6.5 \mathrm{~Hz}$, $\left.\mathrm{H}_{1}\right), 4.87\left(\mathrm{q}, J 6.5 \mathrm{~Hz}, \mathrm{H}_{2}\right), 7.30\left(\mathrm{~m}, 4 \mathrm{H}, \mathrm{H}_{2},+\mathrm{H}_{3},+\mathrm{H}_{5},+\right.$ $\left.\mathrm{H}_{6}\right) ;{ }^{13} \mathrm{C} \mathrm{NMR}\left(\mathrm{CDCl}_{3}, 75.5 \mathrm{MHz}\right): \delta 25.1\left(\mathrm{C}_{2}\right), 69.6\left(\mathrm{C}_{1}\right)$, $126.7\left(\mathrm{C}_{2}\right), 128.5\left(\mathrm{C}_{3}\right), 132.9\left(\mathrm{C}_{4}\right), 144.1\left(\mathrm{C}_{1}\right)$. Conditions for determination of the conversion by GC: Injector $225^{\circ} \mathrm{C}$, Detector $250{ }^{\circ} \mathrm{C}, 90{ }^{\circ} \mathrm{C}\left(3{ }^{\circ} \mathrm{C} \mathrm{min}^{-1}\right) 105^{\circ} \mathrm{C}\left(5^{\circ} \mathrm{C} \mathrm{min}^{-1}\right)$ $120^{\circ} \mathrm{C}\left(20^{\circ} \mathrm{C} \mathrm{min}^{-1}\right) 200^{\circ} \mathrm{C}(0 \mathrm{~min}), t_{\mathrm{R}}(\mathbf{8 a}) 5.0 \mathrm{~min}$ and $t_{\mathrm{R}}$ (8b) 5.6 min. Column HP-1. Conditions for determination of the ee by HPLC: $0.8 \mathrm{~mL} \mathrm{~min}{ }^{-1}$, hexane:IPA (95:5), $20{ }^{\circ} \mathrm{C}, t_{\mathrm{R}}$ 7. $\min (S)$ and $t_{\mathrm{R}} 8.5 \mathrm{~min}(R)$. Column OB-H. $[\alpha]_{\mathrm{D}}^{25}=-32.4, \mathrm{CH}_{2} \mathrm{Cl}_{2}, \mathrm{c} 0.5$, for $62 \%$ ee of $(S)$-enantiomer. ${ }^{24}$

\section{(R)-2-Chlorophenylethan-1-ol, $9 \boldsymbol{b}$}

${ }^{1} \mathrm{H}$ NMR $\left(\mathrm{CDCl}_{3}, 300.13 \mathrm{MHz}\right): \delta 3.56(1 \mathrm{H}, \mathrm{dd}, J 11.4$ and $\left.3.3 \mathrm{~Hz}, \mathrm{H}_{2}\right), 3.66\left(1 \mathrm{H}, \mathrm{dd}, J 11.4\right.$ and $\left.8.7 \mathrm{~Hz}, \mathrm{H}_{2}\right), 4.81$ $\left(1 \mathrm{H}, \mathrm{dd}, J 8.7\right.$ and $\left.3.6 \mathrm{~Hz}, \mathrm{H}_{1}\right), 7.30\left(5 \mathrm{H}, \mathrm{m}, \mathrm{H}_{2},+\mathrm{H}_{3},+\right.$ $\left.\mathrm{H}_{4},+\mathrm{H}_{5},+\mathrm{H}_{6}\right) ;{ }^{13} \mathrm{C} \mathrm{NMR}\left(\mathrm{CDCl}_{3}, 75.5 \mathrm{MHz}\right): \delta 50.8\left(\mathrm{C}_{2}\right)$, $74.0\left(\mathrm{C}_{1}\right), 126.0\left(\mathrm{C}_{2}, \mathrm{C}_{6}\right), 128.4$ and $128.6\left(\mathrm{C}_{3},+\mathrm{C}_{5}\right)$, $139.9\left(\mathrm{C}_{1}\right)$. Conditions for determination of the conversion by GC: Injector $225^{\circ} \mathrm{C}$, Detector $250^{\circ} \mathrm{C}, 90^{\circ} \mathrm{C}\left(3^{\circ} \mathrm{C} \mathrm{min}^{-1}\right)$ $105^{\circ} \mathrm{C}\left(5^{\circ} \mathrm{C} \mathrm{min}{ }^{-1}\right) 120\left(20^{\circ} \mathrm{C} \mathrm{min}^{-1}\right) 200{ }^{\circ} \mathrm{C}(0 \mathrm{~min}), t_{\mathrm{R}}$ (9a) 4.1 min and $t_{\mathrm{R}}(\mathbf{9 b}) 4.3 \mathrm{~min}$. Column HP-1. Conditions for determination of the ee by HPLC: $0.8 \mathrm{~mL} \mathrm{~min}^{-1}$, hexane:IPA (95:5), $20^{\circ} \mathrm{C}, t_{\mathrm{R}} 13.2(R)$ and $t_{\mathrm{R}} 17.2(S)$ min. Column OB-H. $[\alpha]_{\mathrm{D}}^{25}=-18.8, \mathrm{c} 0.26, \mathrm{CH}_{2} \mathrm{Cl}_{2}$, for $89 \%$ ee of $(R)$-enantiomer. ${ }^{26}$
(R)-2-Chloro-1-(3,4-dichlorophenyl)ethan-1-ol, $\mathbf{1 0 b}^{27}$

${ }^{1} \mathrm{H} \mathrm{NMR}\left(\mathrm{CDCl}_{3}, 300.13 \mathrm{MHz}\right): \delta 3.59(1 \mathrm{H}, \mathrm{dd}, J 11.4$, and $\left.8.7 \mathrm{~Hz}, \mathrm{H}_{2}\right), 3.72\left(1 \mathrm{H}, \mathrm{dd}, J 11.4\right.$ and $\left.3.6 \mathrm{~Hz}, \mathrm{H}_{2}\right)$, $4.87\left(1 \mathrm{H}\right.$, dd, $J 8.7$ and $\left.3.6 \mathrm{~Hz}, \mathrm{H}_{1}\right), 7.21(1 \mathrm{H}, \mathrm{dd}, J 8.4$ and $\left.1.8 \mathrm{~Hz}, \mathrm{H}_{6}\right), 7.43\left(1 \mathrm{H}, \mathrm{d}, J 8.4 \mathrm{~Hz}, \mathrm{H}_{5}\right), 7.51(1 \mathrm{H}, \mathrm{d}$, $\left.J 1.8 \mathrm{~Hz}, \mathrm{H}_{2}\right) ;{ }^{13} \mathrm{C}$ NMR $\left(\mathrm{CDCl}_{3}, 75.5 \mathrm{MHz}\right): \delta 50.4\left(\mathrm{C}_{2}\right)$, $72.8\left(\mathrm{C}_{1}\right), 125.4\left(\mathrm{C}_{6}\right), 128.1\left(\mathrm{C}_{2}\right), 130.6\left(\mathrm{C}_{5}\right), 132.4\left(\mathrm{C}_{4}\right)$, $132.8\left(\mathrm{C}_{3}\right), 140.0\left(\mathrm{C}_{1}\right)$. Conditions for determination of the conversion by GC: Injector $225^{\circ} \mathrm{C}$, Detector $250^{\circ} \mathrm{C}$,

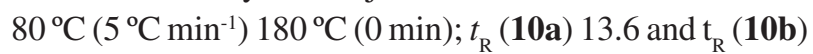
14.8 min. Column HP-1. Conditions for determination of the ee by HPLC: $0.8 \mathrm{~mL} \mathrm{~min}^{-1}$, hexane:IPA (95:5), $20{ }^{\circ} \mathrm{C}, t_{\mathrm{R}} 13.0 \min (S)$ and $t_{\mathrm{R}} 14.9(R)$ min. Column IA. $[\alpha]_{\mathrm{D}}^{25}=-13.3, \mathrm{c} 0.5, \mathrm{CHCl}_{3}$, for $90 \%$ ee of $(R)$-enantiomer. ${ }^{28}$

\section{Supplementary Information}

Supplementary data for $\mathbf{1 b}-\mathbf{1 0 b}$ alcohols are available free of charge at http://jbcs.sbq.org.br, as a PDF file.

\section{Acknowledgments}

The authors thank to the Brazilian and Spanish agencies CAPES-DGU (Process: 149/07), CNPq, FUNCAP, PRONEX, Ministerio de Ciencia e Innovación (MICINN, Project CTQ 2007-61126) for fellowships and financial support. G. de G. and V. G.-F. thank MICINN for personal grants (Juan de la Cierva and Ramon y Cajal program, respectively).

\section{References}

1. Kurbanoglu, E. B.; Zilbeyaz, K.; Kurbanoglu, N. I.; Kilic, H.; Tetrahedron: Asymmetry 2007, 18, 2332.

2. Costa, L. F. A.; Lemos, F.; Ribeiro, F. R.; Cabral, J. M. S.; Catal. Today 2008, 133-135, 625.

3. Andersson, P. G.; Munslow, I. J.; Modern Reduction Methods, Wiley: Weinheim, 2008.

4. Daußmann, T.; Rosen, T. C.; Dünkelmann, P.; Eng. Life Sci. 2006, 6, 125; Matsuda, T.; Yamanaka, R.; Nakamura, K.; Tetrahedron: Asymmetry 2009, 20, 513.

5. Jurcek, O.; Wimmerová, M.; Wimmer, Z.; Coord. Chem. Rev. 2008, 252, 767; Borges, K. B.; Borges, W. S.; Durán-Patrón, R.; Pupo, M. T.; Bonato, P. S.; Collado, I. G.; Tetrahedron: Asymmetry 2009, 20, 385.

6. Patel, R. N.; Stereoselective Biocatalysis, Marcel Dekker: New York, 2000.

7. Banerjee, C.; Soni, P.; Biotechnol. J. 2006, 1, 80.

8. Liria, C. W.; Romagna, C. D.; Rodovalho, N. N.; Marana, S. R.; Miranda, M. T. M.; J. Braz. Chem. Soc. 2008, 19, 1574; Zanotto, S. P.; Romano, I. P.; Lisboa, L. U. S.; Duviosin Jr., S.; 
Martins, M. K.; Lima, F. A.; Silva, S. F.; Albuquerque, P. M.; J. Braz. Chem. Soc. 2009, 20, 1046.

9. Barros-Filho, B. A.; Nunes, F. M.; Oliveira, M. C. F.; Lemos, T. L. G.; Mattos, M. C.; de Gonzalo, G.; Gotor-Fernández, V.; Gotor, V.; J. Mol. Catal. B: Enzym., doi:10.1016/j. molcatb.2010.01.023.

10. Barros-Filho, B. A.; Oliveira, M. C. F.; Lemos, T. L. G.; Mattos, M. C.; de Gonzalo, G.; Gotor-Fernández, V.; Gotor, V.; Tetrahedron: Asymmetry 2009, 20, 1057.

11. Andrade, L. H.; Keppler, A. F.; Schoenlein-Crusius, I. H.; Porto, A. L. M.; Comasseto, J. V.; J. Mol. Catal. B: Enzym. 2004, 31, 129.

12. Almeida, A. C. S.; Araújo, L. A.; Costa, A. M.; Abreu, C. A. M.; Lima, M. A. G. A.; Palha, M. L. A. P. F.; Eletron. J. Biotechnol. 2005, 8, 55 .

13. Silverman, R. B.; The Organic Chemistry of Drug Design and Drug Action, Academic Press: San Diego, 1992; Barret, G. M.; Graboski, G. G.; Chem. Rev. 1986, 86, 751.

14. Trost, B. M.; Fleming, I.; Comprehensive Organic Synthesis, Pergamon Press: New York, 1991, vol. 8; Ram, S.; Ehrenkaufer, R. E.; Tetrahedron Lett. 1984, 25, 3415; Yuste, F.; Saldana, M.; Walls, F.; Tetrahedron Lett. 1982, 23, 147.

15. Mangas-Sánchez, J.; Rodrígez-Mata, M.; Busto, E.; GotorFernández, V.; Gotor, V.; J. Org. Chem. 2009, 15, 5304.

16. Barbieri, C.; Bossi, L.; D’arrigo, P.; Fantoni, G. P.; Servi, S.; J. Mol. Catal. B: Enzym. 2001, 11, 415.

17. Rocha, L. L.; Cordeiro, R. A.; Cavalcante, R. M.; Nascimento, R. F.; Martins, S. C. S.; Santaella, S. T.; Melo, V. M. M.; Mycopathologia 2007, 164, 183.

18. de Hoog, G. S.; Guarro, J.; Gene, J.; Figueras, M. J.; Atlas of Clinical Fungi, $2^{\text {nd }}$ ed., Réus: Centraalbureau voor Schimmelcultures/Universitat Rovira i Virgili: Spain, 2000.
19. Andrade, L. H.; Comasseto, J. V.; Rodrigues, D. F.; Pellizari, V. H.; Porto, A. L. M.; J. Mol. Catal. B: Enzym. 2005, 33, 73.

20. Csajági, C.; Szatzker, G.; Toke, E. R.; Ürge, L.; Darvas, F.; Poppe, L.; Tetrahedron: Asymmetry 2008, 19, 237.

21. Seror, S.; Collin, J.; Fiaud, J. C.; Zouioueche, L. A.; J. Mol. Catal. A: Chem. 2006, 256, 85.

22. Ma, Y.; Liu, H.; Chen, L.; Zhu, J.; Deng, J.; Org. Lett. 2003, 5, 2103.

23. Yang, S. D.; Shi, Y.; Sun, Z. H.; Zhao, Y.; Liang, Y.; Tetrahedron: Asymmetry 2006, 17, 1895.

24. Du, D.; Fang, T.; Xu, J.; Zhang, S.; Org. Lett. 2006, 8, 1327.

25. Morris, D. J.; Hayes, A. M.; Wills, M.; J. Org. Chem. 2006, 71 , 7035.

26. Tanis, S. P.; Evans, B. R.; Nieman, J. A.; Parker, T. T.; Taylor, W. D.; Heasley, S. E.; Herrington, P. M.; Perrault, W. R.; Hohler, R. A.; Dolak, L. A.; Hester, M. R.; Seest, E. P.; Tetrahedron: Asymmetry 2006, 17, 2154.

27. Alcohol 10b is given as example of the numerical locants used for NMR assignment:<smiles>OC(CCl)c1ccc(Cl)c(Cl)c1</smiles>

28. Zhu, D.; Mukherjee, C.; Hua, L.; Tetrahedron: Asymmetry 2005 , 16,3275 .

Received: December 18, 2009

Web Release Date: April 15, 2010 


\section{Candida tropicalis CE017: A New Brazilian Enzymatic Source for the Bioreduction of Aromatic Prochiral Ketones}

Gizelle A. B. Vieira, ${ }^{a}$ Daniel M. de Freitas Araujo, ${ }^{a}$ Telma L. G. Lemos, ${ }^{a}$ Marcos Carlos de Mattos, ${ }^{* a}$ Maria da Conceição F. de Oliveira, ${ }^{a}$ Vânia M. M. Melo, ${ }^{a}$ Gonzalo de Gonzalo, ${ }^{b}$ Vicente Gotor-Fernández ${ }^{b}$ and Vicente Gotor ${ }^{*, b}$

${ }^{a}$ Departamento de Química Orgânica e Inorgânica, Universidade Federal do Ceará, 60451-970 Fortaleza-CE, Brazil

${ }^{b}$ Departamento de Química Orgánica e Inorgánica, Instituto Universitario de Biotecnología de Asturias, Universidad de Oviedo, c/ Julián Clavería 8, 33006, Oviedo, Spain

(S)-1-Phenylethanol, $1 \boldsymbol{b}$<smiles>C[C@@H](O)c1ccccc1</smiles>

${ }^{1} \mathrm{H} \mathrm{NMR}\left(\mathrm{CDCl}_{3}, 300.13 \mathrm{MHz}\right): \delta 1.39(\mathrm{~d}, J 6.5 \mathrm{~Hz}$, $\left.3 \mathrm{H}, \mathrm{H}_{2}\right), 2.03$ (s, 1H, OH), 4.77 (q, J $\left.6.5 \mathrm{~Hz}, 1 \mathrm{H}, \mathrm{H}_{1}\right), 7.25$ $\left(\mathrm{m}, 5 \mathrm{H}, \mathrm{H}_{2},+\mathrm{H}_{3},+\mathrm{H}_{4},+\mathrm{H}_{5},+\mathrm{H}_{6}\right.$ ). (Figure $\mathrm{S} 1$ )
${ }^{13} \mathrm{C} \mathrm{NMR}\left(\mathrm{CDCl}_{3}, 75.5 \mathrm{MHz}\right): \delta 25.3\left(\mathrm{C}_{2}\right), 70.5\left(\mathrm{C}_{1}\right)$, $125.5\left(\mathrm{C}_{2},+\mathrm{C}_{6},\right), 127.6\left(\mathrm{C}_{4}\right), 128.6\left(\mathrm{C}_{3},+\mathrm{C}_{5},\right), 146.0\left(\mathrm{C}_{1}\right)$. (Figure S2)

Conditions for determination of the conversion by HPLC: $0.8 \mathrm{~mL} \mathrm{~min}^{-1}$, hexane:IPA (95:5), $20{ }^{\circ} \mathrm{C}, t_{\mathrm{R}}$ (1a) 5.5 in and $t_{\mathrm{R}}$ (1b) $8.5 \mathrm{~min}$. Column Spherisorb. (Figure S3)

Conditions for determination of the ee by HPLC: $0.8 \mathrm{~mL} \mathrm{~min}^{-1}$, hexane:IPA (95:5), $20^{\circ} \mathrm{C}, t_{\mathrm{R}} 10.2(S)$ and $t_{\mathrm{R}} 15.4(R) \min$. Column OB-H. $[\alpha]_{\mathrm{D}}^{25}=-47.0, \mathrm{c} 1.1, \mathrm{CHCl}_{3}$, for $97 \%$ ee of $(S)$-enantiomer. lit.: $[\alpha]_{\mathrm{D}}^{22}=-62.8$ (c 1.0, $\mathrm{CHCl}_{3}$ ), 98.5\% ee. (Figures $\mathrm{S} 4$ and S5)

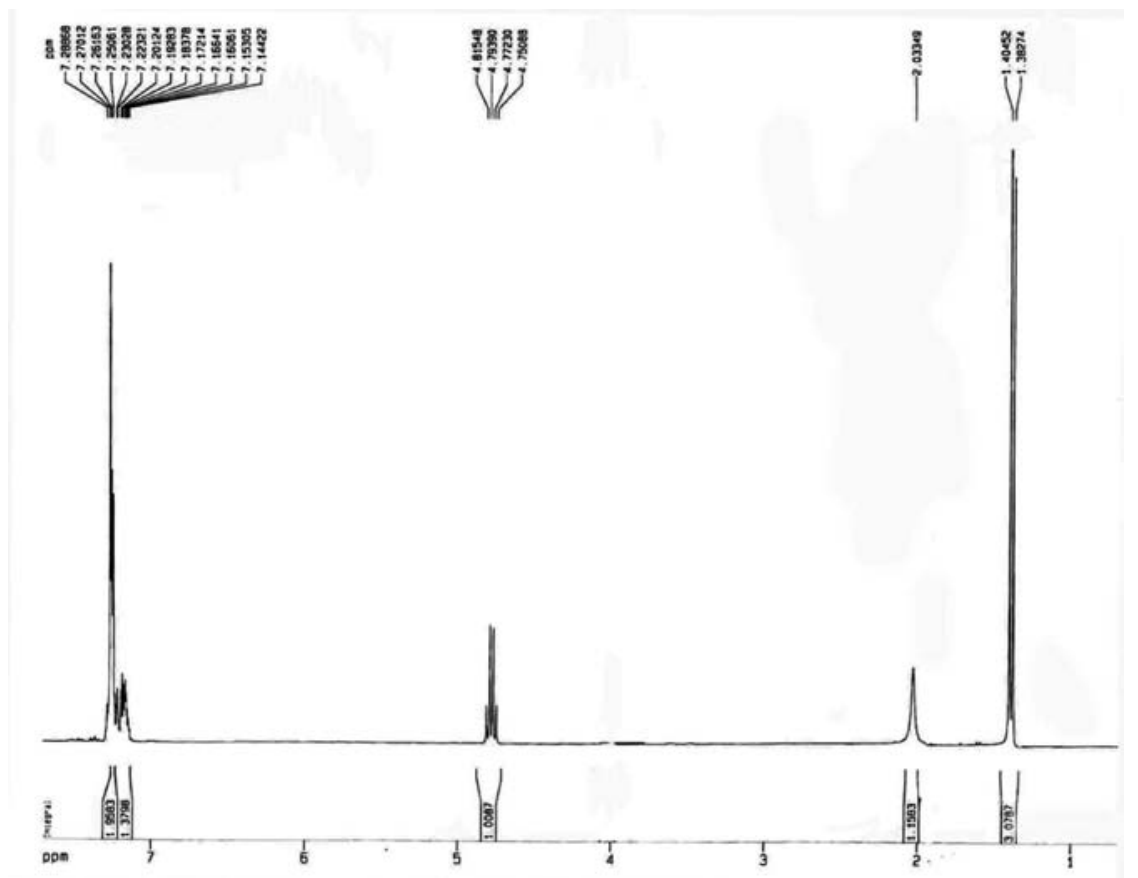

Figure S1. ${ }^{1} \mathrm{H}$ NMR spectrum of $\mathbf{1 b}\left(\mathrm{CDCl}_{3}, 300.13 \mathrm{MHz}\right)$. 


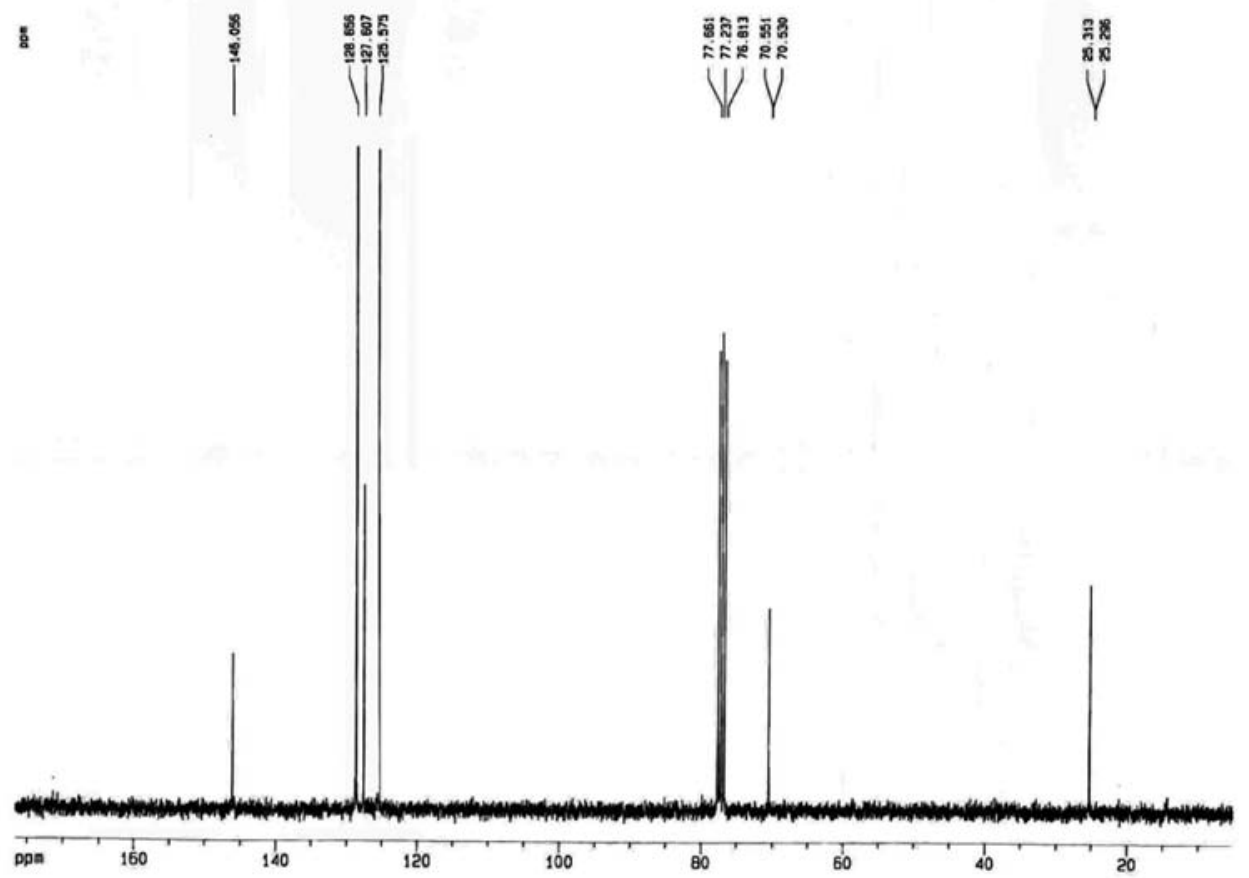

Figure S2. ${ }^{13} \mathrm{C}$ NMR spectrum of $\mathbf{1 b}\left(\mathrm{CDCl}_{3}, 75.5 \mathrm{MHz}\right)$.

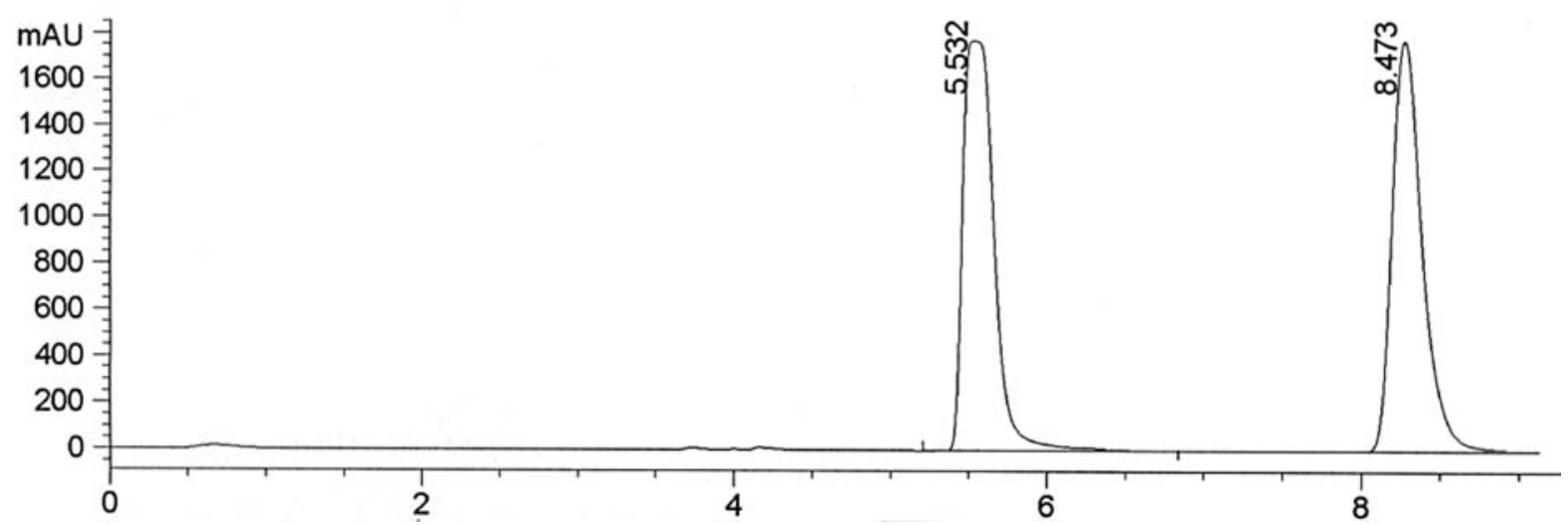

Figure S3. Chromatogram of the separation: $t_{\mathrm{R}}(\mathbf{1 a}) 5.5 \mathrm{~min}$ and $t_{\mathrm{R}}(\mathbf{1 b}) 8.5 \mathrm{~min}$.

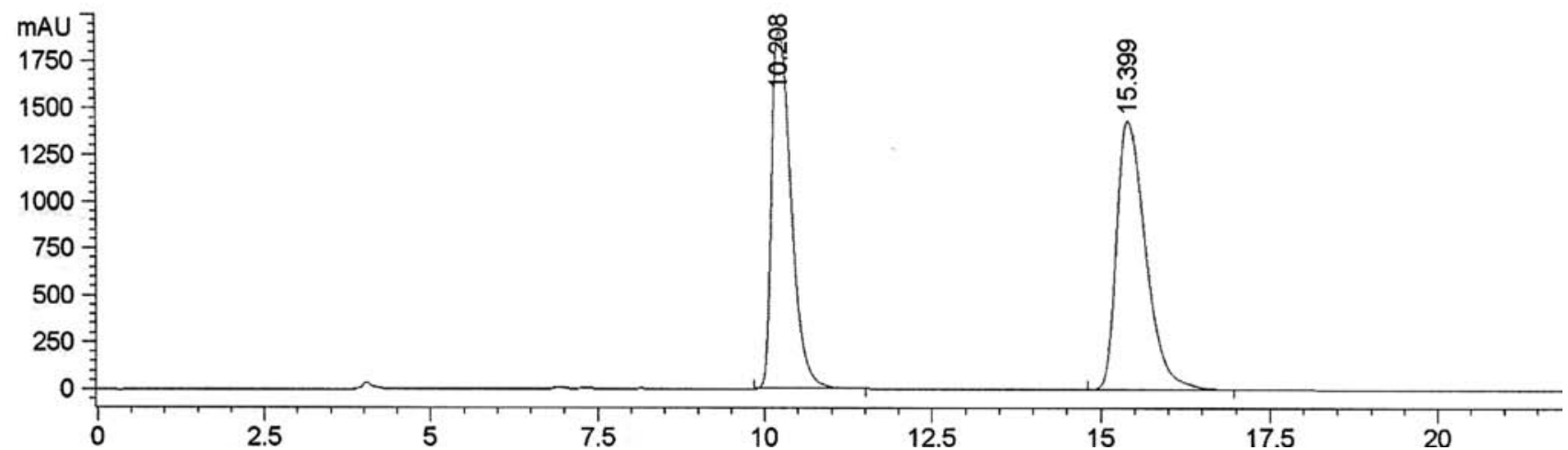

Figure S4. Chromatogram of the racemic mixture of $\mathbf{1 b}: t_{\mathrm{R}} 10.2(S)$ and $t_{\mathrm{R}} 15.4(R) \mathrm{min}$. 


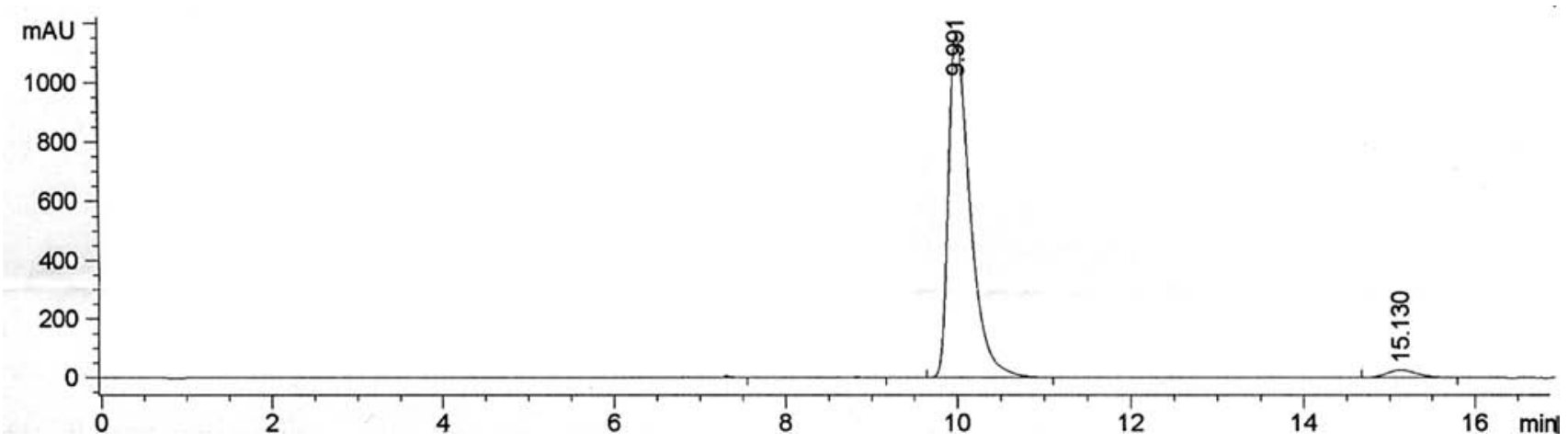

Figure S5. Chromatogram of the product by $C$. tropicalis (1b).

(S)-1-(2-Nitrophenyl)ethanol, $2 \boldsymbol{b}$<smiles>C[C@H](O)c1ccccc1[N+](=O)[O-]</smiles>

${ }^{1} \mathrm{H} \mathrm{NMR}\left(\mathrm{CDCl}_{3}, 300.13 \mathrm{MHz}\right): \delta 1.55(3 \mathrm{H}, \mathrm{d}, J 6.3 \mathrm{~Hz}$, $\left.\mathrm{H}_{2}\right), 5.40\left(1 \mathrm{H}, \mathrm{q}, J 6.3 \mathrm{~Hz}, \mathrm{H}_{1}\right), 7.41(1 \mathrm{H}, \mathrm{dt}, J 8.1$ and $1.2 \mathrm{~Hz}$, $\left.\mathrm{H}_{4}\right), 7.63\left(1 \mathrm{H}, \mathrm{dt}, J 8.1\right.$ and $\left.1.5 \mathrm{~Hz}, \mathrm{H}_{5}\right), 7.82(1 \mathrm{H}, \mathrm{dd}, J 8.1$ and $\left.1.2 \mathrm{~Hz}, \mathrm{H}_{6}\right), 7.88\left(1 \mathrm{H}, \mathrm{dd}, J 8.1\right.$ and $1.5 \mathrm{~Hz}, \mathrm{H}_{3}$ ). (Figure $\mathrm{S6}$ )
${ }^{13} \mathrm{C} \mathrm{NMR}\left(\mathrm{CDCl}_{3}, 75.5 \mathrm{MHz}\right): \delta 24.2\left(\mathrm{C}_{2}\right), 65.4\left(\mathrm{C}_{1}\right)$, $124.2\left(\mathrm{C}_{3}\right), 127.5\left(\mathrm{C}_{6}\right), 128.0\left(\mathrm{C}_{4}\right), 133.5\left(\mathrm{C}_{5}\right), 140.9$ $\left(\mathrm{C}_{1},+\mathrm{C}_{2}\right.$ ). (Figure $\mathrm{S} 7$ )

Conditions for determination of the conversion by GC: Injector $225^{\circ} \mathrm{C}$, Detector $250^{\circ} \mathrm{C}, 80^{\circ} \mathrm{C}\left(5^{\circ} \mathrm{C} \mathrm{min}{ }^{-1}\right) 180^{\circ} \mathrm{C}$ $(0 \mathrm{~min}), t_{\mathrm{R}}$ (2a) $8.4 \mathrm{~min}$ and $t_{\mathrm{R}}$ (2b) $9.2 \mathrm{~min}$. Column HP-1. (Figure S8)

Conditions for determination of the ee by HPLC: $0.8 \mathrm{~mL} \mathrm{~min}^{-1}$, hexane:IPA $(97: 3), 20^{\circ} \mathrm{C}, t_{\mathrm{R}} 22.1 \mathrm{~min}(R)$ and $t_{\mathrm{R}} 23.9(S)$ min. Column AS. $[\alpha]_{\mathrm{D}}^{25}=+29.8$, c $0.4, \mathrm{CHCl}_{3}$, for $99 \%$ ee of $(S)$-enantiomer. (Figures S9 and S10)

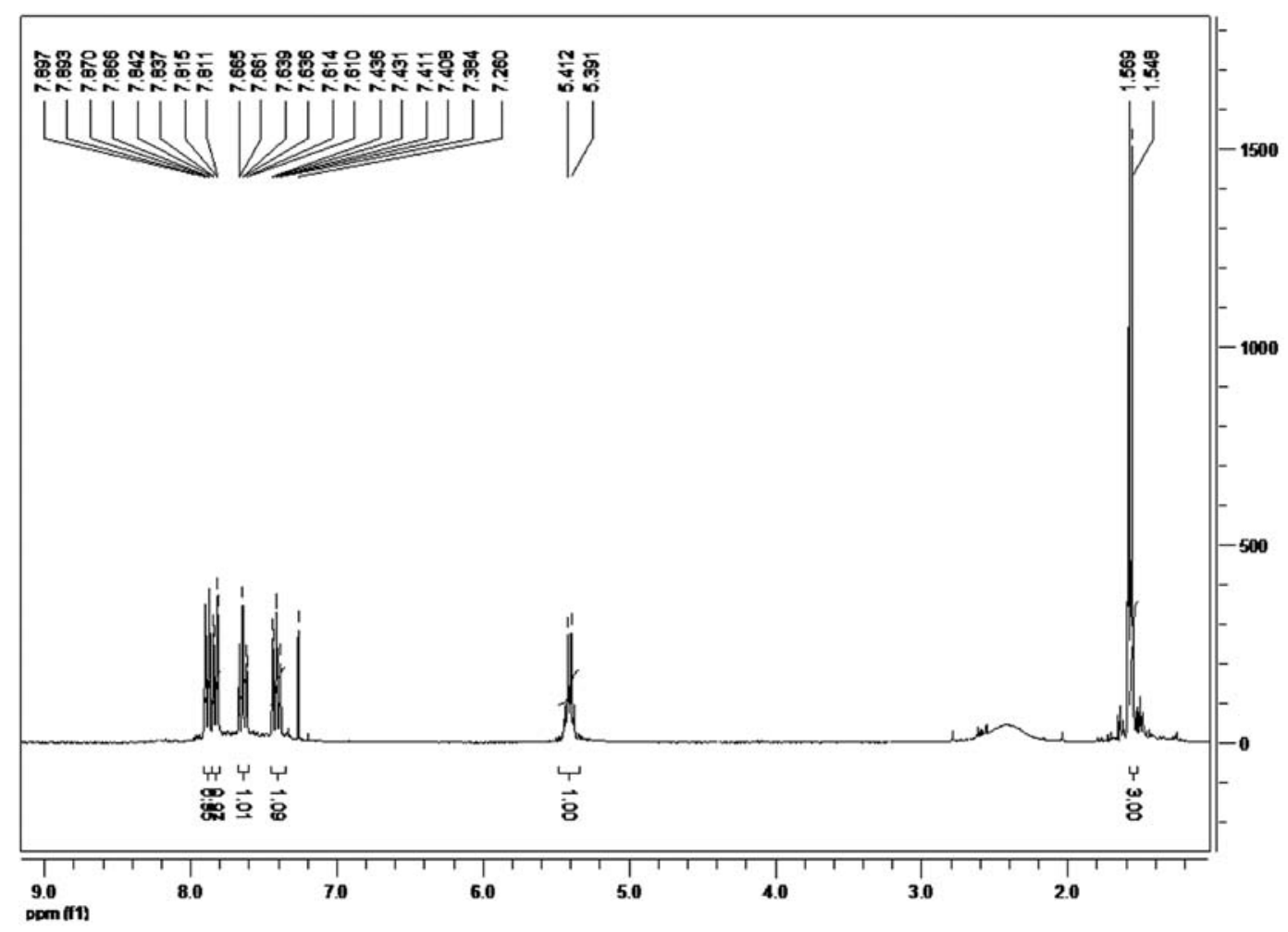

Figure S6. ${ }^{1} \mathrm{H}$ NMR spectrum of $\mathbf{2 b}\left(\mathrm{CDCl}_{3}, 300.13 \mathrm{MHz}\right)$. 


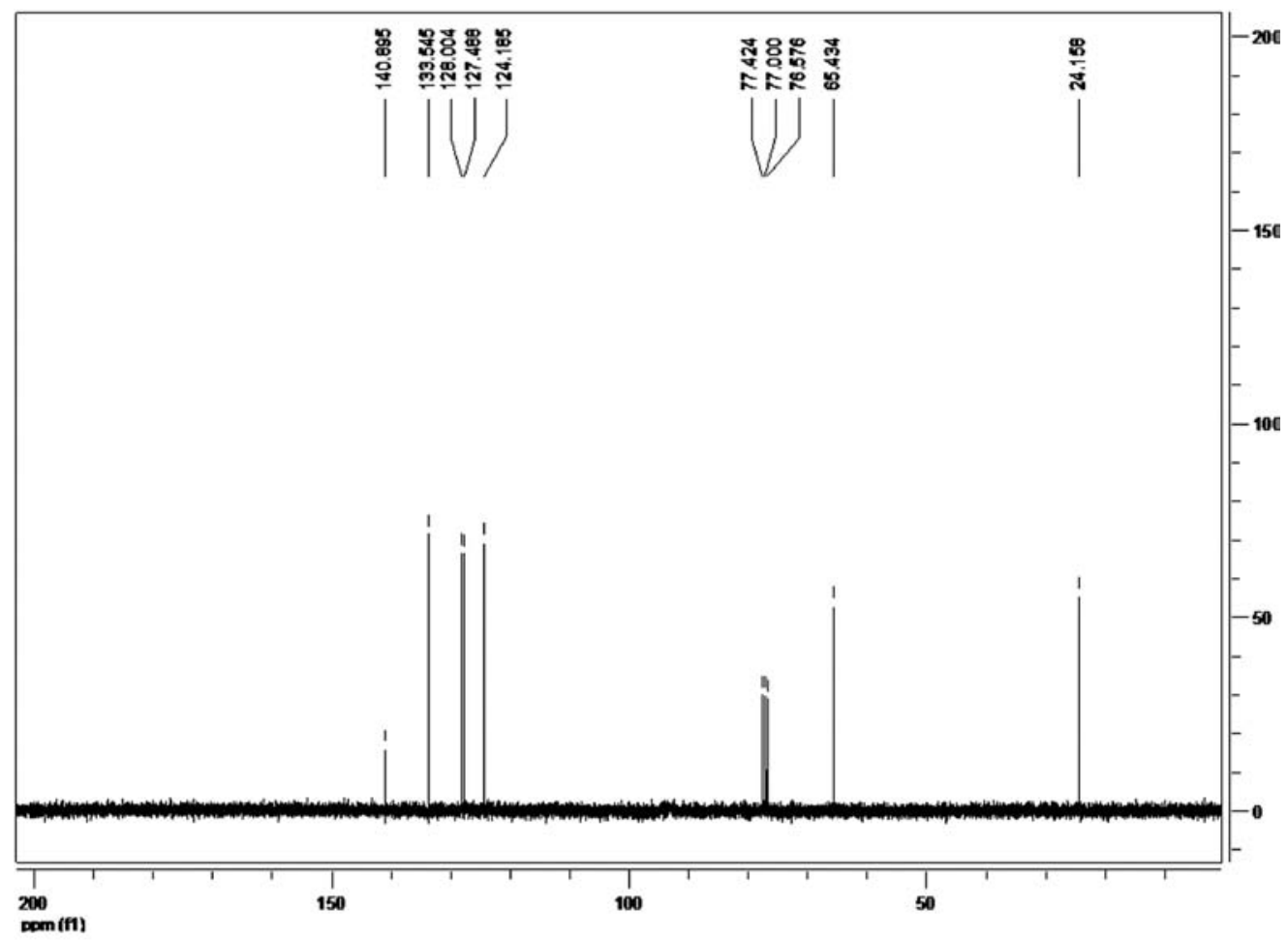

Figure S7. ${ }^{13} \mathrm{C}$ NMR spectrum of $\mathbf{2 b}\left(\mathrm{CDCl}_{3}, 75.5 \mathrm{MHz}\right)$.

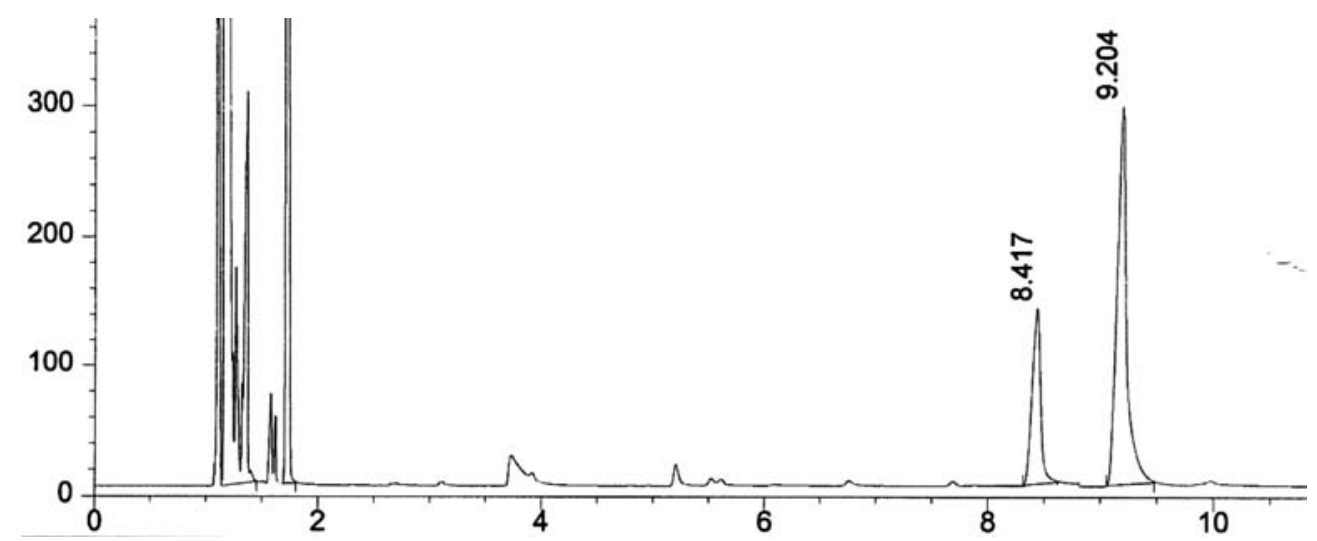

Figure S8. Chromatogram of the separation: $t_{\mathrm{R}}(\mathbf{2 a}) 8.4 \mathrm{~min}$ and $t_{\mathrm{R}}(\mathbf{2 b}) 9.2 \mathrm{~min}$.

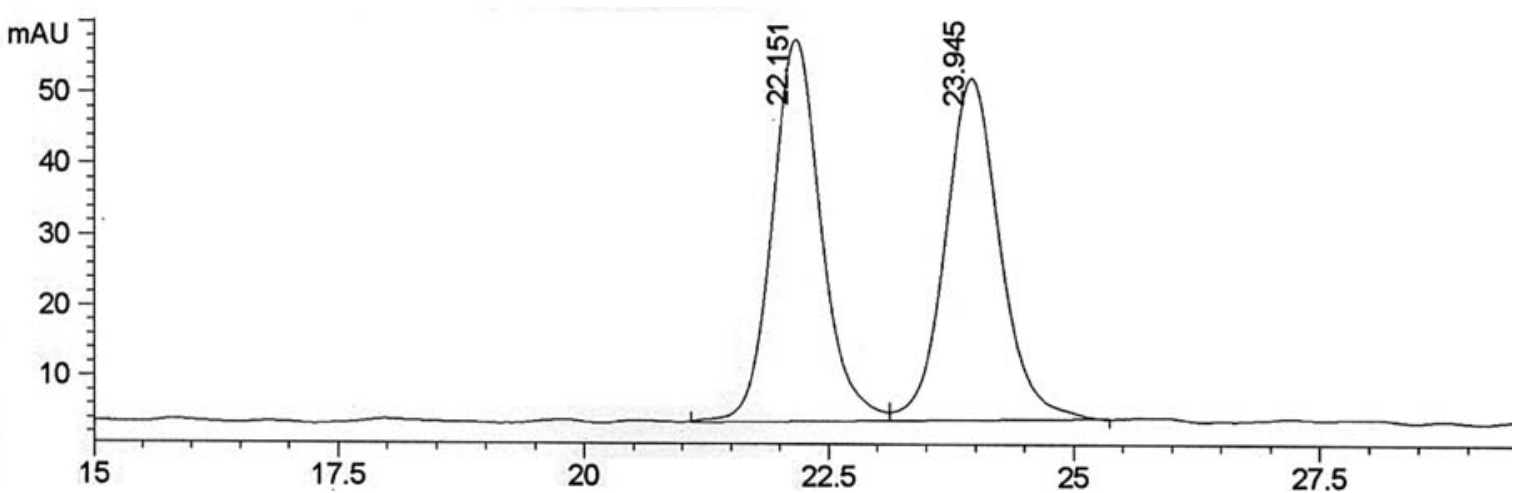

Figure S9. Chromatogram of the racemic mixture of $\mathbf{2 b}: t_{\mathrm{R}} 22.1 \mathrm{~min}(R)$ and $t_{\mathrm{R}} 23.9(S) \min$. 


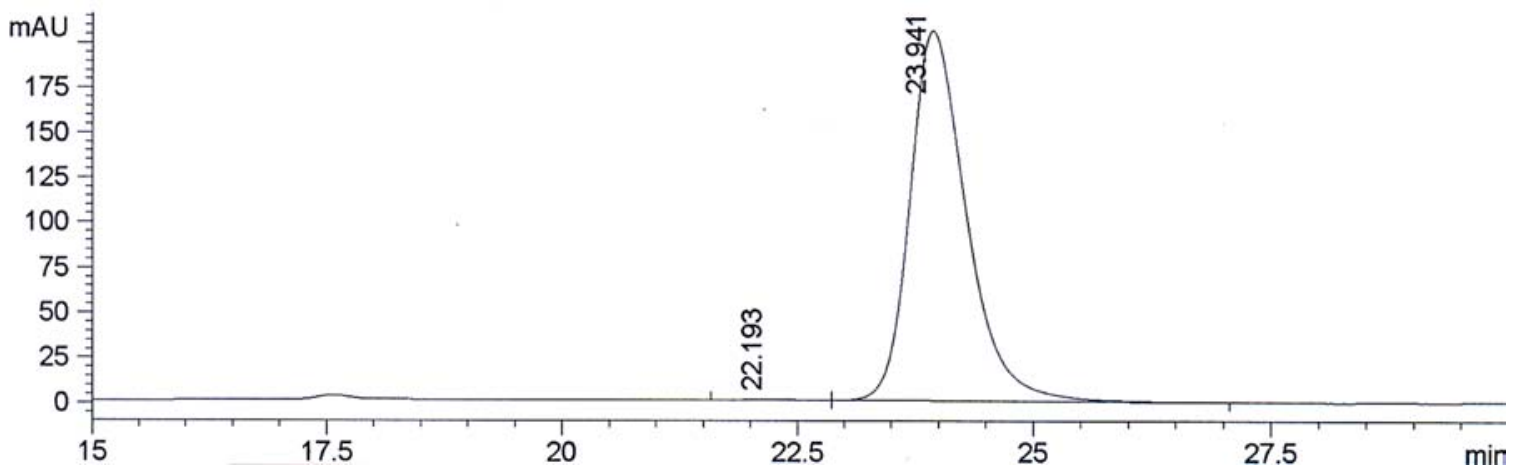

Figure S10. Chromatogram of the product by C. tropicalis (2b).

(S)-1-(3-Nitrophenyl)ethanol, $\mathbf{3 b}$<smiles>CC(O)c1cccc([N+](=O)[O-])c1</smiles>

${ }^{1} \mathrm{H}$ NMR $\left(\mathrm{CDCl}_{3}, 300.13 \mathrm{MHz}\right): \delta 1.47(3 \mathrm{H}, \mathrm{d}, J 6.6$ $\left.\mathrm{Hz}, \mathrm{H}_{2}\right), 4.96\left(1 \mathrm{H}, \mathrm{q}, J 6.6 \mathrm{~Hz}, \mathrm{H}_{1}\right), 7.47(1 \mathrm{H}, \mathrm{t}, J 7.8 \mathrm{~Hz}$, $\mathrm{H}_{5}$,) $7.67\left(1 \mathrm{H}, \mathrm{d}, J 7.8 \mathrm{~Hz}, \mathrm{H}_{6}\right), 8.04$ (1H, ddd, J 8.3, 2.1 and $0.9 \mathrm{~Hz}, \mathrm{H}_{4}$ ), $8.18\left(1 \mathrm{H}, \mathrm{t}, J 1.8 \mathrm{~Hz}, \mathrm{H}_{2}\right.$,). (Figure $\mathrm{S} 11$ ) ${ }^{13} \mathrm{C} \mathrm{NMR}\left(\mathrm{CDCl}_{3}, 75.5 \mathrm{MHz}\right): \delta 25.2\left(\mathrm{C}_{2}\right), 69.1\left(\mathrm{C}_{1}\right)$, $120.2\left(\mathrm{C}_{4}\right), 122.1\left(\mathrm{C}_{2}\right), 129.3\left(\mathrm{C}_{5}\right), 131.6\left(\mathrm{C}_{6}\right), 147.8\left(\mathrm{C}_{1}\right)$, $148.1\left(\mathrm{C}_{3}\right)$. (Figure S12)

Conditions for determination of the conversion by $\mathrm{GC}$ : Injector $225^{\circ} \mathrm{C}$, Detector $250{ }^{\circ} \mathrm{C}, 80^{\circ} \mathrm{C}\left(5^{\circ} \mathrm{C} \mathrm{min}{ }^{-1}\right) 180^{\circ} \mathrm{C}$ $(0 \mathrm{~min}), t_{\mathrm{R}}$ (3a) $9.5 \mathrm{~min}$ and $t_{\mathrm{R}}(\mathbf{3 b}) 11.4 \mathrm{~min}$. Column HP1. (Figure S13)

Conditions for determination of the ee by HPLC: $0.8 \mathrm{~mL} \mathrm{~min}^{-1}$, hexane:IPA (90:10), $20^{\circ} \mathrm{C}, t_{\mathrm{R}} 12.8 \mathrm{~min}(S)$ and $t_{\mathrm{R}} 14.2(R)$ min. Column OB-H. $[\alpha]_{\mathrm{D}}^{25}=-34.9, \mathrm{c} 0.5 \mathrm{CH}_{2} \mathrm{Cl}_{2}$, for $99 \%$ ee of $(S)$-enantiomer. (Figures S14 and S15)

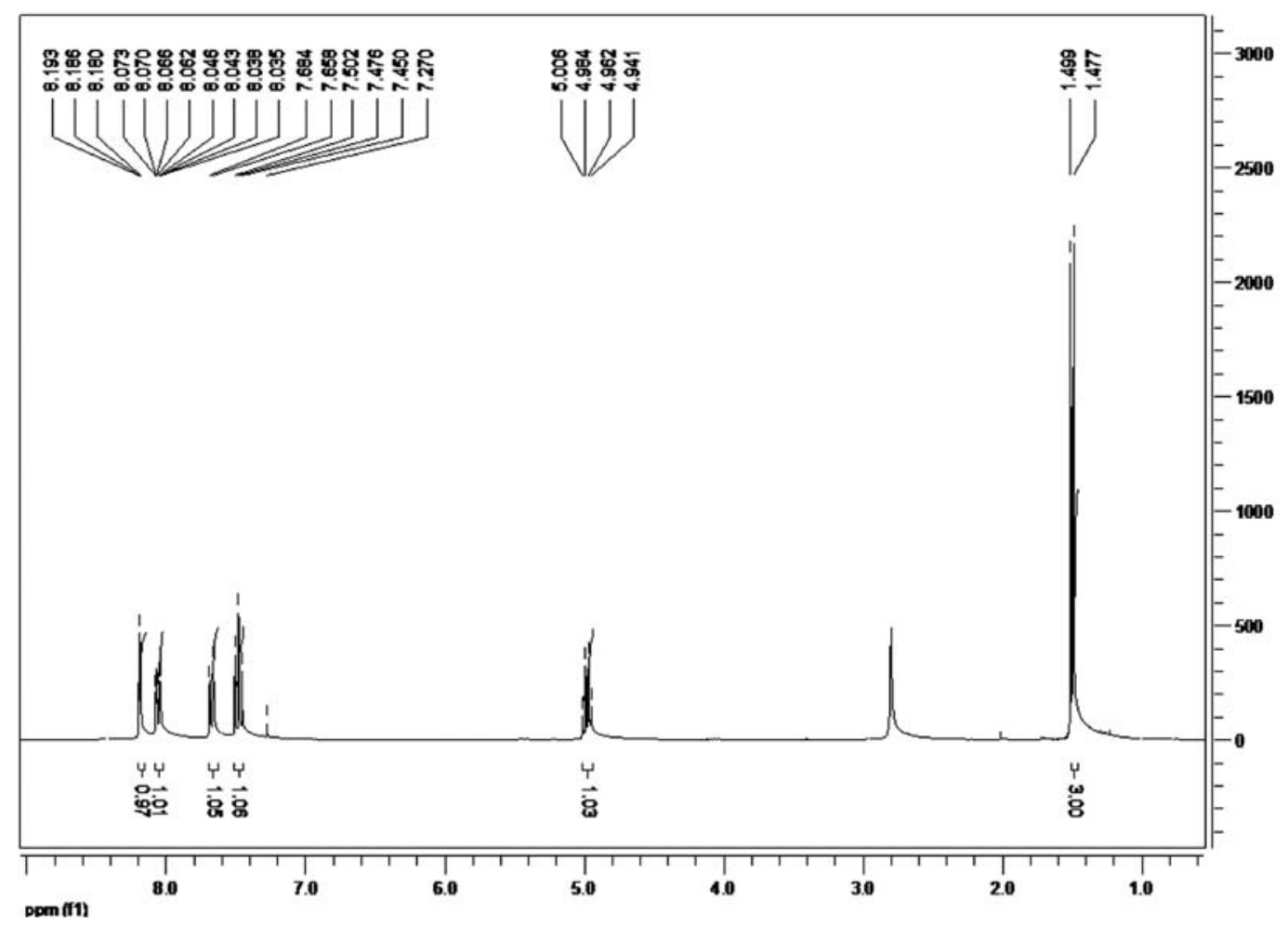

Figure S11. ${ }^{1} \mathrm{H}$ NMR spectrum of $\mathbf{3 b}\left(\mathrm{CDCl}_{3}, 300.13 \mathrm{MHz}\right)$. 


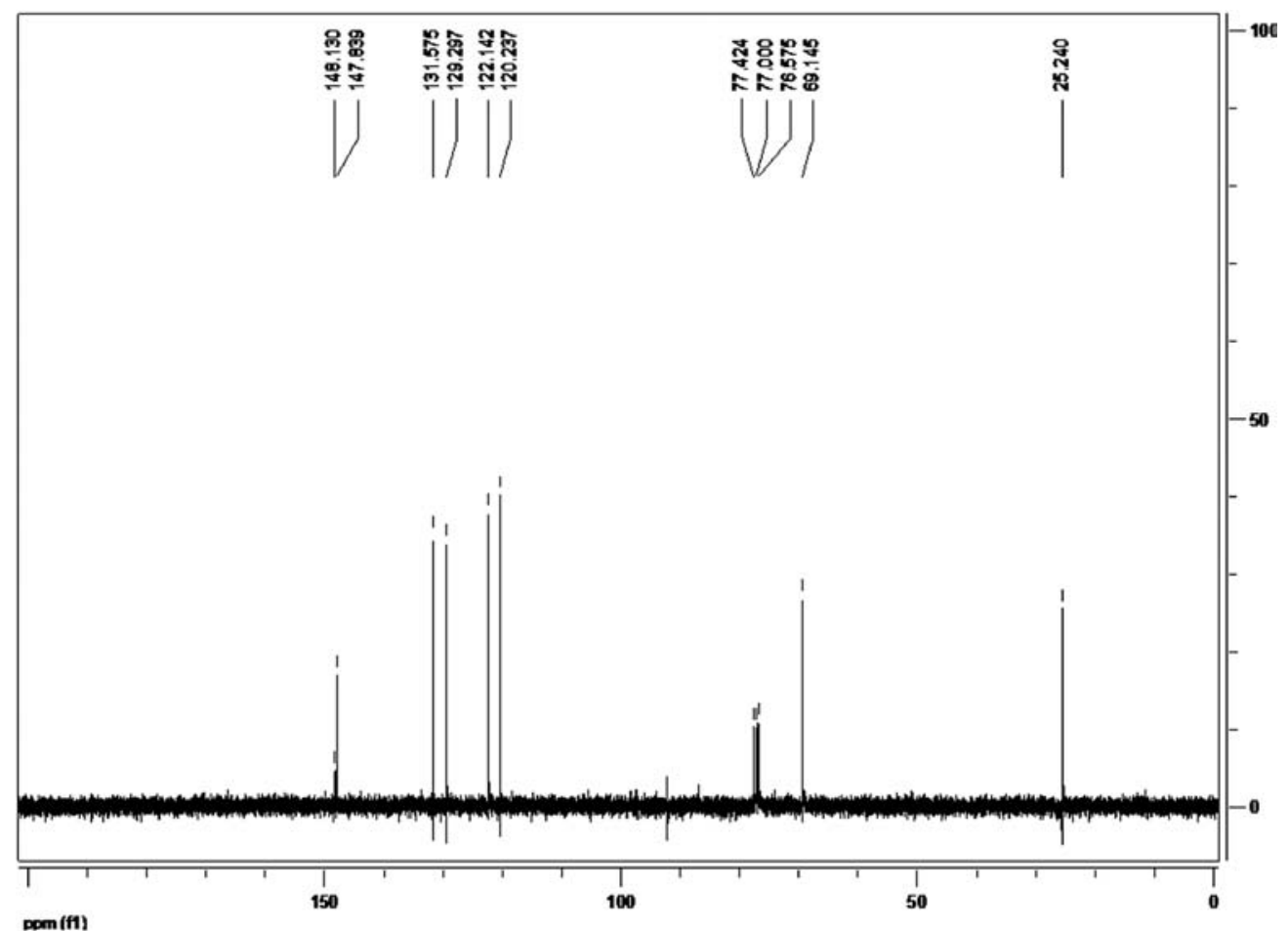

Figure S12. ${ }^{13} \mathrm{C}$ NMR spectrum of $\mathbf{3 b}\left(\mathrm{CDCl}_{3}, 75.5 \mathrm{MHz}\right)$.

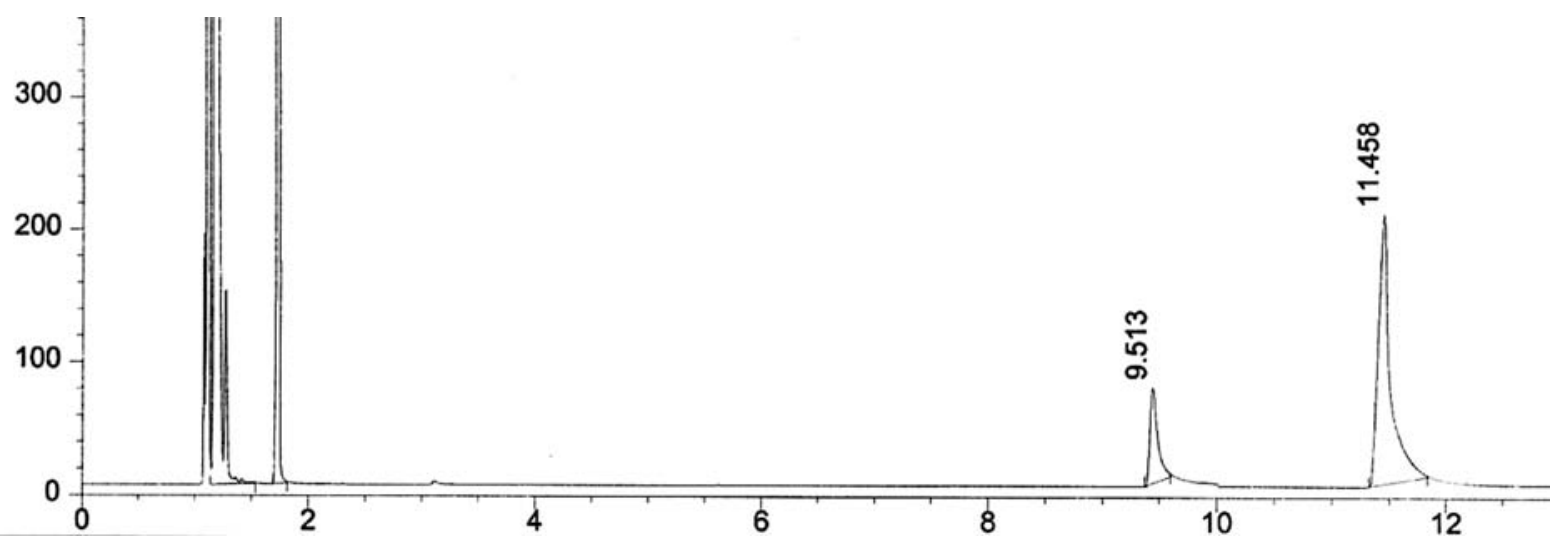

Figure S13. Chromatogram of the separation: $t_{\mathrm{R}}(\mathbf{3 a}) 9.5 \mathrm{~min}$ and $t_{\mathrm{R}}(\mathbf{3 b}) 11.4 \mathrm{~min}$.

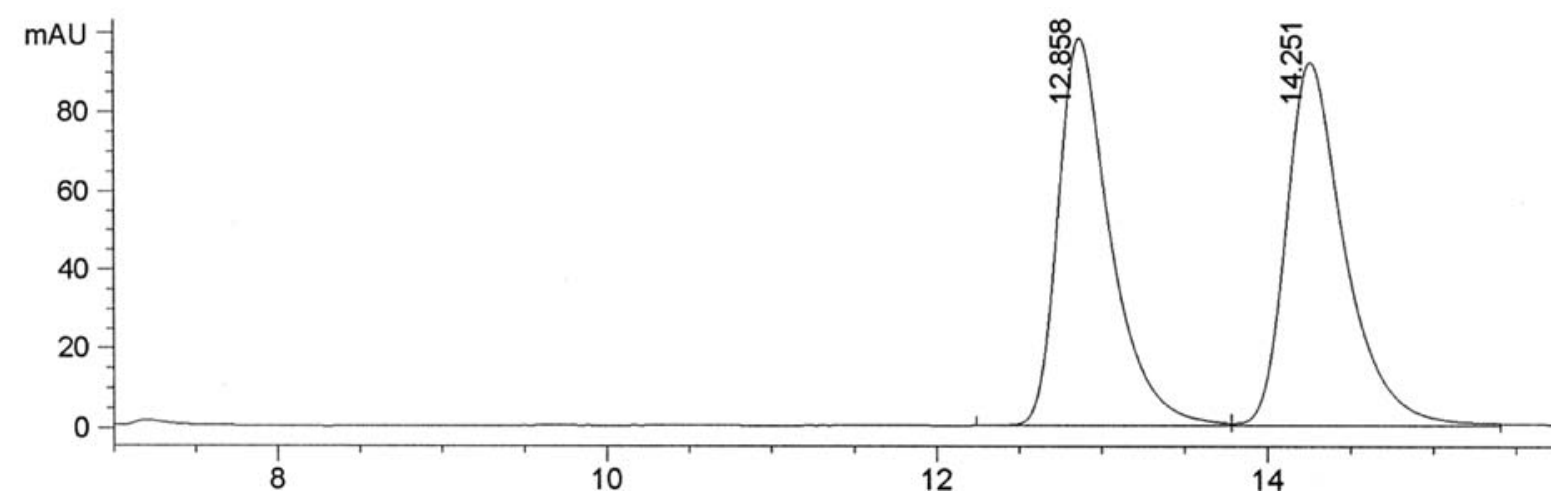

Figure S14. Chromatogram of the racemic mixture of 3b: $t_{\mathrm{R}} 12.8 \min (S)$ and $t_{\mathrm{R}} 14.2(R) \min$. 


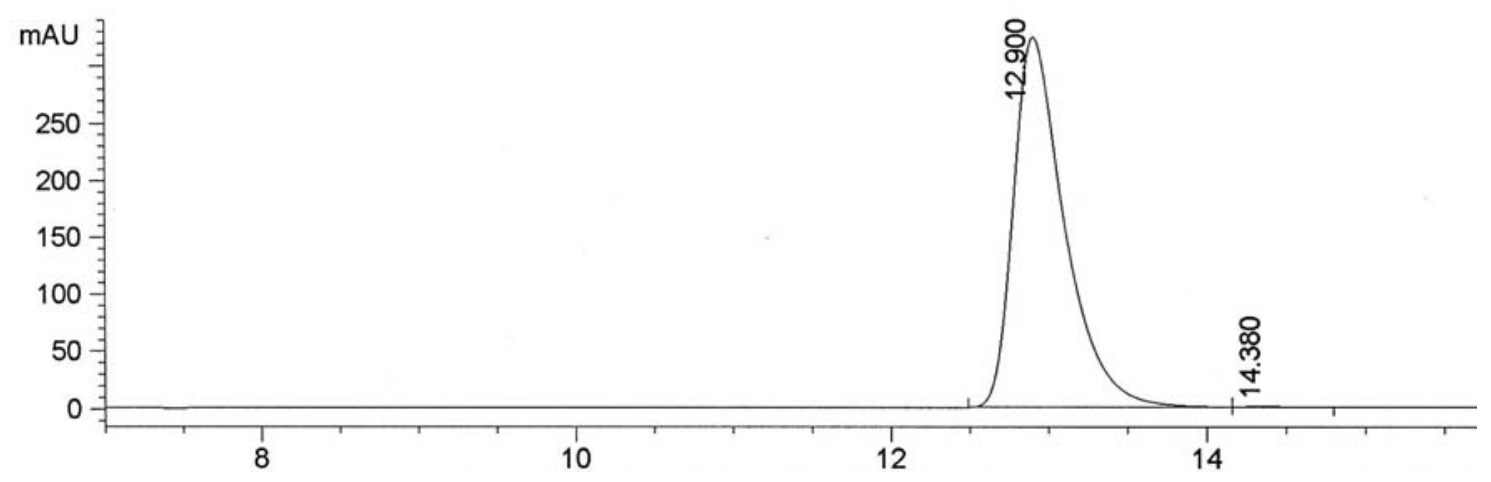

Figure S15. Chromatogram of the product by $C$. tropicalis (3b).

(S)-1-(4-Nitrophenyl)ethanol, $4 \boldsymbol{b}$<smiles>C[C@H](O)c1ccc([N+](=O)[O-])cc1</smiles>

${ }^{1} \mathrm{H} \mathrm{NMR}\left(\mathrm{CDCl}_{3}, 300.13 \mathrm{MHz}\right): \delta 1.50(3 \mathrm{H}, \mathrm{d}, J 6.6 \mathrm{~Hz}$, $\left.\mathrm{H}_{2}\right), 5.01\left(1 \mathrm{H}, \mathrm{q}, J 6.6 \mathrm{~Hz}, \mathrm{H}_{1}\right), 7.53\left(2 \mathrm{H}, \mathrm{d}, J 8.7 \mathrm{~Hz}, \mathrm{H}_{2},+\right.$ $\mathrm{H}_{6}$ ), $8.17\left(2 \mathrm{H}, \mathrm{d}, J 8.7 \mathrm{~Hz}, \mathrm{H}_{3},+\mathrm{H}_{5}\right.$ ). (Figure S16)
${ }^{13} \mathrm{C} \mathrm{NMR}\left(\mathrm{CDCl}_{3}, 75.5 \mathrm{MHz}\right): \delta 25.3\left(\mathrm{C}_{2}\right), 69.5\left(\mathrm{C}_{1}\right)$, $123.6\left(\mathrm{C}_{2},+\mathrm{C}_{6}\right), 126.0\left(\mathrm{C}_{3},+\mathrm{C}_{5},\right), 147.0\left(\mathrm{C}_{1}\right), 153.1\left(\mathrm{C}_{4}\right)$. (Figure $\mathrm{S} 17$ )

Conditions for determination of the conversion by GC: Injector $225^{\circ} \mathrm{C}$, Detector $250{ }^{\circ} \mathrm{C}, 80^{\circ} \mathrm{C}\left(5^{\circ} \mathrm{C} \mathrm{min}{ }^{-1}\right) 180{ }^{\circ} \mathrm{C}$ (0 min), $t_{\mathrm{R}}$ (4a) $9.6 \mathrm{~min}$ and $t_{\mathrm{R}}$ (4b) $11.8 \mathrm{~min}$. Column HP-1. (Figure S18)

Conditions for determination of the ee by HPLC: $0.8 \mathrm{~mL} \mathrm{~min}^{-1}$, hexane:IPA $(95: 5), 20^{\circ} \mathrm{C}, t_{\mathrm{R}} 11.7 \mathrm{~min}(R)$ and $t_{\mathrm{R}} 13.6(S)$ min. Column AS. $[\alpha]_{\mathrm{D}}^{25}=-24.6$, c $0.5, \mathrm{CHCl}_{3}$, for $96 \%$ ee of $(S)$-enantiomer. (Figures S19 and S20)

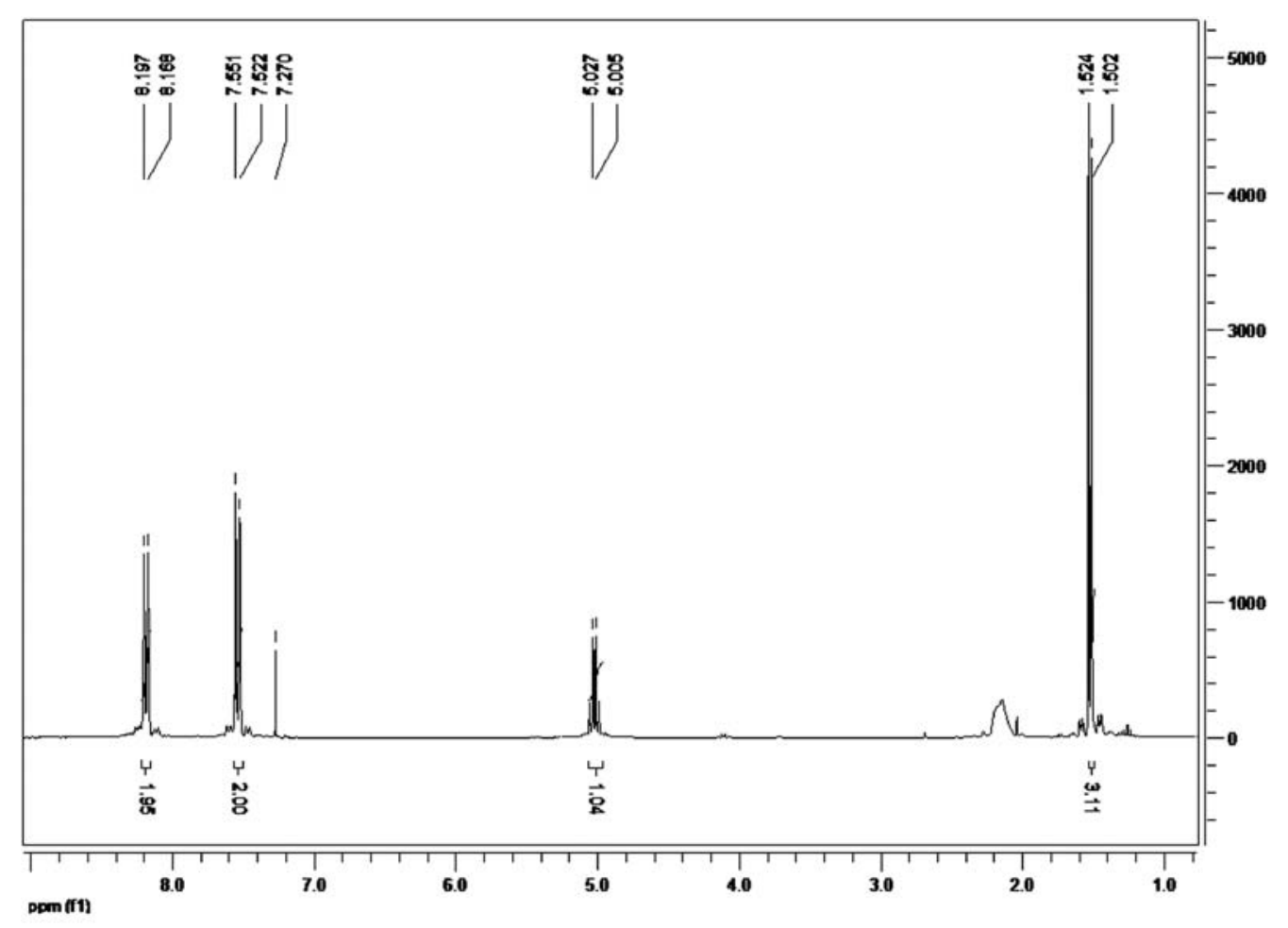

Figure S16. ${ }^{1} \mathrm{H}$ NMR spectrum of $\mathbf{4 b}\left(\mathrm{CDCl}_{3}, 300.13 \mathrm{MHz}\right)$. 


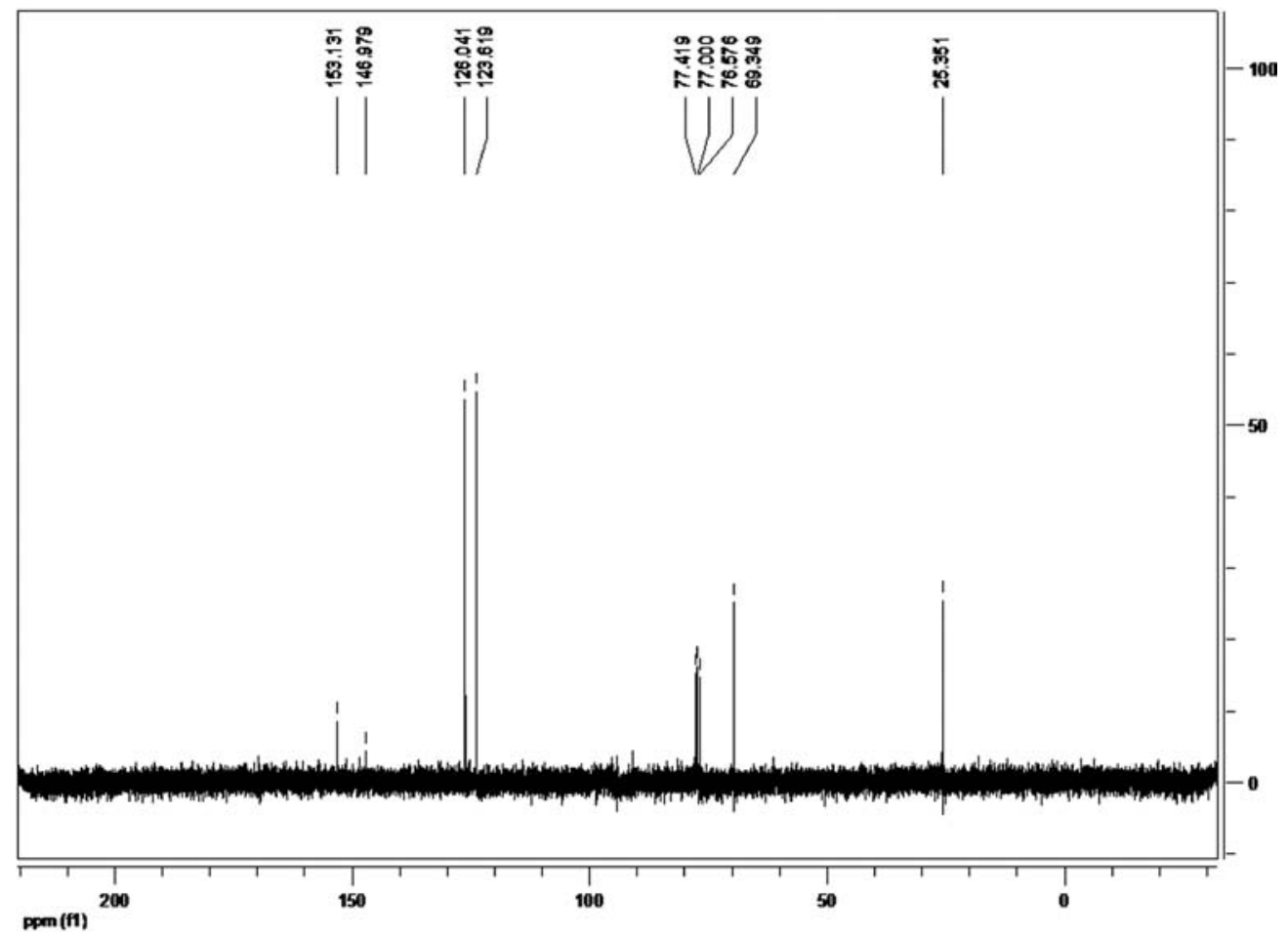

Figure S17. ${ }^{13} \mathrm{C}$ NMR spectrum of $\mathbf{4 b}\left(\mathrm{CDCl}_{3}, 75.5 \mathrm{MHz}\right)$.

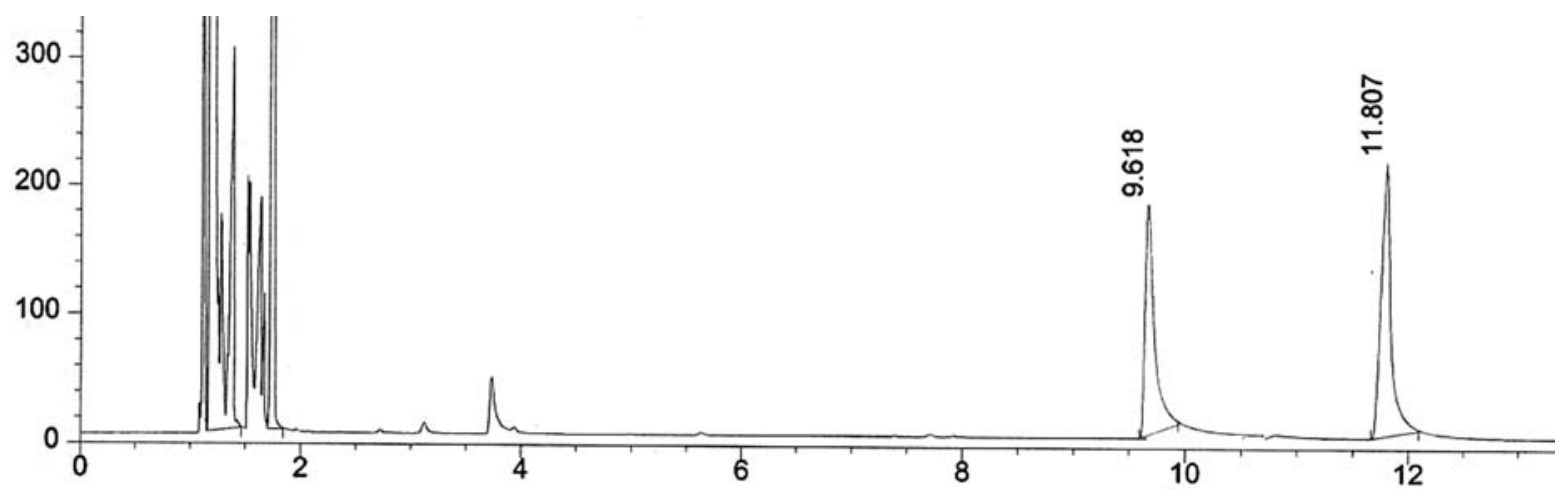

Figure S18. Chromatogram of the separation: $t_{\mathrm{R}}(\mathbf{4 a}) 9.6 \mathrm{~min}$ and $t_{\mathrm{R}}(\mathbf{4 b}) 11.8 \mathrm{~min}$.

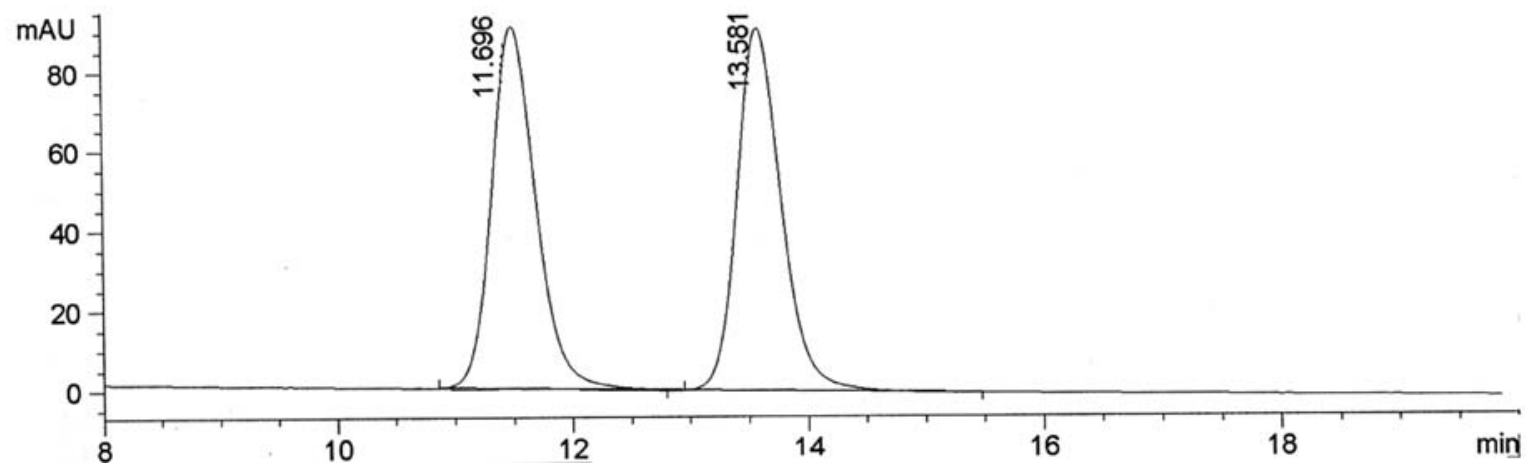

Figure S19. Chromatogram of the racemic mixture of $4 \mathbf{b}: t_{\mathrm{R}} 11.7 \min (R)$ and $t_{\mathrm{R}} 13.6(S)$. min. 


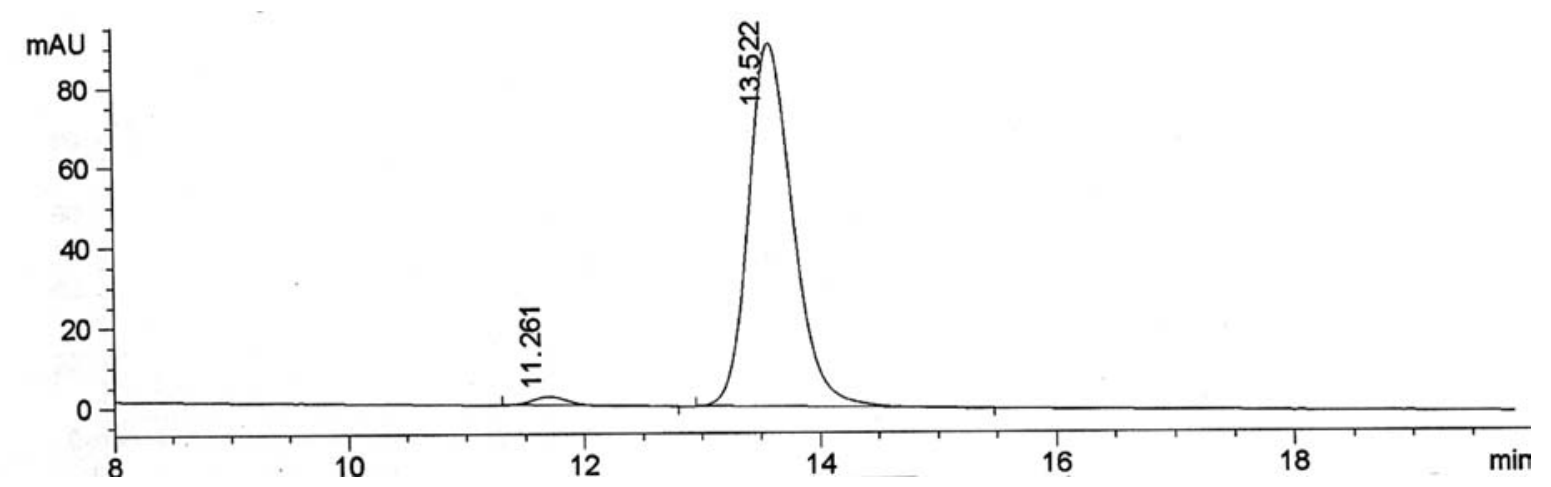

Figure S20. Chromatogram of the product by $C$. tropicalis $(\mathbf{4 b})$.

(S)-1-(2-Methoxyphenyl)ethanol, $5 \boldsymbol{b}$<smiles>COc1ccccc1[C@@H](C)O</smiles>

${ }^{1} \mathrm{H} \mathrm{NMR}\left(\mathrm{CDCl}_{3}, 300.13 \mathrm{MHz}\right): \delta 1.52(3 \mathrm{H}, \mathrm{d}, J 6.6 \mathrm{~Hz}$, $\left.\mathrm{H}_{2}\right), 3.88\left(3 \mathrm{H}, \mathrm{s}, \mathrm{OCH}_{3}\right), 5.11\left(1 \mathrm{H}, \mathrm{q}, J 6.6 \mathrm{~Hz}, \mathrm{H}_{1}\right), 6.90$ $\left(1 \mathrm{H}, \mathrm{dd}, J 7.5\right.$ and $\left.1.5 \mathrm{~Hz}, \mathrm{H}_{3}\right), 6.98(1 \mathrm{H}, \mathrm{dt}, J 8.5$ and 1.5
$\left.\mathrm{Hz}, \mathrm{H}_{5}\right), 7.29\left(1 \mathrm{H}, \mathrm{dt}, J 8.5\right.$ and $\left.1.5 \mathrm{~Hz}, \mathrm{H}_{6}\right), 7.36(1 \mathrm{H}, \mathrm{dd}$, $J 7.5$ and $1.5 \mathrm{~Hz}, \mathrm{H}_{4}$ ). (Figure $\mathrm{S} 21$ )

${ }^{13} \mathrm{C} \mathrm{NMR}\left(\mathrm{CDCl}_{3}, 75.5 \mathrm{MHz}\right): \delta 22.8\left(\mathrm{C}_{2}\right), 55.2\left(\mathrm{OCH}_{3}\right)$, $66.3\left(\mathrm{C}_{1}\right), 110.3\left(\mathrm{C}_{3^{\prime}}\right), 120.7\left(\mathrm{C}_{5},\right), 126.0\left(\mathrm{C}_{6}\right), 128.2\left(\mathrm{C}_{4}\right)$, $133.4\left(\mathrm{C}_{1}\right), 156.4\left(\mathrm{C}_{2}\right)$. (Figure S22)

Conditions for determination of the conversion by HPLC:

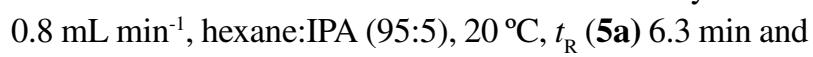
$t_{\mathrm{R}}(\mathbf{5 b}) 7.1 \mathrm{~min}$. Column Spherisorb. (Figure S23)

Conditions for determination of the ee by HPLC: $0.8 \mathrm{~mL} \mathrm{~min}^{-1}$, hexane:IPA (95:5), $20^{\circ} \mathrm{C}, t_{\mathrm{R}} 10.3(S)$ and $t_{\mathrm{R}}$ $16.8(R)$ min. Column OB-H. $[\alpha]_{\mathrm{D}}^{25}=-4.5, \mathrm{c} 0.4, \mathrm{CH}_{2} \mathrm{Cl}_{2}$, for $56 \%$ ee of $(S)$-enantiomer. (Figures S24 and S25)

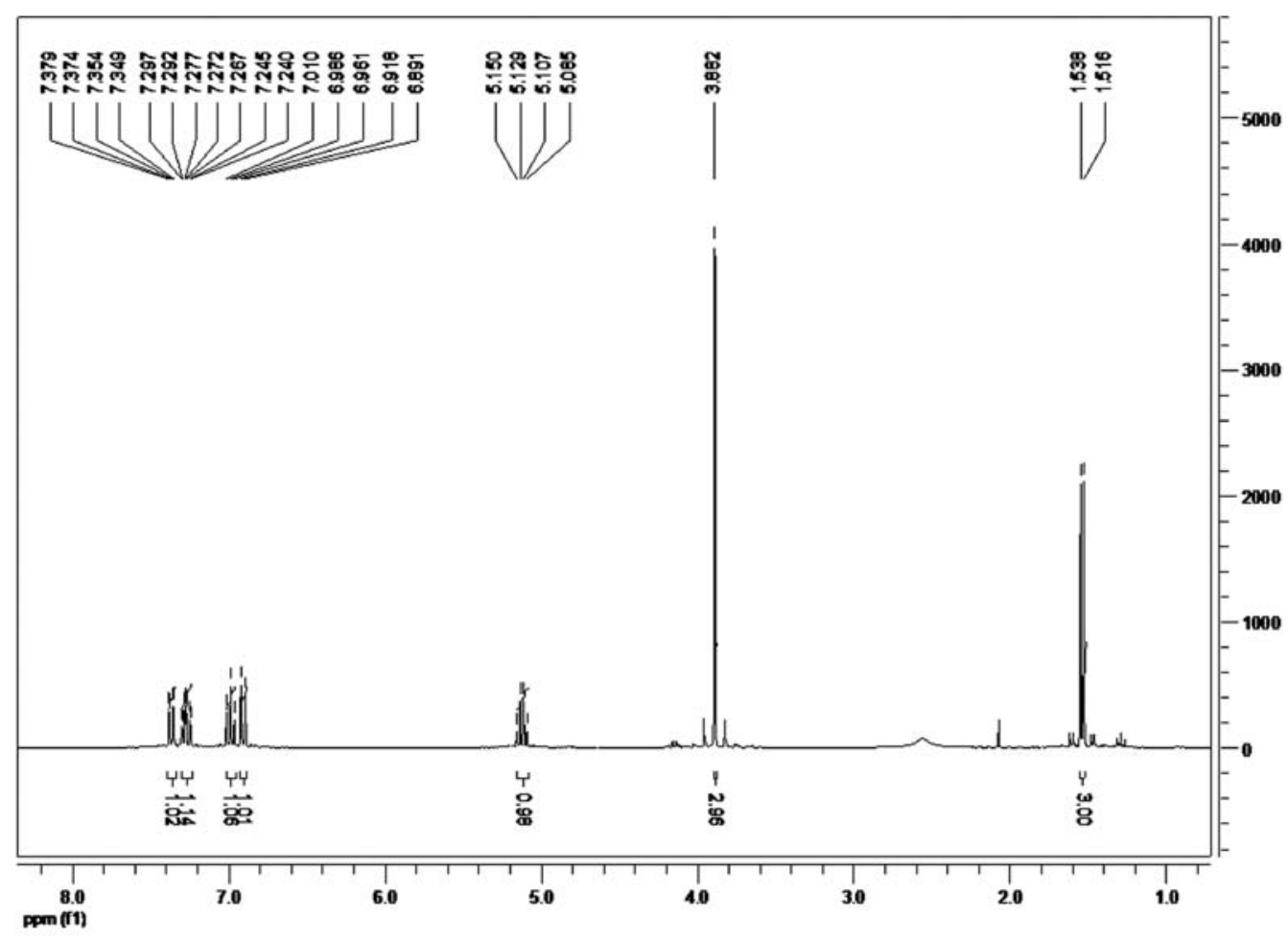

Figure S21. ${ }^{1} \mathrm{H}$ NMR spectrum of $\mathbf{5 b}\left(\mathrm{CDCl}_{3}, 300.13 \mathrm{MHz}\right)$. 


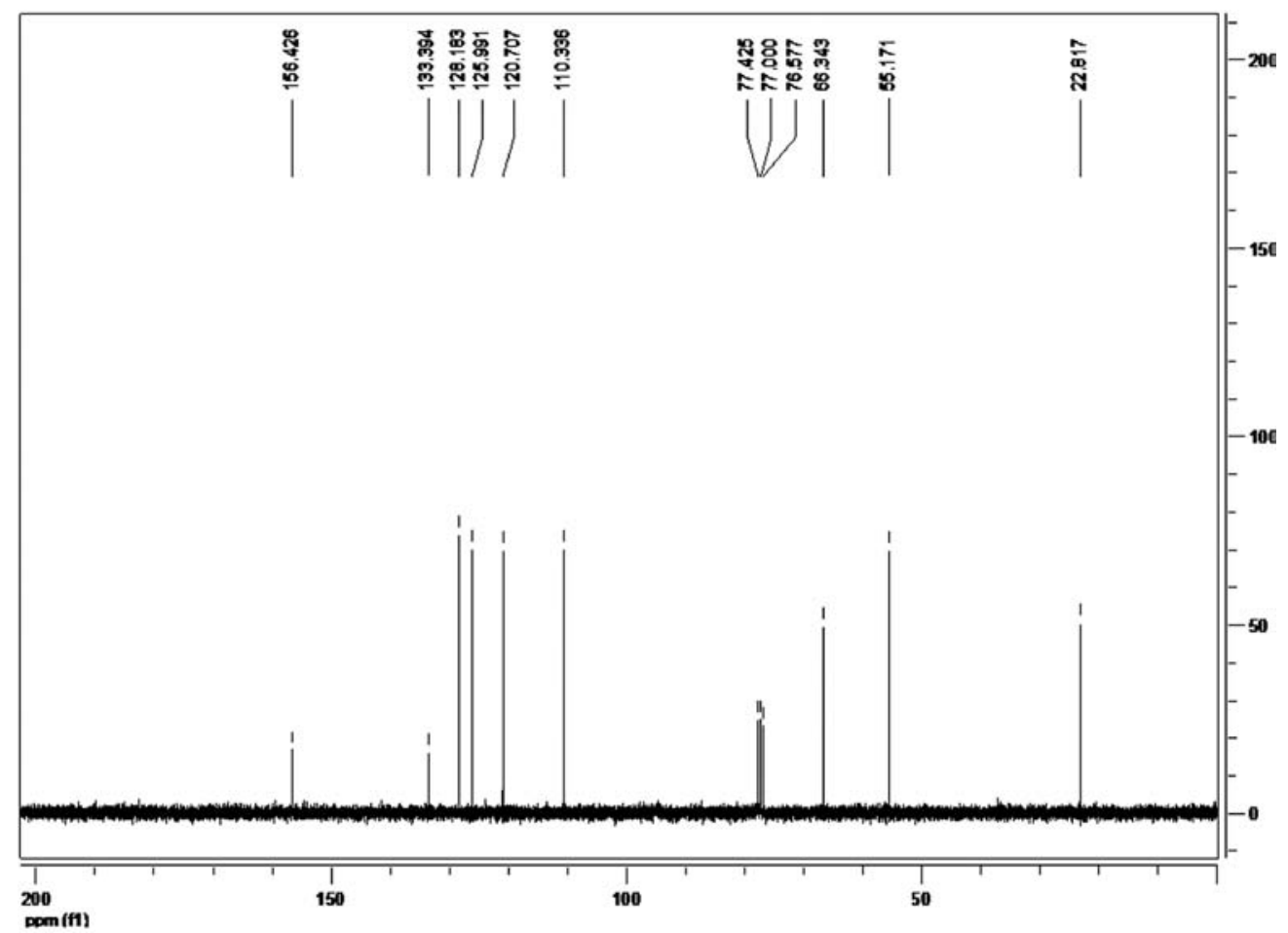

Figure S22. ${ }^{13} \mathrm{C}$ NMR spectrum of $\mathbf{5 b}\left(\mathrm{CDCl}_{3}, 75.5 \mathrm{MHz}\right)$.

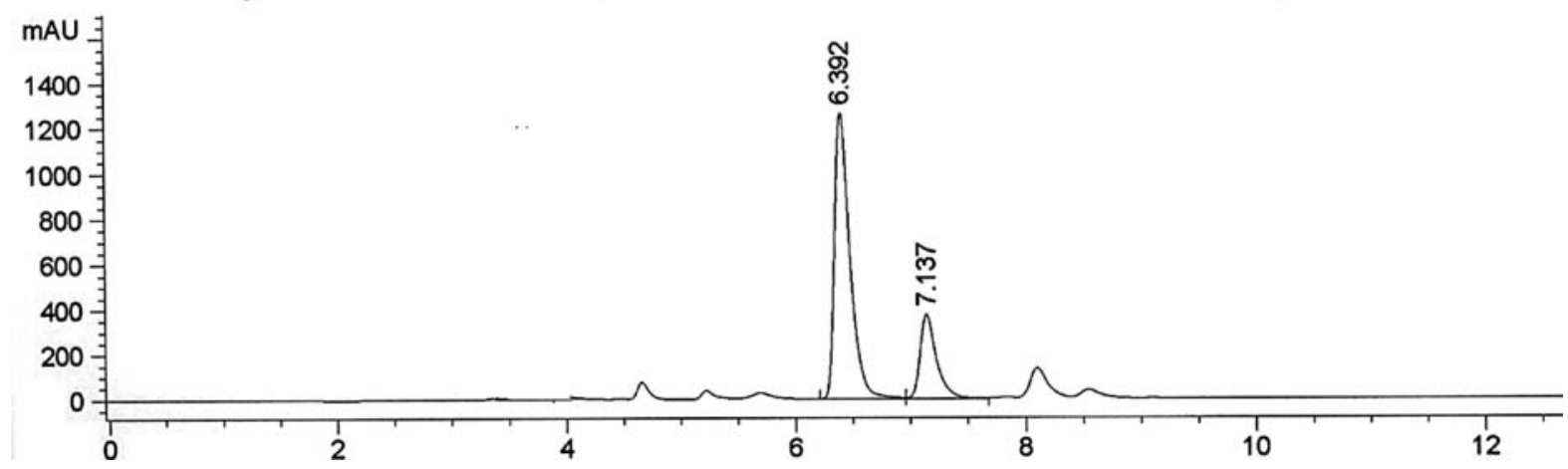

Figure S23. Chromatogram of the separation: $t_{\mathrm{R}}(\mathbf{5 a}) 6.3 \mathrm{~min}$ and $t_{\mathrm{R}}(\mathbf{5 b})$.

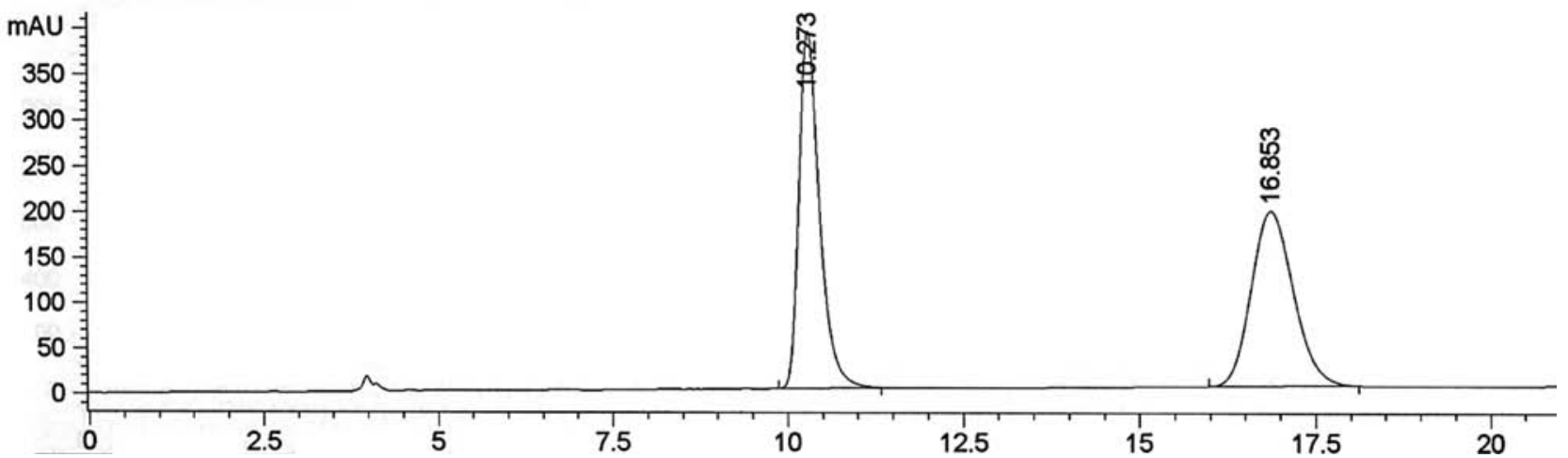

Figure S24. Chromatogram of the racemic mixture of $\mathbf{5 b} t_{\mathrm{R}} 10.3(S)$ and $t_{\mathrm{R}} 16.8(R)$ min. 


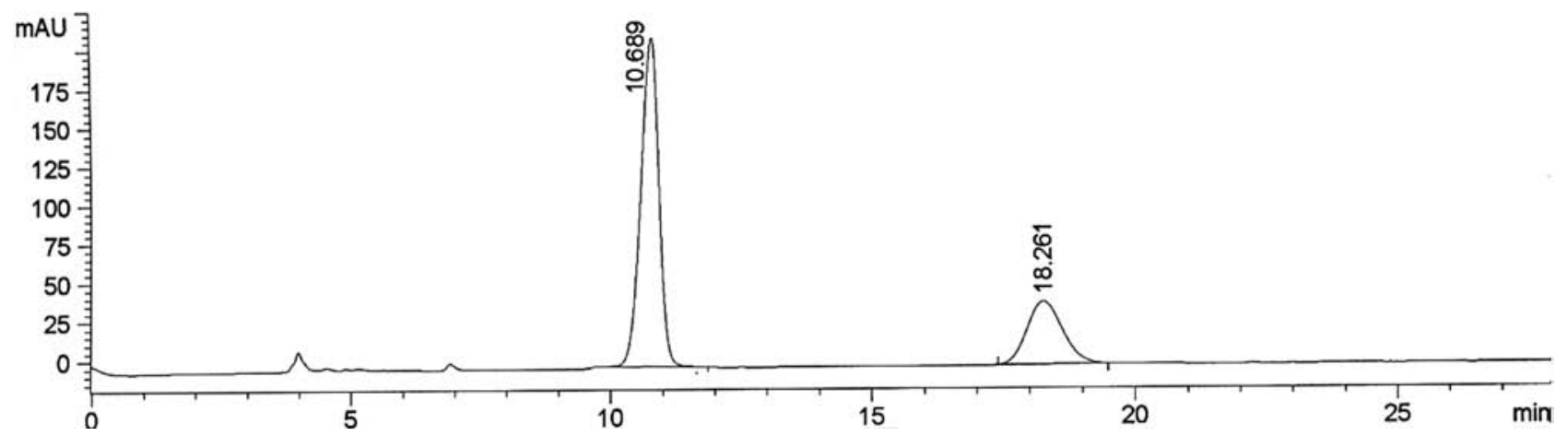

Figure S25. Chromatogram of the product by $C$. tropicalis $(\mathbf{5 b})$.

(S)-1-(3-Methoxyphenyl)ethanol, $6 \boldsymbol{b}$<smiles>COc1cccc([C@@H](C)O)c1</smiles>

${ }^{1} \mathrm{H}$ NMR ( $\left.\mathrm{CDCl}_{3}, 300.13 \mathrm{MHz}\right): \delta 1.47$ (3H, d, J 6.6 $\left.\mathrm{Hz}, \mathrm{H}_{2}\right), 3.81\left(3 \mathrm{H}, \mathrm{s}, \mathrm{OCH}_{3}\right), 4.83\left(1 \mathrm{H}, \mathrm{q}, J 6.6 \mathrm{~Hz}, \mathrm{H}_{1}\right)$, $6.81\left(1 \mathrm{H}, \mathrm{dd}, J 8.5\right.$ and $\left.1.2 \mathrm{~Hz}, \mathrm{H}_{6}\right), 6.93\left(2 \mathrm{H}, \mathrm{m}_{,} \mathrm{H}_{2},+\mathrm{H}_{4}\right)$, $7.26\left(1 \mathrm{H}, \mathrm{t}, J 8.5 \mathrm{~Hz}, \mathrm{H}_{5}\right.$ ). (Figure $\mathrm{S} 26$ )

${ }^{13} \mathrm{C} \mathrm{NMR}\left(\mathrm{CDCl}_{3}, 75.5 \mathrm{MHz}\right): \delta 25.0\left(\mathrm{C}_{2}\right), 55.1\left(\mathrm{OCH}_{3}\right)$, $70.0\left(\mathrm{C}_{1}\right), 110.8\left(\mathrm{C}_{2^{\prime}}\right), 112.7\left(\mathrm{C}_{4}\right), 117.6\left(\mathrm{C}_{6}\right), 129.3\left(\mathrm{C}_{5}\right)$, $147.6\left(\mathrm{C}_{1}\right), 159.6\left(\mathrm{C}_{3}\right)$. (Figure S27)

Conditions for determination of the conversion by HPLC: $0.8 \mathrm{~mL} \mathrm{~min}^{-1}$, hexane:IPA $(95: 5), 20^{\circ} \mathrm{C}, t_{\mathrm{R}}(\mathbf{6 a}) 5.1 \mathrm{~min}$ and $t_{\mathrm{R}}(\mathbf{6 b}) 5.9$ min. Column Spherisorb. (Figure S28)

Conditions for determination of the ee by HPLC: $0.8 \mathrm{~mL} \mathrm{~min}^{-1}$, hexane:IPA (95:5), $20^{\circ} \mathrm{C}, t_{\mathrm{R}} 20.1 \mathrm{~min}(S)$ and $t_{\mathrm{R}} 29.6 \min (R)$. Column OB-H. $[\alpha]_{\mathrm{D}}^{25}=-21.6, \mathrm{c} 0.34$, $\mathrm{MeOH}$, for $80 \%$ ee of $(S)$-enantiomer. (Figures S29 and S30)

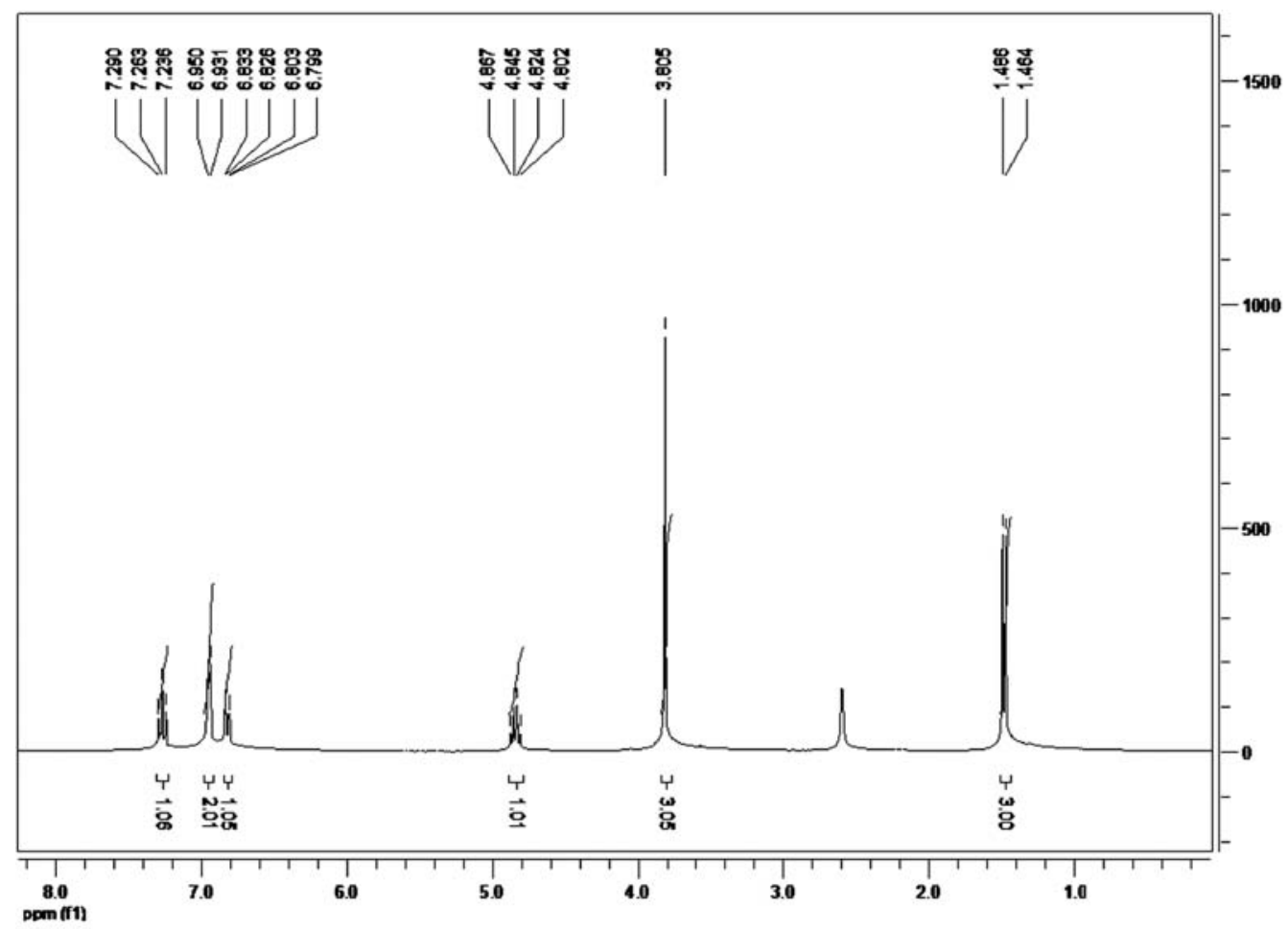

Figure S26. ${ }^{1} \mathrm{H}$ NMR spectrum of $\mathbf{6 b}\left(\mathrm{CDCl}_{3}, 300.13 \mathrm{MHz}\right)$. 


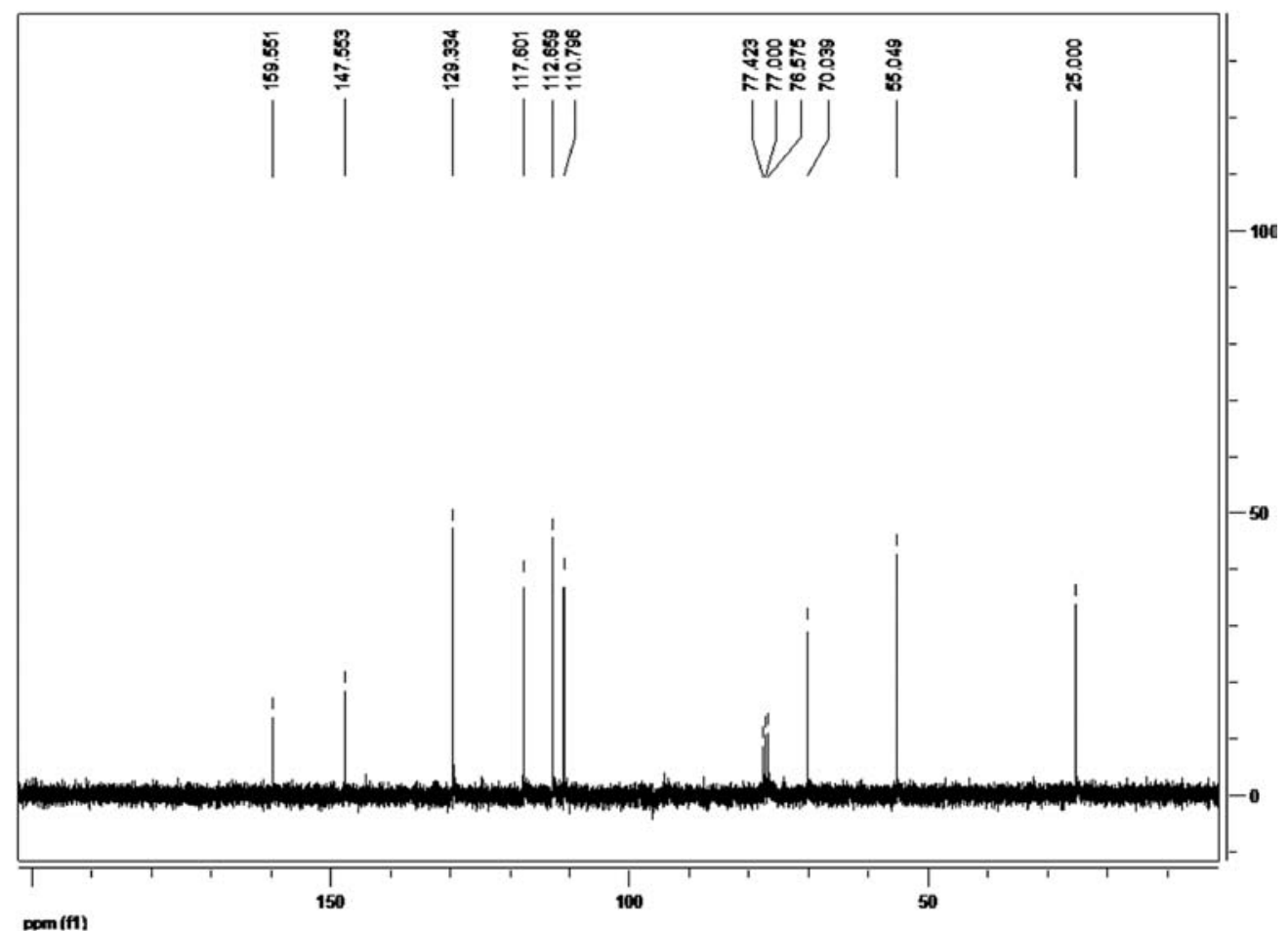

Figure S27. ${ }^{13} \mathrm{C}$ NMR spectrum of $\mathbf{6 b}\left(\mathrm{CDCl}_{3}, 75.5 \mathrm{MHz}\right)$.

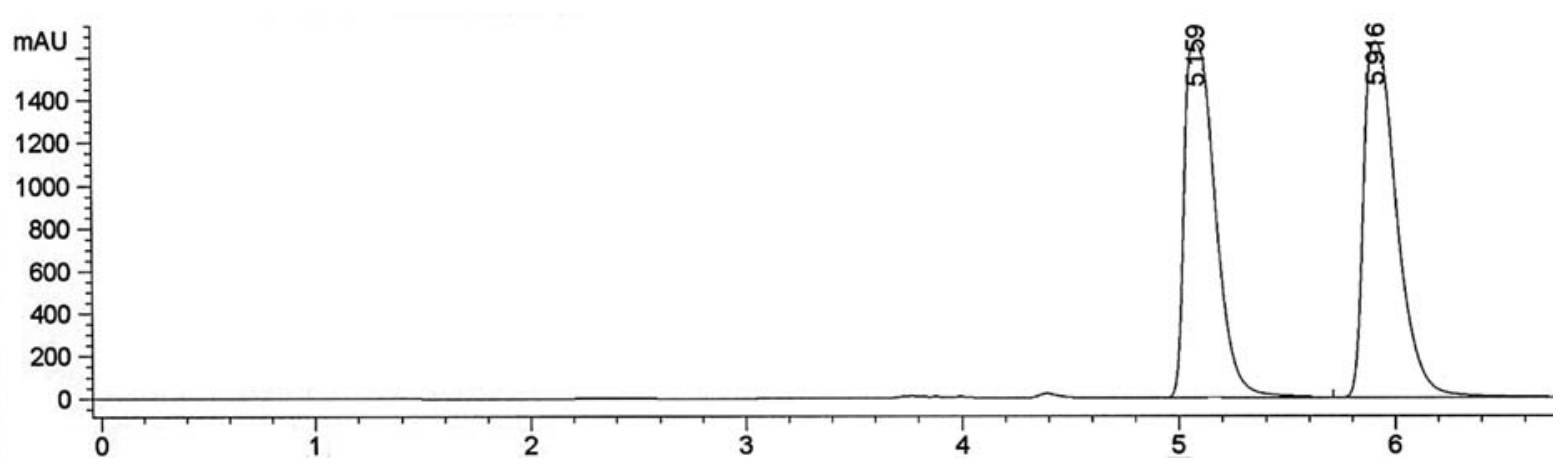

Figure S28. Chromatogram of the separation: $t_{\mathrm{R}}(\mathbf{6 a}) 5.1 \mathrm{~min}$ and $t_{\mathrm{R}}(\mathbf{6 b}) 5.9 \mathrm{~min}$.

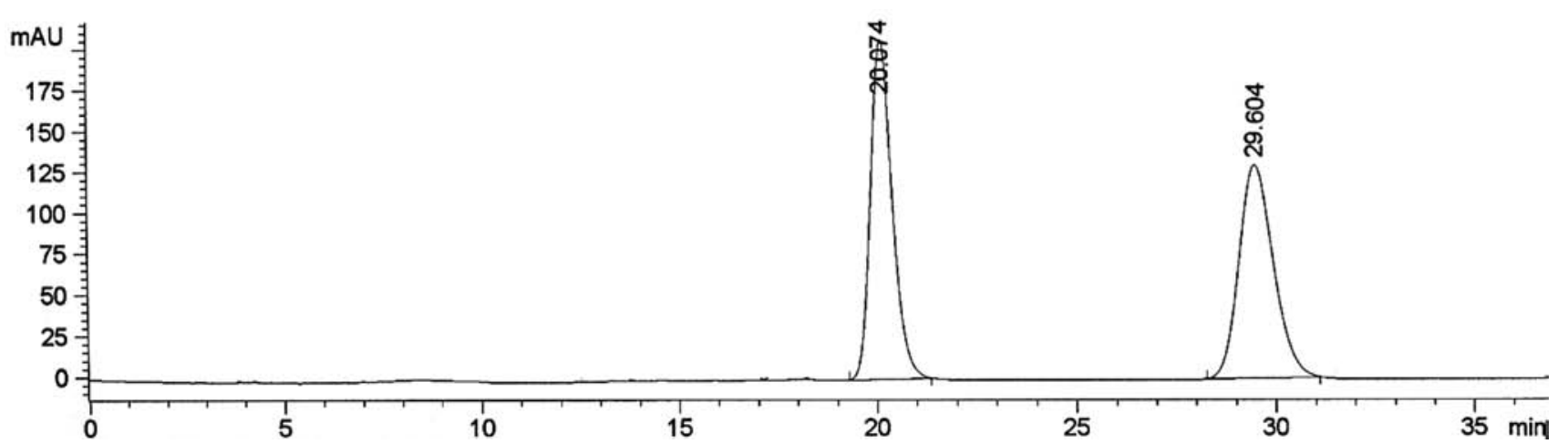

Figure S29. Chromatogram of the racemic mixture of $6 \mathbf{b}: t_{\mathrm{R}} 20.1 \min (S)$ and $t_{\mathrm{R}} 29.6 \min (R)$. 


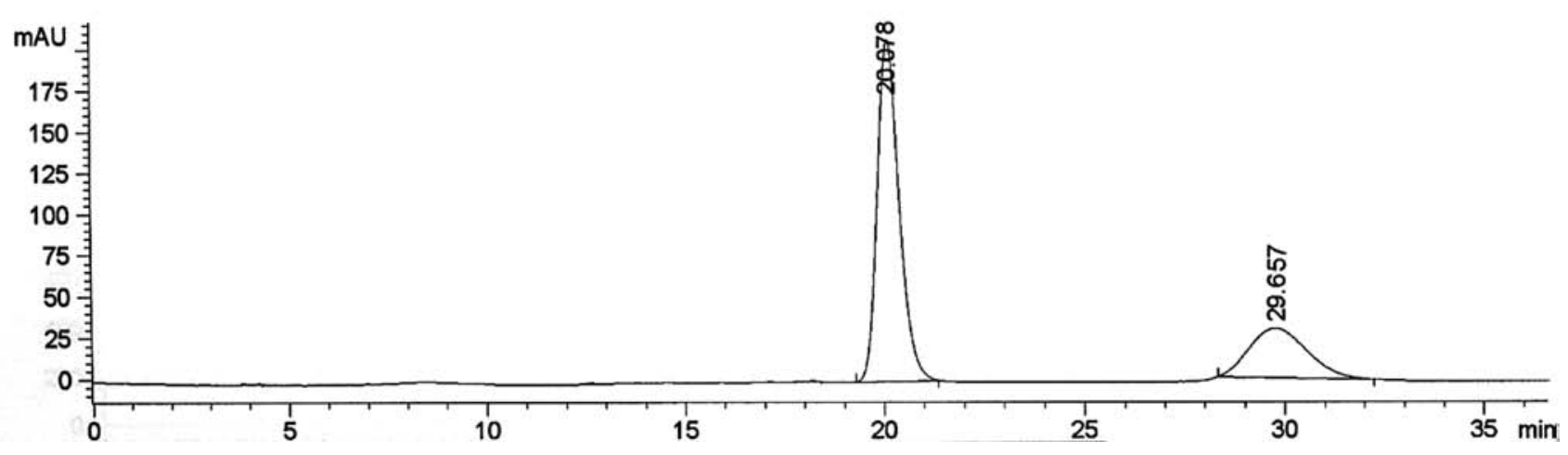

Figure S30. Chromatogram of the product by C. tropicalis $(\mathbf{6 b})$.

(S)-1-(4-Methoxyphenyl)ethanol, $7 \boldsymbol{b}$<smiles>COc1ccc(C(C)(C)O)cc1</smiles>

${ }^{1} \mathrm{H}$ NMR $\left(\mathrm{CDCl}_{3}, 300.13 \mathrm{MHz}\right): \delta 1.48(3 \mathrm{H}, \mathrm{d}, J 6.3$ $\left.\mathrm{Hz}, \mathrm{H}_{2}\right), 3.82\left(3 \mathrm{H}, \mathrm{s}, \mathrm{OCH}_{3}\right), 4.84\left(1 \mathrm{H}, \mathrm{q}, J 6.3 \mathrm{~Hz}, \mathrm{H}_{1}\right)$, $6.88\left(2 \mathrm{H}, \mathrm{d}, J 8.7 \mathrm{~Hz}, \mathrm{H}_{3}, \mathrm{H}_{5},\right), 7.30\left(2 \mathrm{H}, \mathrm{d}, J 8.7 \mathrm{~Hz}, \mathrm{H}_{2}\right.$. and $\mathrm{H}_{6}$ ). (Figure $\mathrm{S} 31$ )
${ }^{13} \mathrm{C} \mathrm{NMR}\left(\mathrm{CDCl}_{3}, 75.5 \mathrm{MHz}\right): \delta 24.3\left(\mathrm{C}_{2}\right), 55.2(\mathrm{OMe})$, $69.8\left(\mathrm{C}_{1}\right), 126.6\left(\mathrm{C}_{2}, \mathrm{C}_{6}\right), 113.8\left(\mathrm{C}_{3}, \mathrm{C}_{5^{\prime}}\right), 137.9\left(\mathrm{C}_{1}\right)$, $158.9\left(\mathrm{C}_{4}\right)$. (Figure S32)

Conditions for determination of the conversion by HPLC: $0.8 \mathrm{~mL} \mathrm{~min}{ }^{-1}$, hexane:IPA (95:5), $20{ }^{\circ} \mathrm{C}, t_{\mathrm{R}}(\mathbf{7 a})$ $7.3 \mathrm{~min}$ and $t_{\mathrm{R}}$ (7b) $8.5 \mathrm{~min}$. Column Spherisorb. (Figure S33)

Conditions for determination of the ee by HPLC: $0.8 \mathrm{~mL} \mathrm{~min}^{-1}$; hexane:IPA (95:5); $20^{\circ} \mathrm{C}, t_{\mathrm{R}} 13.4 \mathrm{~min}(S)$ and $t_{\mathrm{R}} 18.7(R)$ min. Column OB-H. $[\alpha]_{\mathrm{D}}^{25}=-2.2, \mathrm{c} 0.5$, $\mathrm{CH}_{2} \mathrm{Cl}_{2}$, for $9 \%$ ee of $(S)$-enantiomer. (Figures $\mathrm{S} 34$ and S35)

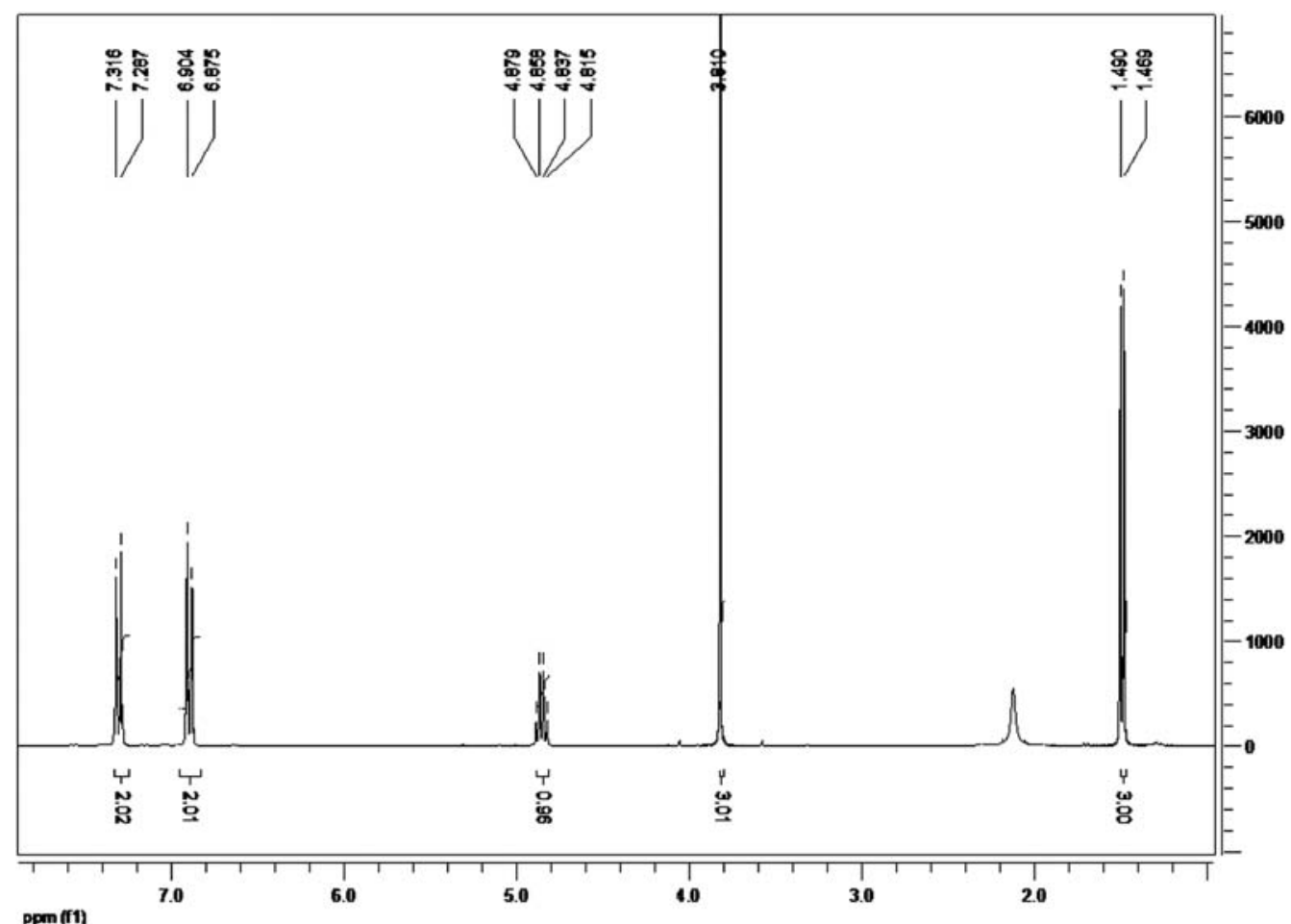

Figure S31. ${ }^{1} \mathrm{H}$ NMR spectrum of $\mathbf{7 b}\left(\mathrm{CDCl}_{3}, 300.13 \mathrm{MHz}\right)$. 


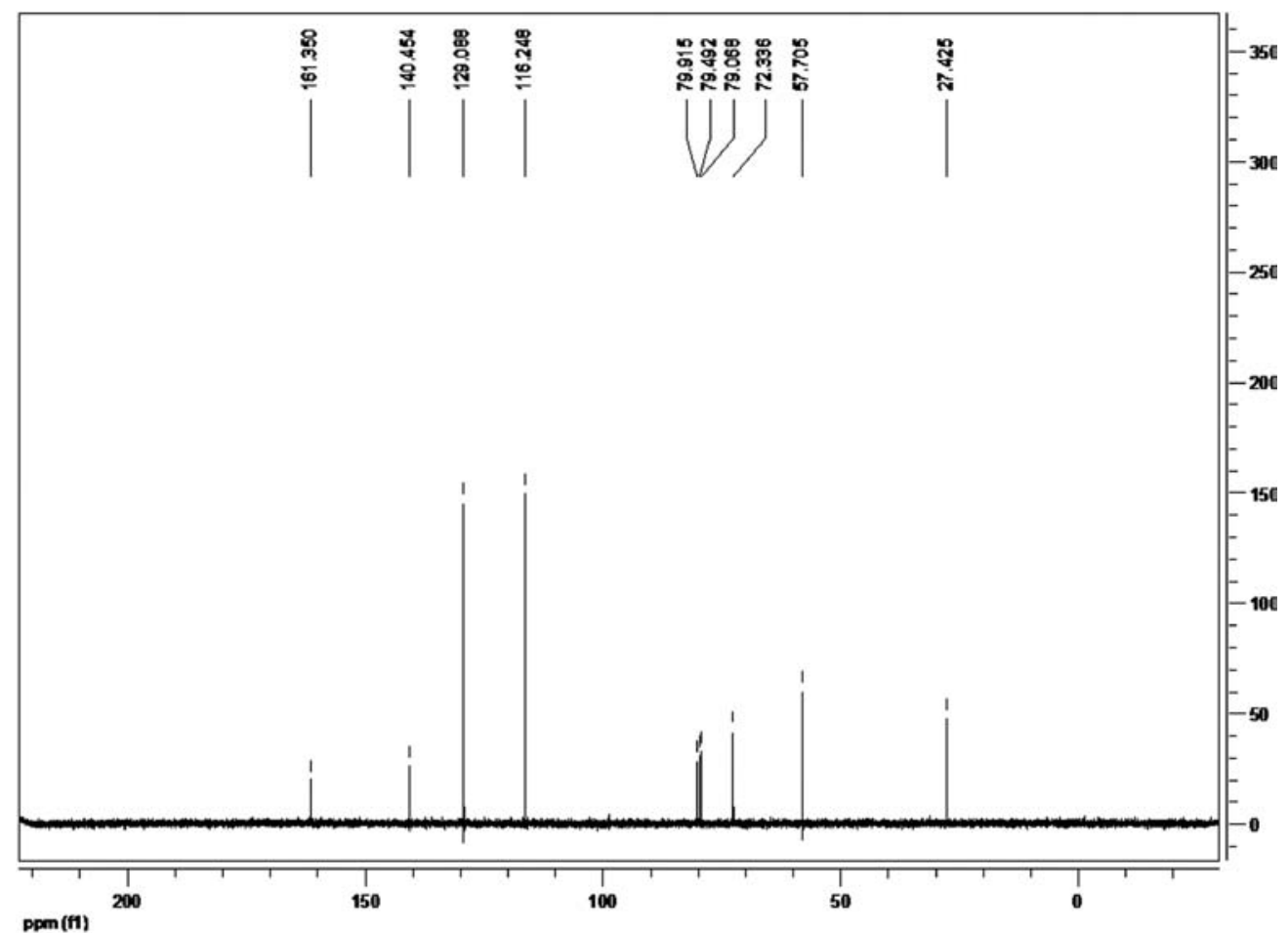

Figure S32. ${ }^{13} \mathrm{C}$ NMR spectrum of $\mathbf{7 b}\left(\mathrm{CDCl}_{3}, 75.5 \mathrm{MHz}\right)$.

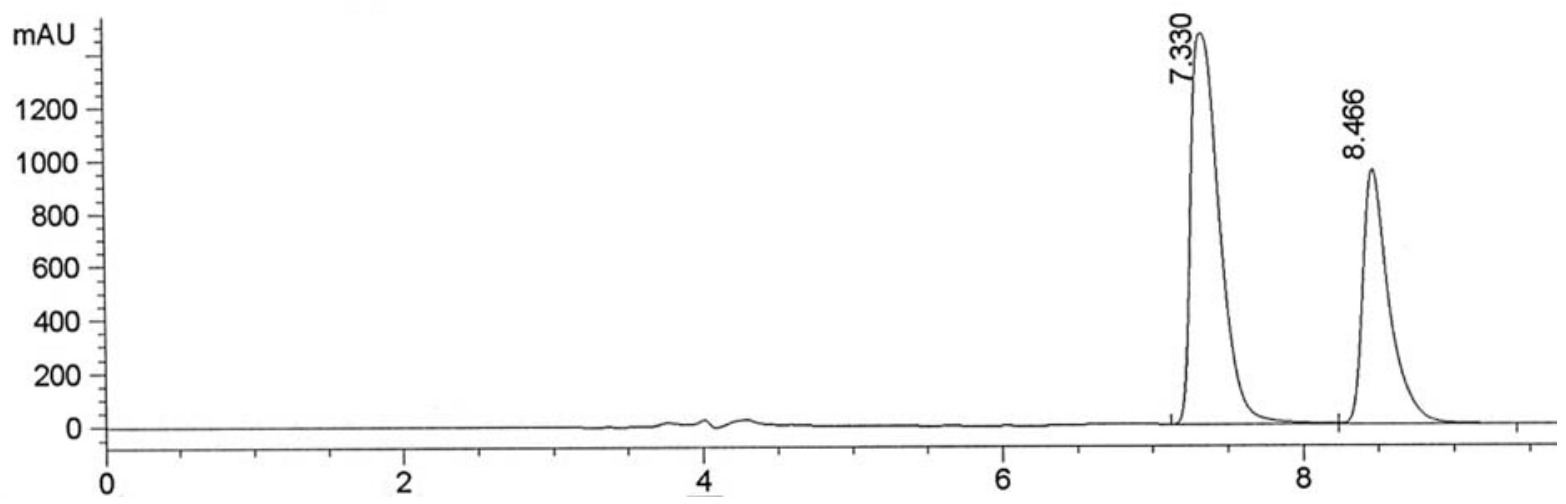

Figure S33. Chromatogram of the separation: $t_{\mathrm{R}}(\mathbf{7 a}) 7.3 \mathrm{~min}$ and $t_{\mathrm{R}}(\mathbf{7 b}) 8.5 \mathrm{~min}$.

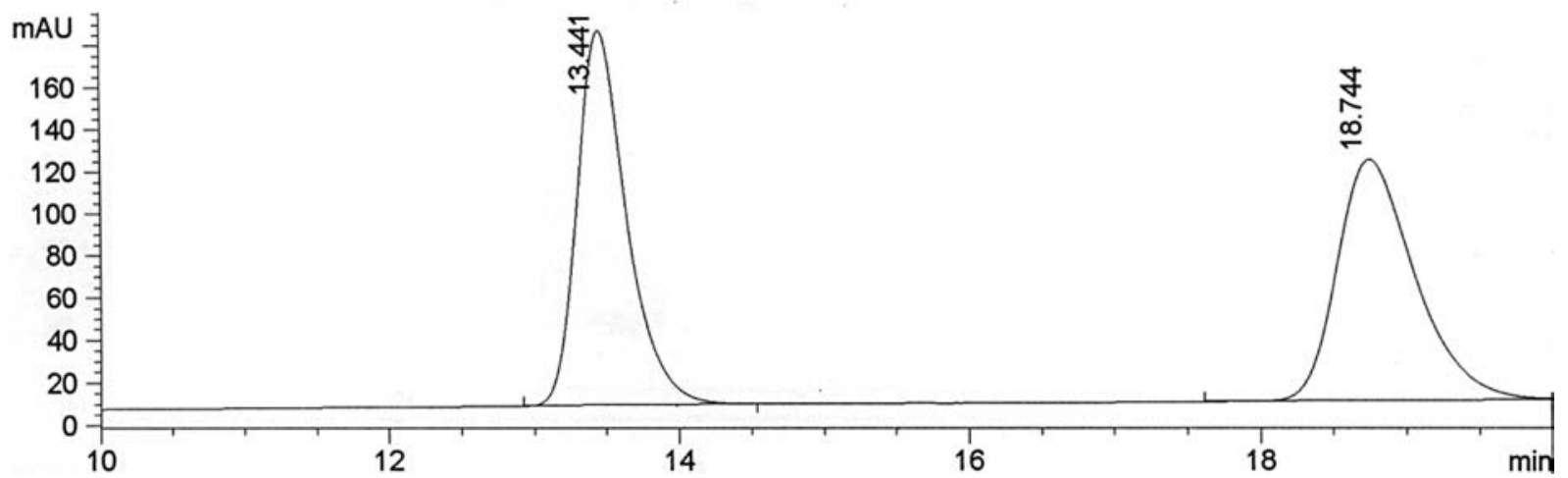

Figure S34. Chromatogram of the racemic mixture of 7b: $t_{\mathrm{R}} 13.4 \mathrm{~min}(S)$ and $t_{\mathrm{R}} 18.7(R) \min$. 


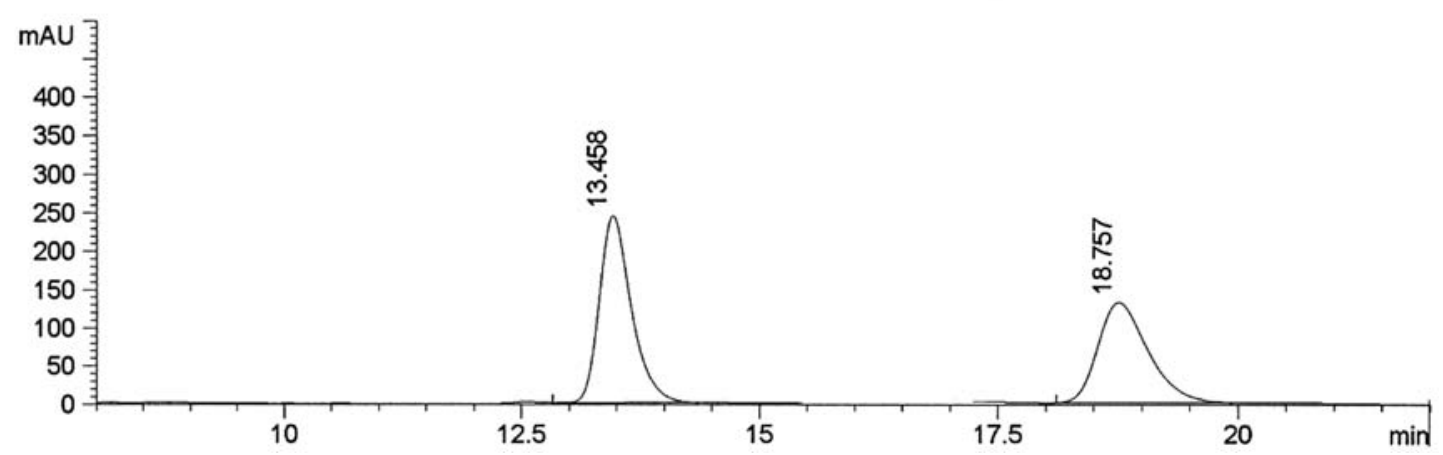

Figure S35. Chromatogram of the product by $C$. tropicalis $(\mathbf{7 b})$.

(S)-1-(4-Chlorophenyl)ethanol, $8 \boldsymbol{b}$<smiles>C[C@@H](O)c1ccc(Cl)cc1</smiles>

${ }^{1} \mathrm{H} \mathrm{NMR}\left(\mathrm{CDCl}_{3}, 300.13 \mathrm{MHz}\right): \delta 1.46(3 \mathrm{H}, \mathrm{d}, J 6.5 \mathrm{~Hz}$, $\left.\mathrm{H}_{1}\right), 4.85\left(1 \mathrm{H}, \mathrm{q}, J 6.5 \mathrm{~Hz}, \mathrm{H}_{2}\right), 7.30\left(4 \mathrm{H}, \mathrm{m}, \mathrm{H}_{2},+\mathrm{H}_{3},+\mathrm{H}_{5},+\right.$ $\mathrm{H}_{6}$ ). (Figure S36)
${ }^{13} \mathrm{C} \mathrm{NMR}\left(\mathrm{CDCl}_{3}, 75.5 \mathrm{MHz}\right): \delta 25.1\left(\mathrm{C}_{2}\right), 69.6\left(\mathrm{C}_{1}\right)$, $126.7\left(\mathrm{C}_{2}\right), 128.5\left(\mathrm{C}_{3}\right), 132.9\left(\mathrm{C}_{4}\right), 144.1\left(\mathrm{C}_{1}\right)$ ). (Figure S37)

Conditions for determination of the conversion by $\mathrm{GC}$ : Injector $225^{\circ} \mathrm{C}$, Detector $250^{\circ} \mathrm{C}, 90^{\circ} \mathrm{C}\left(3^{\circ} \mathrm{C} \mathrm{min}{ }^{-1}\right) 105^{\circ} \mathrm{C}$ $\left(5^{\circ} \mathrm{C} \mathrm{m^{-1 }}\right) 120^{\circ} \mathrm{C}\left(20^{\circ} \mathrm{C} \mathrm{min}^{-1}\right) 200{ }^{\circ} \mathrm{C}(0 \mathrm{~min}), t_{\mathrm{R}}(\mathbf{8 a})$ 5.0 min and $t_{\mathrm{R}}(\mathbf{8 b}) 5.6 \mathrm{~min}$. Column HP-1. (Figure S38)

Conditions for determination of the $e e$ by HPLC: $0.8 \mathrm{~mL} \mathrm{~min}^{-1}$, hexane:IPA $(95: 5), 20{ }^{\circ} \mathrm{C}, t_{\mathrm{R}} 7.5 \mathrm{~min}$ $(S)$ and $t_{\mathrm{R}} 8.5 \min (R)$. Column OB-H. $[\alpha]_{\mathrm{D}}^{25}=-32.4$, $\mathrm{CH}_{2} \mathrm{Cl}_{2}, \mathrm{c} 0.5$, for $62 \%$ ee of $(S)$-enantiomer. (Figures S39 and $\mathrm{S} 40$ )

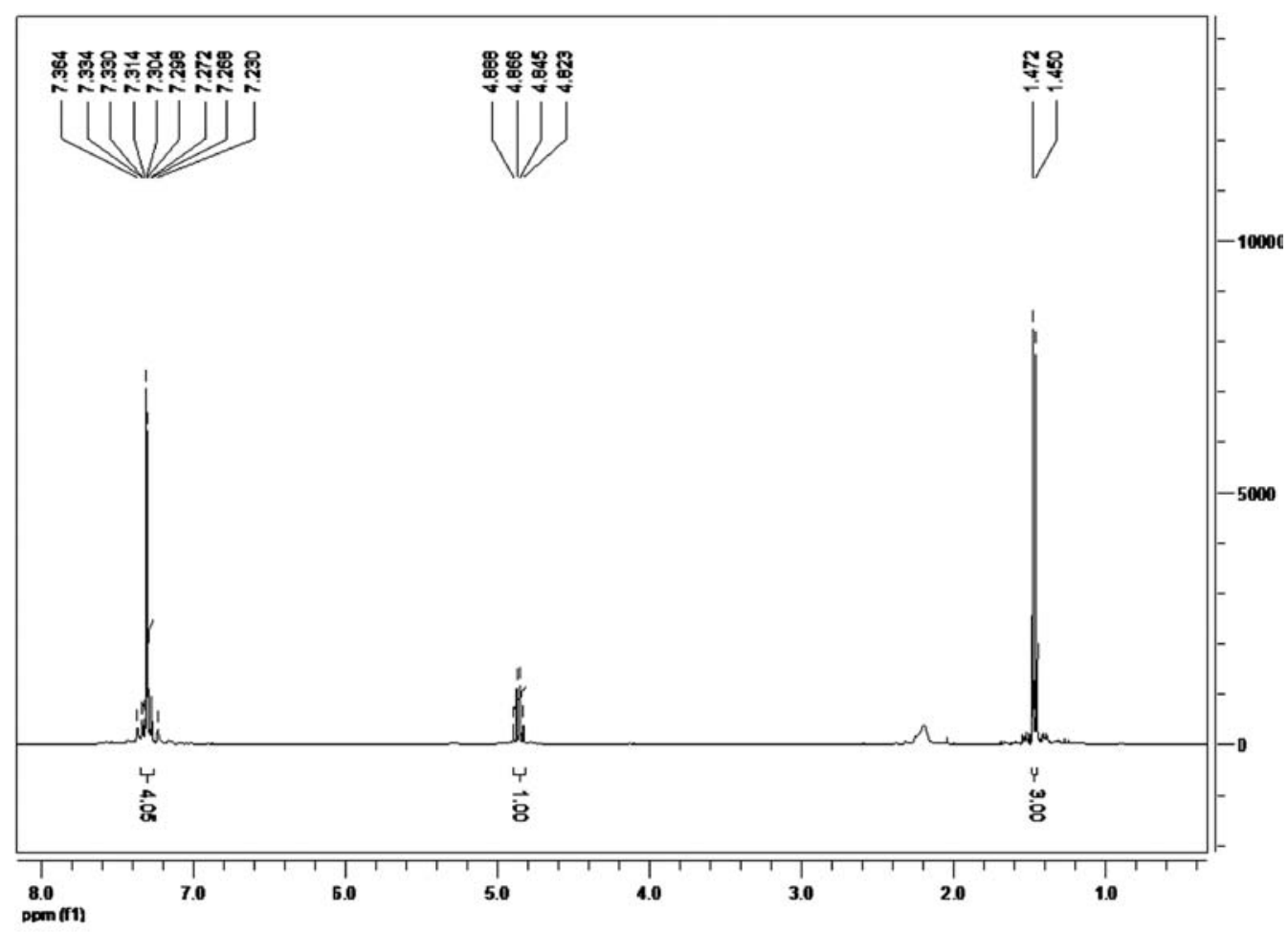

Figure S36. ${ }^{1} \mathrm{H}$ NMR spectrum of $\mathbf{8 b}\left(\mathrm{CDCl}_{3}, 300.13 \mathrm{MHz}\right)$. 


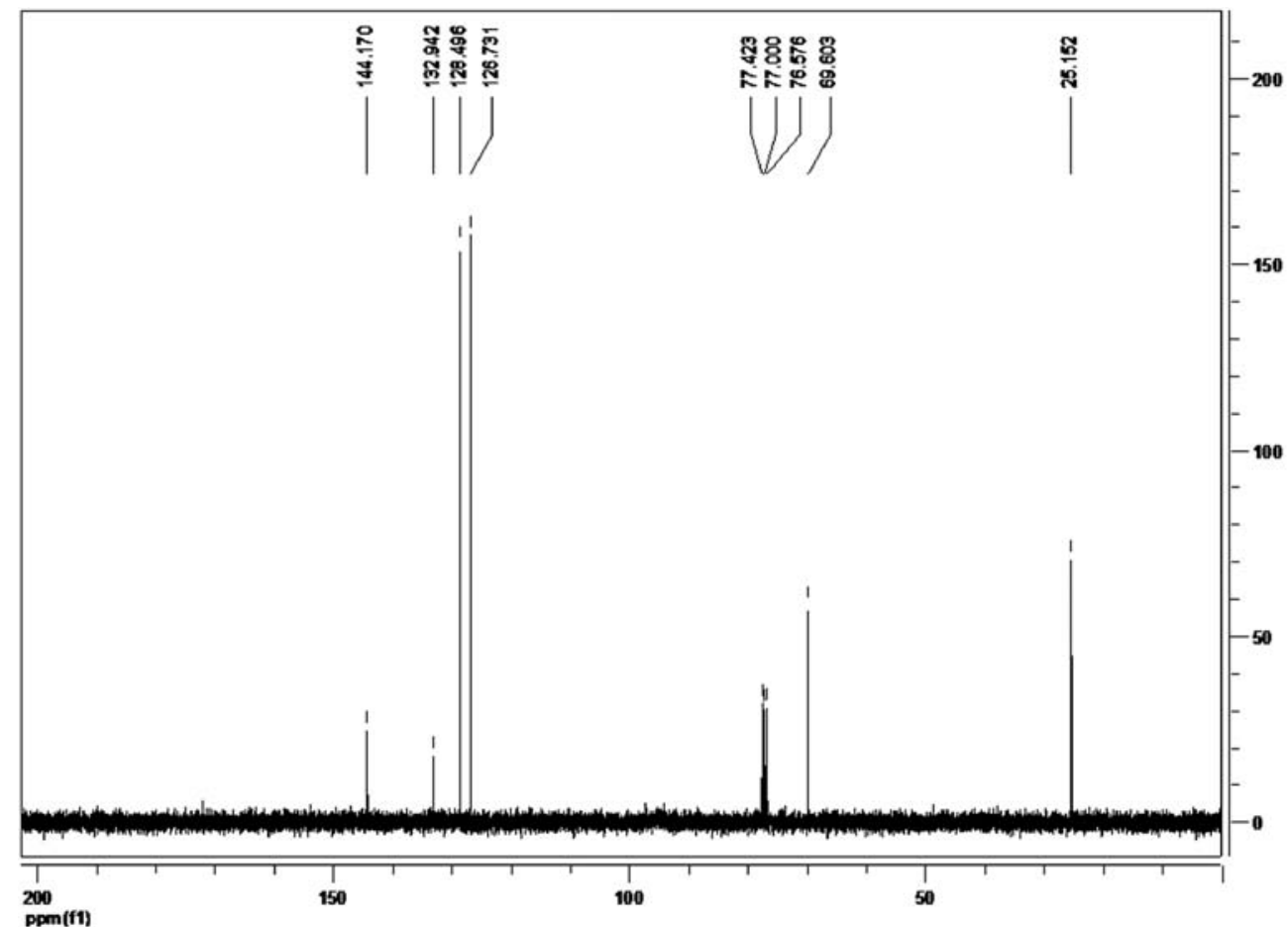

Figure S37. ${ }^{13} \mathrm{C}$ NMR spectrum of $\mathbf{8 b}\left(\mathrm{CDCl}_{3}, 75.5 \mathrm{MHz}\right)$.

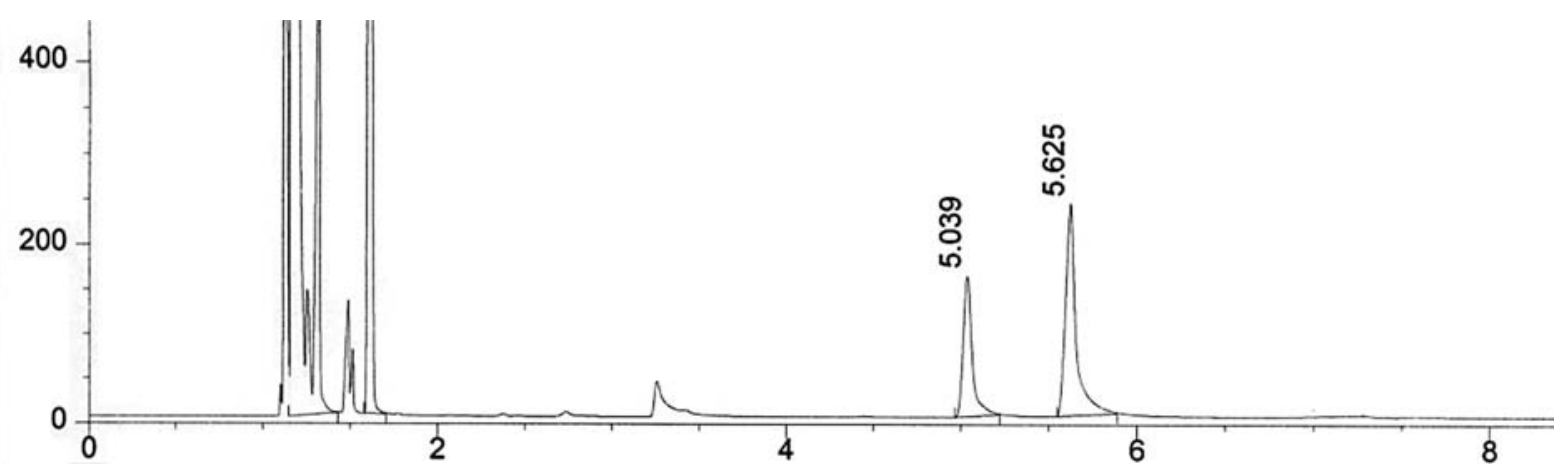

Figure S38. Chromatogram of the separation: $t_{\mathrm{R}}(\mathbf{8 a}) 5.0 \min$ and $t_{\mathrm{R}}(\mathbf{8 b}) 5.6 \mathrm{~min}$.

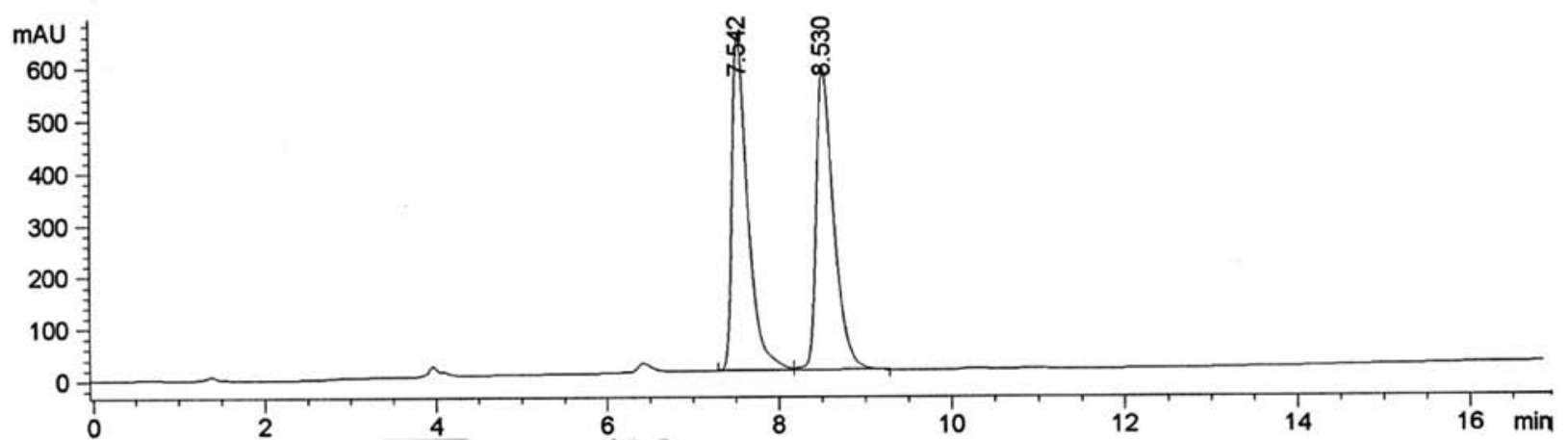

Figure S39. Chromatogram of the racemic mixture of $8 \mathbf{b}: t_{\mathrm{R}} 7.5 \min (S)$ and $t_{\mathrm{R}} 8.5 \min (R)$. 


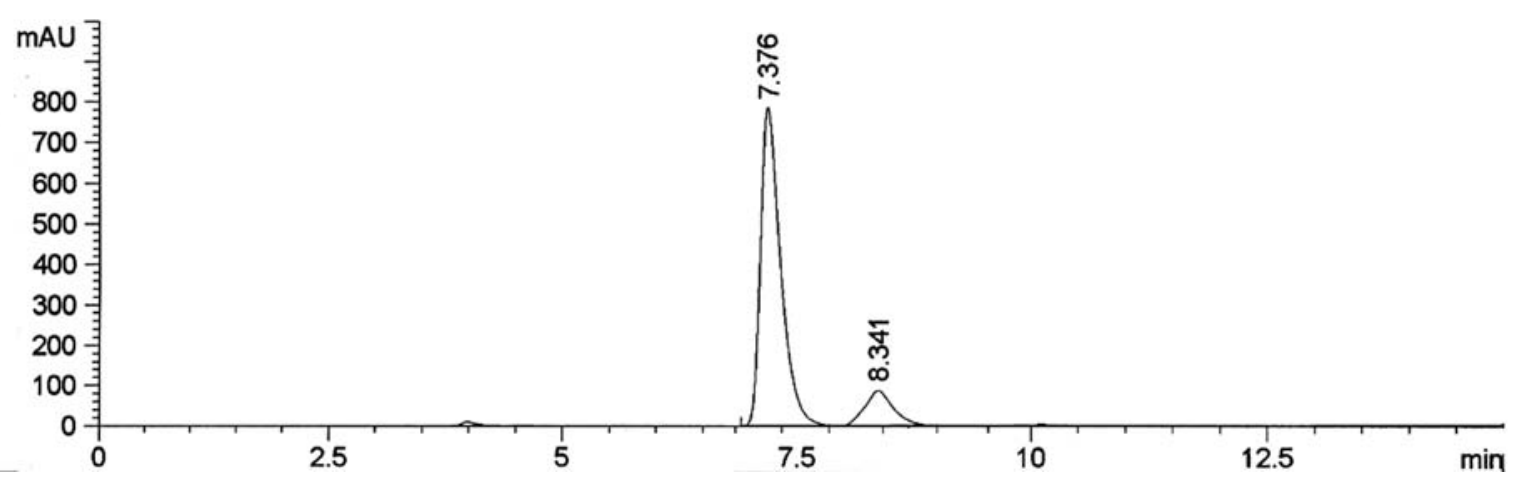

Figure S40. Chromatogram of the product by $C$. tropicalis $(\mathbf{8 b})$.

(R)-2-Chlorophenylethan-1-ol, $9 \boldsymbol{b}$<smiles>O[C@H](CCl)c1ccccc1</smiles>

${ }^{1} \mathrm{H}$ NMR $\left(\mathrm{CDCl}_{3}, 300.13 \mathrm{MHz}\right): \delta 3.56(1 \mathrm{H}, \mathrm{dd}, J 11.4$ and $\left.3.3 \mathrm{~Hz}, \mathrm{H}_{2}\right), 3.66\left(1 \mathrm{H}, \mathrm{dd}, J 11.4\right.$ and $\left.8.7 \mathrm{~Hz}, \mathrm{H}_{2}\right), 4.81$ $\left(1 \mathrm{H}, \mathrm{dd}, J 8.7\right.$ and $\left.3.6 \mathrm{~Hz}, \mathrm{H}_{1}\right), 7.30\left(5 \mathrm{H}, \mathrm{m}, \mathrm{H}_{2},+\mathrm{H}_{3},+\mathrm{H}_{4}+\right.$ $\mathrm{H}_{5},+\mathrm{H}_{6}$ ). (Figure $\mathrm{S} 41$ )
${ }^{13} \mathrm{C} \mathrm{NMR}\left(\mathrm{CDCl}_{3}, 75.5 \mathrm{MHz}\right): \delta 50.8\left(\mathrm{C}_{2}\right), 74.0\left(\mathrm{C}_{1}\right)$, $126.0\left(\mathrm{C}_{2},+\mathrm{C}_{6}\right), 128.4$ and $128.6\left(\mathrm{C}_{3}, \mathrm{C}_{5}\right), 139.9\left(\mathrm{C}_{1}\right)$. (Figure S42)

Conditions for determination of the conversion by GC: Injector $225^{\circ} \mathrm{C}$, Detector $250^{\circ} \mathrm{C}, 90^{\circ} \mathrm{C}\left(3^{\circ} \mathrm{C} \mathrm{min}^{-1}\right) 105^{\circ} \mathrm{C}$

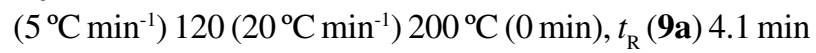
and $t_{\mathrm{R}}(9 \mathrm{~b}) 4.3$ min. Column HP-1. (Figure S43)

Conditions for determination of the ee by HPLC: $0.8 \mathrm{~mL} \mathrm{~min}^{-1}$, hexane:IPA (95:5), $20^{\circ} \mathrm{C}, t_{\mathrm{R}} 13.2(R)$ and $t_{\mathrm{R}}$ $17.6(S)$ min. Column OB-H. $[\alpha]_{\mathrm{D}}^{25}=-18.8, \mathrm{c} 0.26, \mathrm{CH}_{2} \mathrm{Cl}_{2}$, for $89 \%$ ee of $(R)$-enantiomer. (Figures S44 and S45)

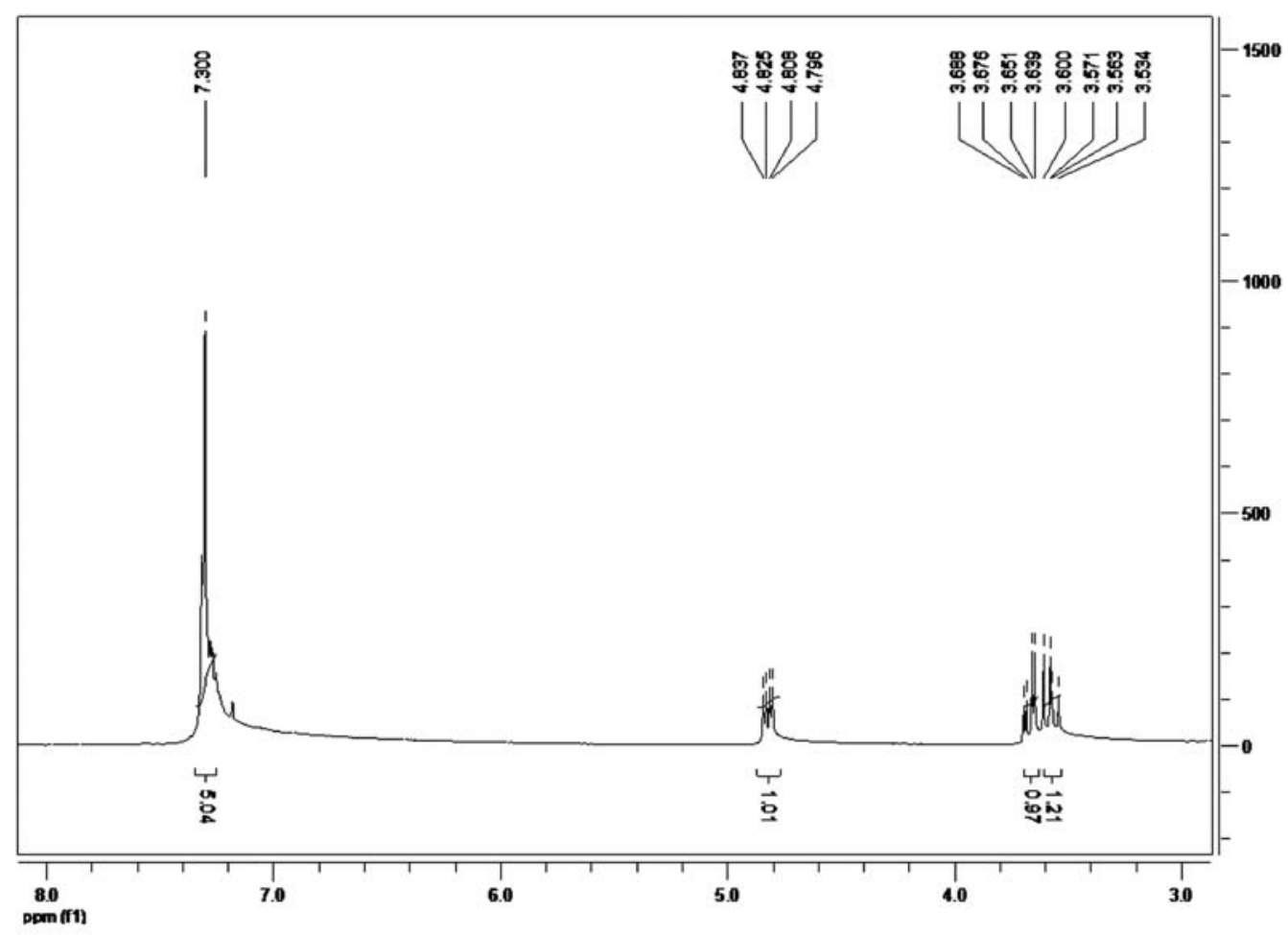

Figure S41. ${ }^{1} \mathrm{H}$ NMR spectrum of $\mathbf{9 b}\left(\mathrm{CDCl}_{3}, 300.13 \mathrm{MHz}\right)$. 


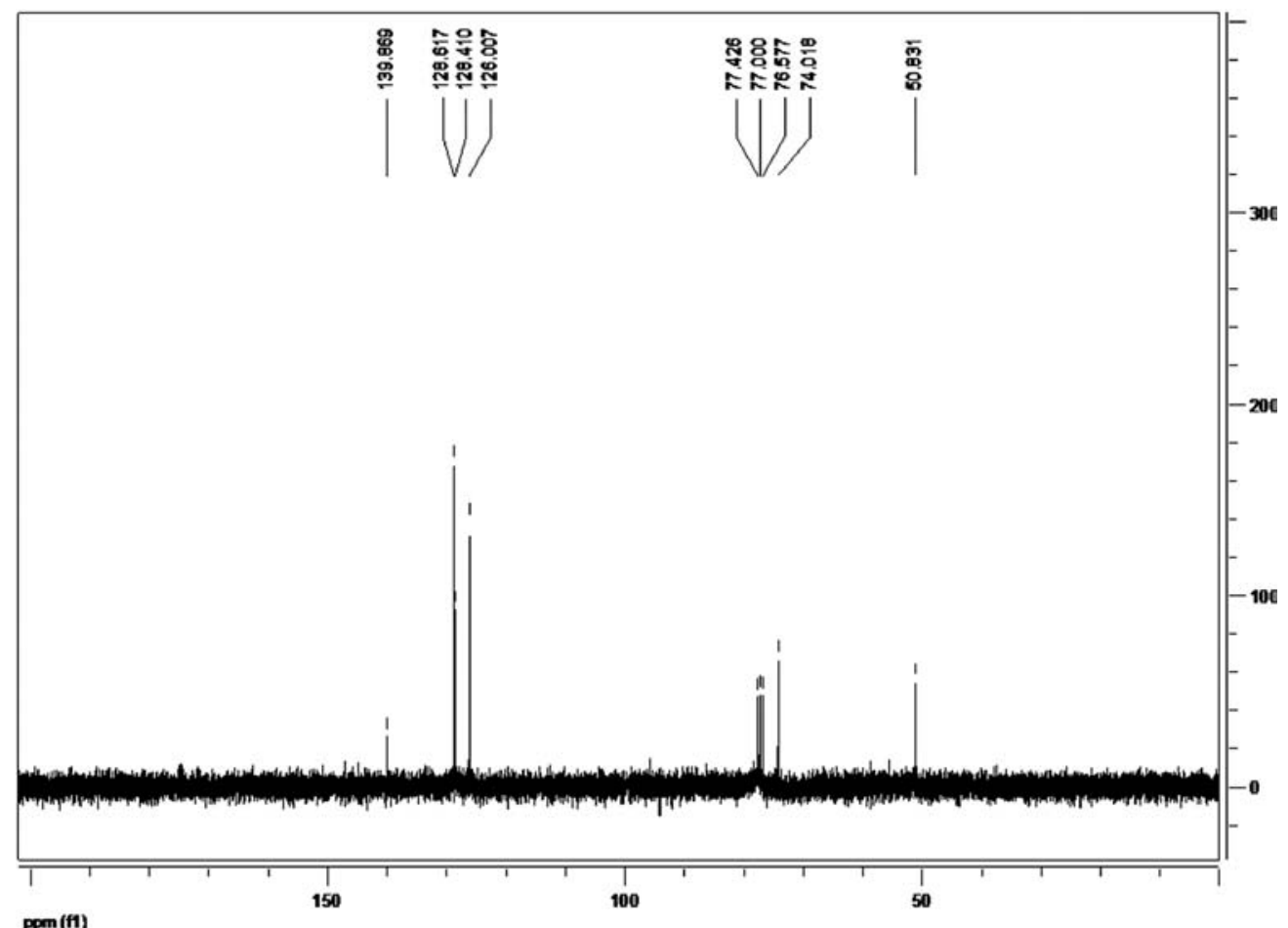

Figure S42. ${ }^{13} \mathrm{C}$ NMR spectrum of $\mathbf{9 b}\left(\mathrm{CDCl}_{3}, 75.5 \mathrm{MHz}\right)$.

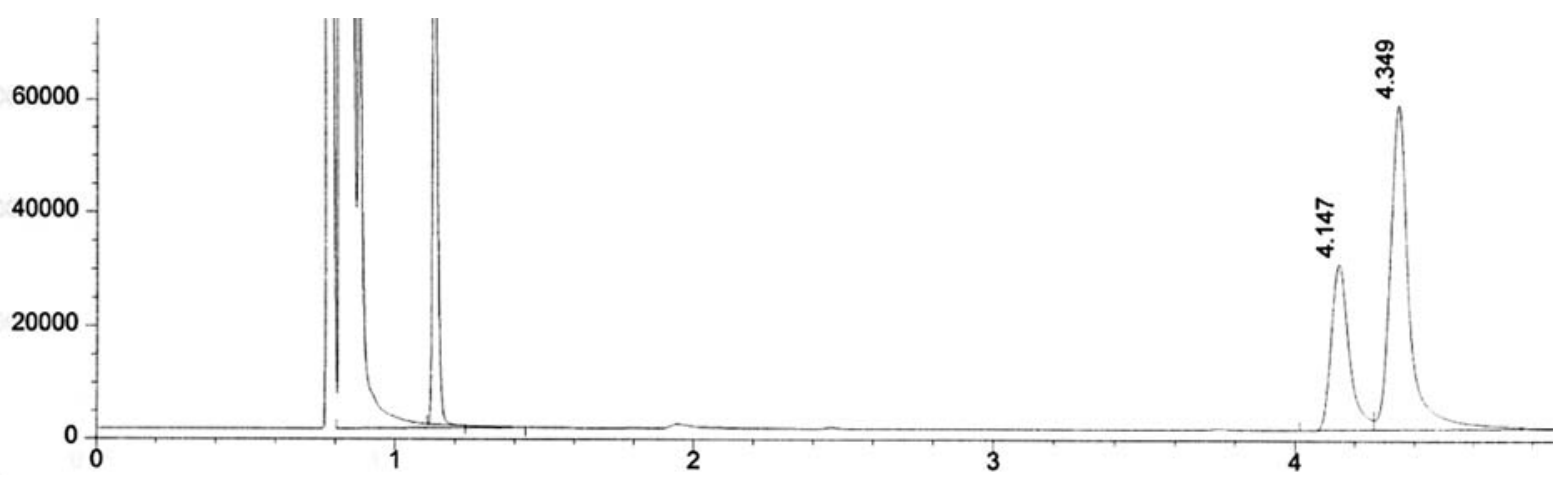

Figure S43. Chromatogram of the separation: $t_{\mathrm{R}}(\mathbf{9 a}) 4.1 \mathrm{~min}$ and $t_{\mathrm{R}}(\mathbf{9 b}) 4.3 \mathrm{~min}$.

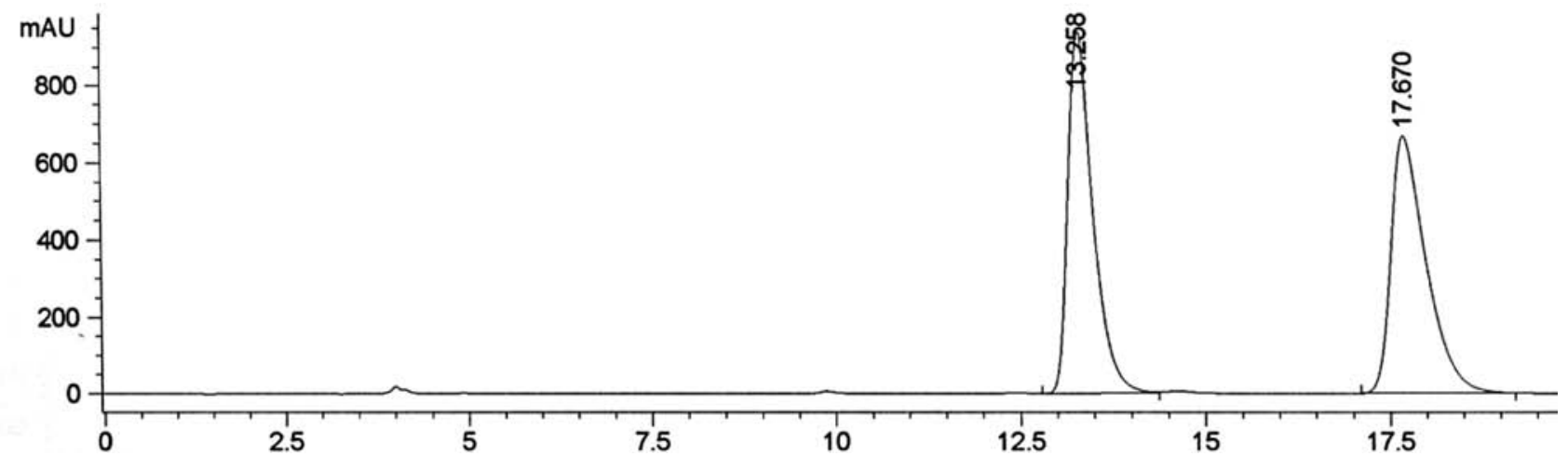

Figure S44. Chromatogram of the racemic mixture of $9 \mathbf{b}: t_{\mathrm{R}} 13.2(R)$ and $t_{\mathrm{R}} 17.6(S) \mathrm{min}$. 


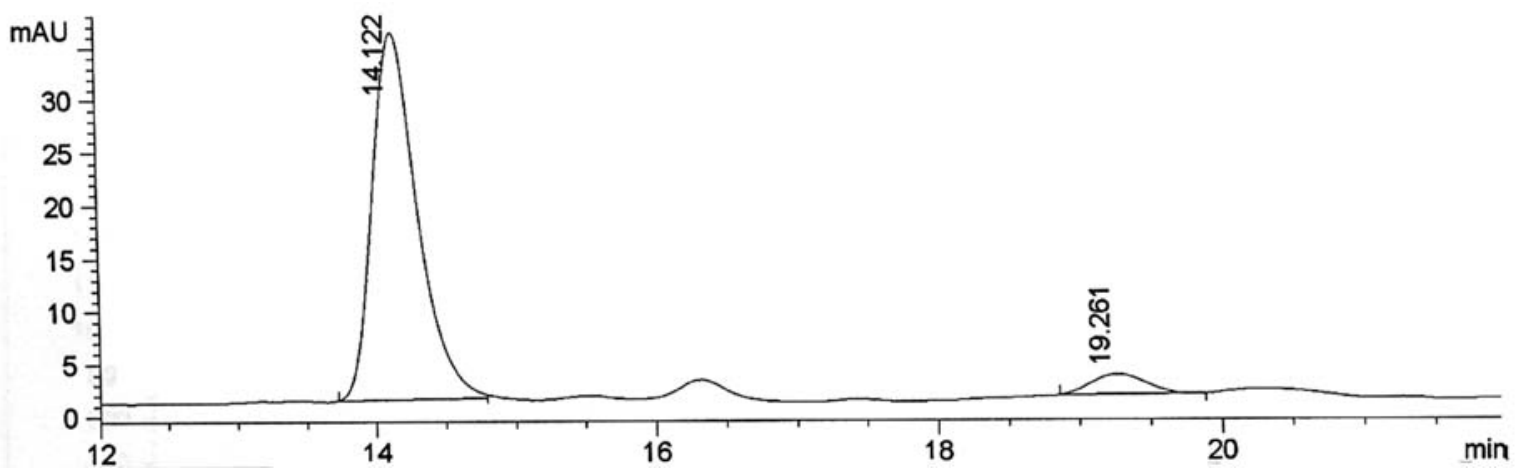

Figure S45. Chromatogram of the product by C. tropicalis $(\mathbf{9 b})$.

(R)-2-Chloro-1-(3,4-dichlorophenyl)ethan-1-ol, $10 \mathrm{~b}$<smiles>O[C@H](I)c1ccc(Cl)c(Cl)c1</smiles>

${ }^{1} \mathrm{H} \mathrm{NMR}\left(\mathrm{CDCl}_{3}, 300.13 \mathrm{MHz}\right): \delta 3.59(1 \mathrm{H}, \mathrm{dd}, J 11.4$ and $\left.8.7 \mathrm{~Hz}, \mathrm{H}_{2}\right), 3.72\left(1 \mathrm{H}, \mathrm{dd}, J 11.4\right.$ and $\left.3.6 \mathrm{~Hz}, \mathrm{H}_{2}\right), 4.87$ $\left(1 \mathrm{H}\right.$, dd, $J 8.7$ and $\left.3.6 \mathrm{~Hz}, \mathrm{H}_{1}\right), 7.21(1 \mathrm{H}$, dd, $J 8.4$ and $\left.1.8 \mathrm{~Hz}, \mathrm{H}_{6}\right), 7.43\left(1 \mathrm{H}, \mathrm{d}, J 8.4 \mathrm{~Hz}, \mathrm{H}_{5}\right), 7.51(1 \mathrm{H}, \mathrm{d}, J 1.8$ $\mathrm{Hz}, \mathrm{H}_{2}$,). (Figure S46)

${ }^{13} \mathrm{C} \mathrm{NMR}\left(\mathrm{CDCl}_{3}, 75.5 \mathrm{MHz}\right): \delta 50.4\left(\mathrm{C}_{2}\right), 72.8\left(\mathrm{C}_{1}\right)$, $125.4\left(\mathrm{C}_{6}\right), 128.1\left(\mathrm{C}_{2},\right), 130.6\left(\mathrm{C}_{5}\right), 132.4\left(\mathrm{C}_{4}\right), 132.8\left(\mathrm{C}_{3}\right)$, $140.0\left(\mathrm{C}_{1}\right.$ ). (Figure S47)

Conditions for determination of the conversion by GC: Injector $225^{\circ} \mathrm{C}$, Detector $250^{\circ} \mathrm{C}, 80^{\circ} \mathrm{C}\left(5^{\circ} \mathrm{C} \mathrm{min}{ }^{-1}\right) 180^{\circ} \mathrm{C}$ (0 min); $t_{\mathrm{R}}$ (10a) 13.6 and $\mathrm{t}_{\mathrm{R}}$ (10b) $14.8 \mathrm{~min}$. Column HP-1. (Figure S48)

Conditions for determination of the ee by HPLC: $0.8 \mathrm{~mL} \mathrm{~min}^{-1}$, hexane:IPA $(95: 5), 20^{\circ} \mathrm{C}, t_{\mathrm{R}} 13.0 \mathrm{~min}(S)$ and $t_{\mathrm{R}} 14.9(R) \min$. Column IA. $[\alpha]_{\mathrm{D}}^{25}=-13.3, \mathrm{c} 0.5, \mathrm{CHCl}_{3}$, for $90 \%$ ee of $(R)$-enantiomer. (Figures S49 and S50)

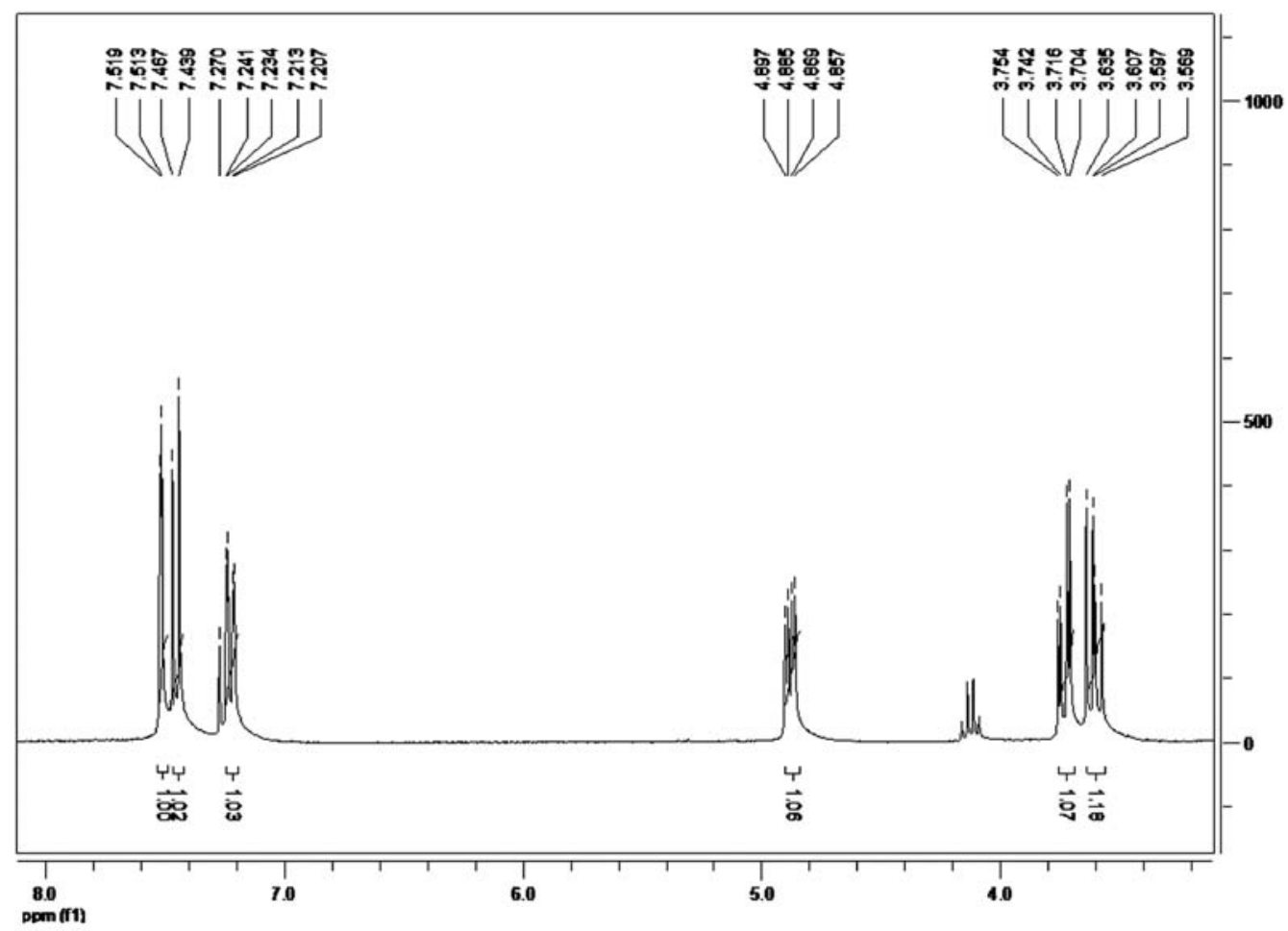

Figure S46. ${ }^{1} \mathrm{H}$ NMR spectrum of $\mathbf{1 0 b}\left(\mathrm{CDCl}_{3}, 300.13 \mathrm{MHz}\right)$. 


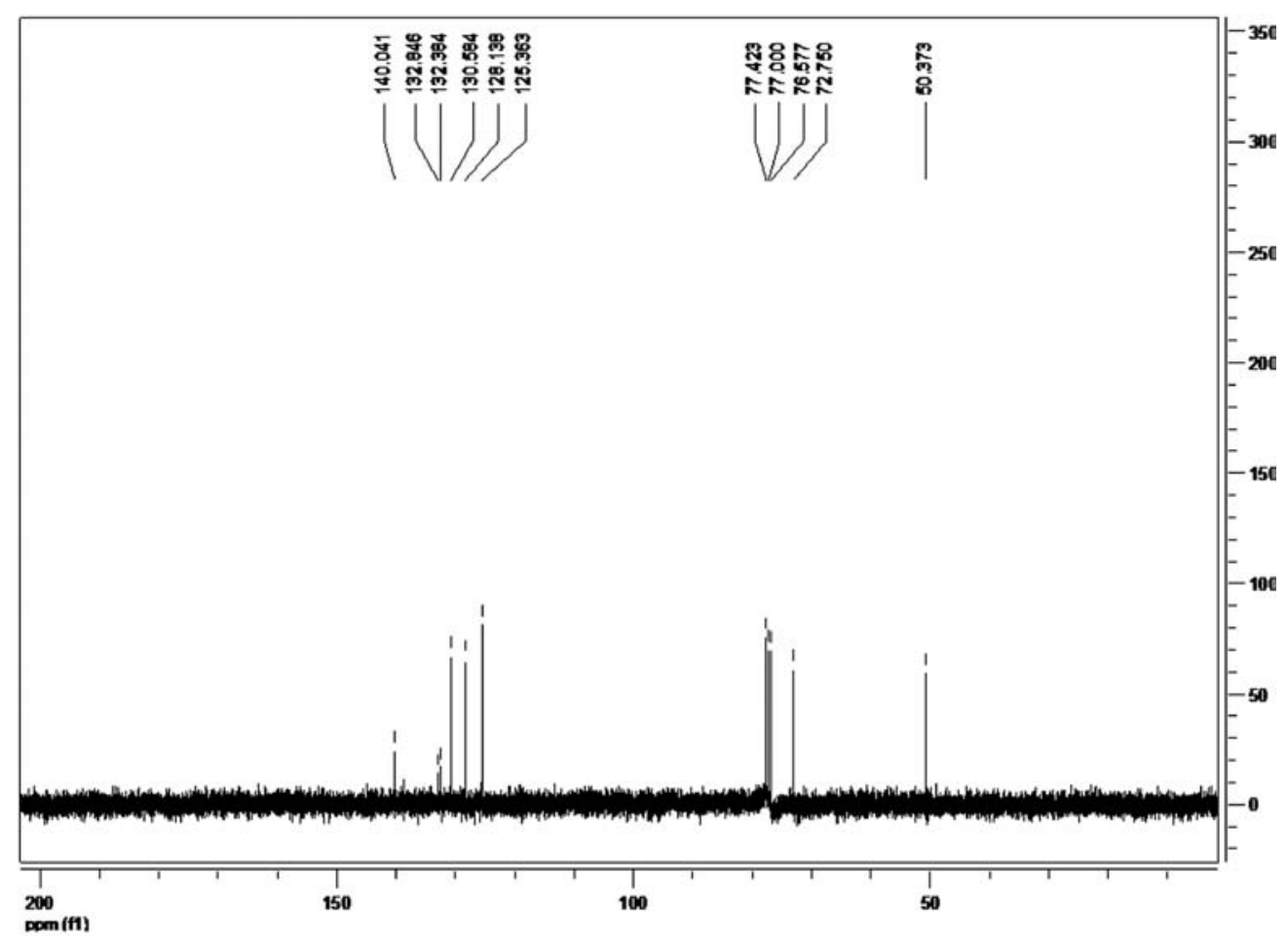

Figure S47. ${ }^{13} \mathrm{C}$ NMR spectrum of $\mathbf{1 0 b}\left(\mathrm{CDCl}_{3}, 75.5 \mathrm{MHz}\right)$.

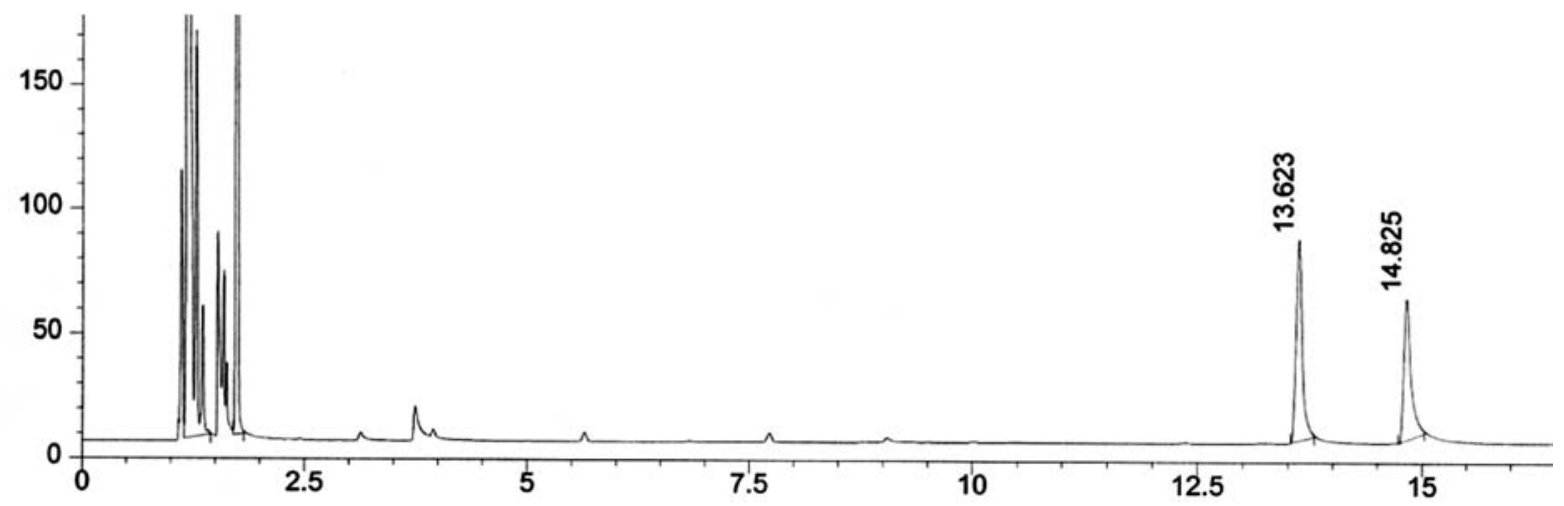

Figure S48. Chromatogram of the separation: $t_{\mathrm{R}}(\mathbf{1 0 a}) 13.6$ and $\mathrm{t}_{\mathrm{R}}(\mathbf{1 0 b}) 14.8 \mathrm{~min}$.

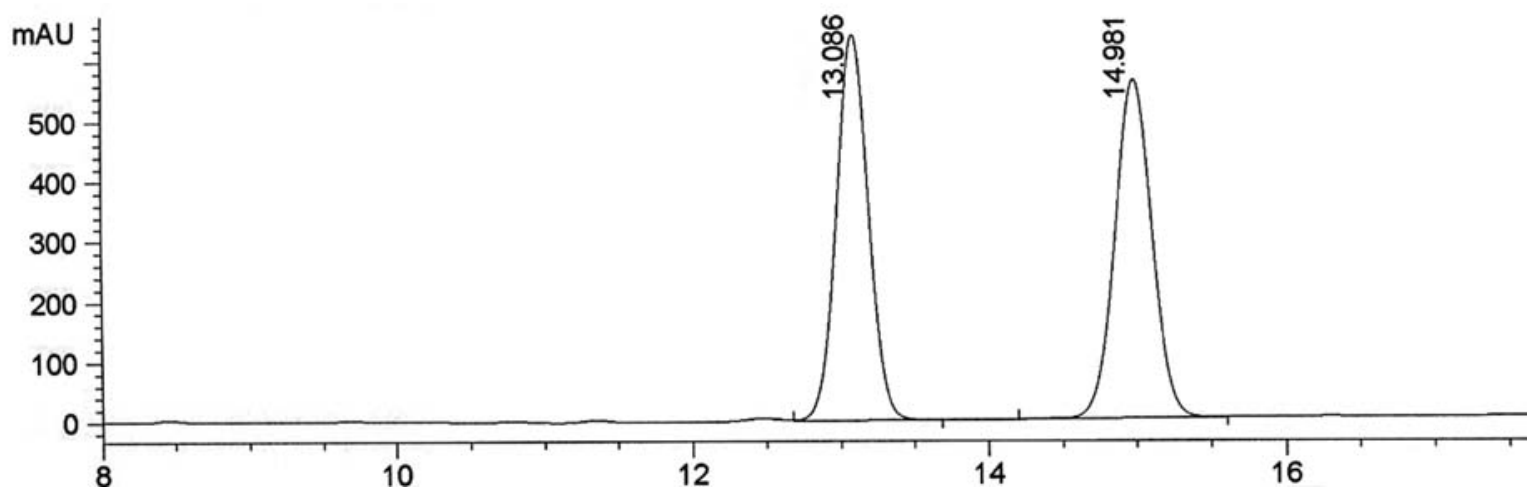

Figure S49. Chromatogram of the racemic mixture of 10b: $t_{\mathrm{R}} 13.0 \mathrm{~min}(S)$ and $t_{\mathrm{R}} 14.9(R) \mathrm{min}$. 


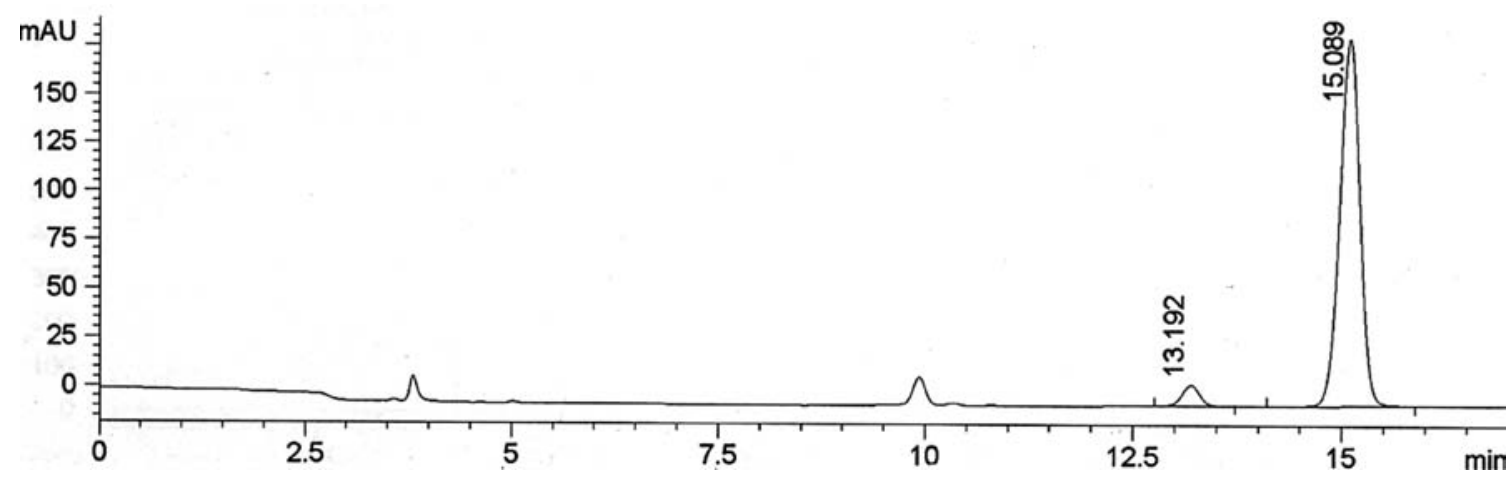

Figure S50. Chromatogram of the product by C. tropicalis $(\mathbf{1 0 b})$. 